\title{
Crecimiento y desindustrialización prematura en Perú 1950-2015, un análisis kaldoriano*
}

FÉLIX JiMÉNEZ

\begin{abstract}
RESUMEN
El objetivo de este estudio es mostrar si la industria manufacturera peruana mantiene su liderazgo en el proceso de crecimiento económico y en el aumento de la productividad del trabajo, después de veinticinco años de reformas y política neoliberales. El enfoque del trabajo es kaldorianokeynesiano, según el cual el crecimiento económico está determinado fundamentalmente por factores de demanda. Se evalúan estadística y econométricamente las leyes de Kaldor, según las cuales el crecimiento de la manufactura impulsa el crecimiento del PBI, el crecimiento de la productividad laboral en la propia manufactura y en la economía en su conjunto. El período de análisis cubre 65 ańos de 1950 a 2015, que incorpora tanto el periodo de industrialización dirigida por el Estado como los veinticinco años de neoliberalismo también dirigido por el Estado.

Palabras clave: crecimiento económico, crecimiento liderado por la manufactura, desarrollo económico, Leyes de Kaldor, productividad, rendimientos crecientes a escala en la manufactura.
\end{abstract}

Códigos JEL: O11, O14

\section{Growth and premature deindustrialization in Peru 1950-2015: A Kaldorian analysis}

\begin{abstract}
The main purpose of this study is to show if the Peruvian manufacturing industry maintains its leadership in the process of economic growth and in the increase of labor productivity, after twenty-five years of reforms and neoliberal policies. The theoretical basis of this study is Kaldorian-Keynesian, according to which economic growth is determined primarily by demand factors. Kaldor's laws, according to which the growth of manufacturing drives growth in GDP, the growth of labor productivity in manufacturing itself and in the economy as a whole, are statistically and econometrically evaluated. The period of analysis covers 65 years from 1950 to 2015, incorporating both the period of state-led industrialization and the twenty-five years of neoliberalism also led by the State.

Keywords: Economic growth, manufacturing-led growth, economic development, Kaldor Laws, productivity, increased returns to scale in manufacturing.

JEL Codes: O11, O14

* El autor agradece a José Antonio Uzuriaga por su excelente asistencia en las estimaciones econométricas de los modelos y su contribución en la edición del documento. También agradece a Erika Collantes y a Ángela Vilca, quienes participaron en la primera etapa de esta investigación recopilando y procesando tanto la información estadística necesaria como la correspondiente literatura teórica y empírica. El cambio de base del PBI de 1994 a 2007, obligó a reestimar todas las ecuaciones. fjimenez@pucp.edu.pe
\end{abstract}




\section{INTRODUCCIÓN}

El objetivo de este estudio es mostrar si la industria manufacturera peruana mantiene su liderazgo en el proceso de crecimiento económico y en el aumento de la productividad del trabajo en la economía en su conjunto. Esta es la hipótesis de Kaldor (1966) que fue corroborada por nosotros en dos investigaciones anteriores para los períodos 1950-1978 (Jiménez, 2010[1982]) y 1950-1997 (Jiménez, 1999). Durante el primer período la industria manufacturera era la que lideraba el crecimiento económico, mientras los sectores terciarios funcionaban como auxiliares y se expandían impulsados por ella. La industria manufacturera crecía generando aumentos en la productividad y respondiendo al crecimiento de la demanda. En el segundo período (extendido) también se corroboraba la misma hipótesis, aunque ya empezaba a debilitarse el liderazgo de la industria manufacturera. Los años de ajustes y reformas estructurales habían iniciado un proceso de desindustrialización que continuó hasta nuestros días.

El período 1950-2015 cubre: a) los años de apogeo del modelo industrialista basado en la sustitución de importaciones que se inicia formalmente en 1959; b) el largo período de estancamiento económico de los años 1975-1990; y, c) los siguientes veinticinco años de liberalización y desregulación de la economía. Hasta cerca de 1990, cuando ocurre un cambio estructural en el comportamiento de las series de producción y empleo manufacturero, la actividad económica (o el comportamiento del PBI agregado) sigue el desempeńo de la industria manufacturera. La manufactura crecía a tasas más altas impulsando el crecimiento del PBI. Después, en los años del neoliberalismo, las tasas de crecimiento de la manufactura se sitúan por debajo de las tasas de crecimiento del PBI agregado.

Durante 1950-1990 el PBI de la manufactura crece a la tasa de 3,7\%, mientras el PBI agregado lo hace a la tasa de 3,3\% promedio anual. Las fluctuaciones del PBI siguen a las fluctuaciones de la actividad manufacturera. Nótese que este período incorpora los ańos de apogeo de la industria, y el largo período de crisis y estancamiento económico que va de 1975 a 1990. Entre 1950 y 1975, la manufactura crece a la tasa de 6,6\% y el PBI a la tasa de 5,4\% promedio anual. En los ańos de crisis la manufactura decrece a la tasa de $0,8 \%$ y el PBI a la tasa de $0,1 \%$ promedio anual.

Durante $1990-2015$ el PBI de la manufactura crece a la tasa de $4 \%$ y el PBI a la tasa de $4,7 \%$ promedio anual. Estos son años de desindustrialización prematura de la economía. Es prematura porque la participación de la manufactura en la generación de empleo y del PBI se reduce sistemáticamente, antes de que se haya alcanzado niveles de ingresos per cápita comparables a los de aquellos países desarrollados que hoy transitan hacia la economía de servicios (Rodrik, 2016; Saeger, 1997). Es importante notar que estos años también coinciden con el crecimiento primario exportador, cuya crisis iniciada en los ańos 2007-2008 y agravada recientemente por el estancamiento internacional, ha generado una tendencia al estancamiento caracterizada por un bajo crecimiento económico y la reducción del ingreso per cápita en dólares. 
Hay que recordar que la industrialización que se inicia formalmente en 1959, aparece como una reacción a la crisis del modelo primario exportador. Este modelo, por su dependencia del capital extranjero y de la demanda externa no fue el camino hacia la modernización e industrialización de la economía. Había consenso en toda América Latina sobre la necesidad de que nuestros países abandonen el papel de productores de materias primas que desempeñaban en el sistema económico internacional. Desafortunadamente el proceso de industrialización, por razones que no vamos a explicar aquí, se agota o fracasa. Al período de alto crecimiento 1950-1975 le siguieron años de estancamiento del PBI, de volatilidad de sus variaciones, de inflación y de crisis de balanza de pagos (véase Jiménez, 1999).

En lugar de corregir los errores del proceso de industrialización y continuar con la modernización del país, las instituciones multilaterales (FMI y Banco Mundial) impusieron reformas y políticas de liberalización y desregulación, y de minimización del papel económico del Estado. El intervencionismo estatal y el proteccionismo, según estas instituciones y el Consenso de Washington de 1989, al impedir el libre juego de las fuerzas del mercado, generaron distorsiones de precios y desequilibrios, interno y externo, que terminaron socavando la sostenibilidad del crecimiento económico.

Luego de veinticinco años de políticas neoliberales nuestra economía enfrenta otra vez problemas estructurales que le impiden crecer sostenidamente. El contexto internacional desfavorable para la producción y exportación de minerales ha puesto al descubierto la ausencia o debilidad de la manufactura para impulsar el crecimiento económico y la expansión del empleo. Hay un alto porcentaje de trabajadores informales $(73,7 \%$ del empleo total) de baja calificación y de bajos ingresos que revelan la incapacidad del modelo primario exportador para situar al país por la ruta del desarrollo.

Ante esta situación, cabe preguntarse si todavía la manufactura puede recuperar su papel de liderazgo en el crecimiento económico. Para responder a esta pregunta, evaluamos las leyes de Kaldor, según las cuales el crecimiento de la manufactura impulsa el crecimiento del PBI, el crecimiento de la productividad laboral en la propia manufactura y en la economía en su conjunto. El período de análisis cubre 65 años de 1950 a 2015, que incorpora tanto el periodo de industrialización dirigida por el Estado ${ }^{1}$ como los veinticinco años de neoliberalismo también dirigido por el Estado.

En la sección 2 de este trabajo se desarrolla el marco teórico de la investigación. Específicamente se presenta lo que dice la teoría asociada a los nombres de Smith, Kaldor, Young y Verdoorn, sobre el papel de la manufactura en el crecimiento económico. En la sección 3 se analiza primero el desempeño de la industria manufacturera durante los años 1950 a 2015. Hay una clara diferencia en el desempeño de la industria manufacturera en los períodos 1950-1990 y 1990-2015. Como ya se ha dicho, en el primer período 1950-1990 también hay dos tipos de desempeño distintos.

1 La expresión «industrialización dirigida por el Estado» pertenece a Bértola y Ocampo (2013). 
De 1950 a 1975 la manufactura crece sostenidamente mientras que en el período 19751990 atraviesa por una larga crisis. De 1990 en adelante cambia radicalmente el estilo de crecimiento haciéndose más dependiente de la producción primaria. En realidad, el proceso de desindustrialización prematura empieza antes del dominio de las políticas del Consenso de Washington, cuando se aplican las políticas de reforma y ajuste estructural patrocinadas por el Banco Mundial y el FMI para enfrentar la crisis de la deuda externa de los ańos 1980. La manufactura pierde dinamismo y con ella la economía en su conjunto en ausencia del motor externo (la demanda por commodities), desde el año 2013. Las fuertes apreciaciones cambiarias en gran parte del periodo neoliberal le hacen perder competitividad y mercado interno. Las importaciones crecen de manera espectacular hasta representar, en el año 2015, el 157\% del total de la producción manufacturera.

En la segunda parte de la sección 3 se presenta la evidencia estadístico-econométrica de las tres leyes de Kaldor, con series de producción, empleo y stock de capital de 1950 a 2015 (65 años). Para corroborar la hipótesis de cada ley, se utilizan tanto el método de mínimos cuadrados ordinarios como el método de cointegración y el análisis de causalidad. Los resultados de las estimaciones de los distintos modelos confirman la hipótesis del liderazgo de la manufactura, que se debilita o pierde dinamismo en los años de las políticas de liberalización comercial y de desregulación de los mercados. Finalmente, en la sección 4 se presentan las conclusiones más importantes de la evidencia empírica encontrada sobre el desempeño de la industria manufacturera en el período 1950-2015.

\section{LA TEORÍA DEL CRECIMIENTO Y EL PAPEL DE LA MANUFACTURA: SMITH, YOUNG, VERDOORN Y KALDOR}

\subsection{Características de la industria manufacturera}

La manufactura es una actividad de transformación de mercancias por medio de mercancias. La industria manufacturera comprende un conjunto de actividades de transformación de insumos y materias primas procedentes de la agricultura, la ganadería, minería u otras actividades primarias, mediante procesos técnicos, el uso de maquinaria y fuerza de trabajo, que le agregan valor. Los resultados de este proceso de transformación pueden ser productos terminados para su venta como los bienes de consumo, de capital, o intermedios que sirven de insumos para otros procesos de producción. En este sentido, podríamos decir parafraseando el título del libro de Piero Sraffa, la industria manufacturera produce mercancías mediante mercancías. Por esta razón, su expansión solo depende del crecimiento del mercado o de la demanda agregada. Además, la expansión de la producción manufacturera que resulta del crecimiento de la demanda, contribuye a ampliar la demanda de bienes de otros sectores y, por lo tanto, el crecimiento de la economía en su conjunto (Salazar Arias, 2013). 
La manufactura impulsa el crecimiento y multiplica el empleo. La industria manufacturera es la que tiene mayor capacidad de generación de empleo directo e indirecto. El crecimiento del sector manufacturero amplifica la demanda por trabajo convirtiéndose en un polo de atracción de trabajadores que se encuentran en sectores tradicionales donde generalmente se ubican los trabajadores de baja calificación y de baja productividad. La transferencia de mano de obra desde sectores de baja productividad, como la agricultura y algunas actividades de servicios, hacia las actividades manufactureras y de servicios con mayores niveles de productividad, genera un efecto favorable en la productividad agregada de la economía, ya que trabajadores poco productivos empleados en actividades tradicionales se convierten en trabajadores industriales más productivos. Esto explica, además por qué debe haber una correlación positiva entre el crecimiento de la producción manufacturera y el crecimiento de la economía en su conjunto (Libanio, 2006a; Jeon, 2006; Ocegueda, 2003; Kathuria y Raj, 2010). Por otro lado, cuando se expande sostenidamente la producción manufacturera, crecen los otros sectores y se crean nuevas actividades productivas. La industrialización es, en este sentido, el mejor vehículo de formalización del empleo en países como el nuestro (Salazar Arias, 2013).

La manufactura es una actividad que se expande con rendimientos crecientes. La industria manufacturera se expande con rendimientos crecientes (su producción se multiplica por una cantidad mayor que la de los insumos que utiliza) porque lo hace generando encadenamientos hacia atrás y hacia adelante (emplea recursos de actividades primarias y produce bienes que son vendidos a través de la actividad comercial) (Kaldor, 1966; Sánchez Juárez, 2010). La capacidad de generación de encadenamientos —al interior de la propia industria y con otros sectores-, es mayor en el caso de la manufactura que en los casos de la agricultura o la minería. Así, el aumento de la demanda de la producción manufacturera impulsará la demanda en los otros sectores que le suministran insumos y materias primas (Kathuria y Raj, 2010). Una industria manufacturera dinámica «estimula la demanda por más y mejores bienes primarios (en los sectores: agrícola, forestal, pesquero y minero) y servicios (tales como servicios bancarios, de seguros, comunicaciones, comercio y transporte). [Pero] también genera «externalidades en el desarrollo tecnológico, la generación de habilidades y la capacitación, que son cruciales para la competitividad» (Onudi, 2013, p. 5). En consecuencia, puede decirse que los rendimientos crecientes a escala son específicos a la manufactura y no se encuentran en la agricultura o los servicios. Esto no significa que otros sectores como la agricultura y los servicios no sean importantes en el desarrollo; sino que «el avance tecnológico se concentra de forma óptima y creciente en el sector de la manufactura y se extiende desde allí a otros sectores económicos, como el sector servicios. Además, los bienes de capital que se emplean en otros sectores se producen en el mismo sector manufacturero» (Szirmai y Verspagen, 2010).

En un estilo de crecimiento liderado por la manufactura, la productividad y el progreso técnico son endógenos. La explicación de la correlación entre el crecimiento económico y 
la productividad en la manufactura se sustenta en la existencia de rendimientos crecientes estáticos y dinámicos en el sector industrial. «Los rendimientos estáticos se refieren principalmente a las economías de escala internas a la empresa, mientras que los rendimientos dinámicos se refieren al aumento de la productividad derivado del aprendizaje en la práctica (learning by doing), el cambio tecnológico «inducido», las economías externas en la producción» (Libanio, 2006a, p. 4).

Cuando se expanden los mercados aumenta la posibilidad de incorporar nuevos métodos y medios de producción que dan lugar a un aumento de la productividad del trabajo. Se producen innovaciones tecnológicas en los procesos productivos y "procesos graduales de aprendizaje por el ajuste de tecnologías que permiten optimizar el uso de los recursos, o por la agregación de pequeńas innovaciones que se adelantan en las empresas para adaptar tecnologías en la generación de nuevos productos bajo condiciones locales» (Villamil, 2003, p. 153). El rápido desarrollo tecnológico y los adelantos generados por la investigación científica, exclusivamente en el sector industrial, han sido los principales pilares que explican la eficacia en la utilización de los factores de producción.

La idea del progreso técnico endógeno pertenece a Kaldor, quien, siguiendo a A. Young (1928) sostiene que los rendimientos crecientes, como fenómeno macroeconómico, provienen de la interacción entre las actividades económicas durante el proceso de crecimiento económico. Es la misma idea que se encuentra en Adam Smith (1937[1776]) para quien el aumento de la productividad resulta de la profundización y extensión de la división del trabajo las mismas que a su vez dependen de la extensión del mercado. Por su parte Arrow hizo énfasis en el aprendizaje en el trabajo (learning by doing) para generar aumentos en la productividad.

A diferencia de otros sectores, entonces, la industria manufacturera ofrece mejores oportunidades para invertir y acumular capital, aprovechar las economías de escala, innovar y adquirir nuevas tecnologías, desarrollar y difundir nuevas tecnologías en su propio ámbito y en los demás sectores de la economía, y mejorar la calidad de empleo y los niveles de ingresos de los trabajadores (Onudi, 2013; Kiliçaslan y Taymaz, 2007). La producción manufacturera, además, es la que más incorpora y desarrolla la ciencia y tecnología, y la que más facilita el proceso de difusión tecnológica.

La relación entre el crecimiento del sector manufacturero, cambio técnico y productividad se expresa en la ley conocida de Verdoorn-Kaldor según la cual un rápido crecimiento del producto manufacturero, a través de rendimientos crecientes a escala, conducirá a un rápido crecimiento de la productividad laboral en la industria. La productividad y el progreso técnico son endógenos; esto quiere decir que existe una relación directa entre el cambio tecnológico y el desarrollo industrial. El aumento de la productividad no se determina en forma exógena, sino que depende del crecimiento de la producción manufacturera y este del incremento de la demanda o, más exactamente, de la expansión del mercado. 
La manufactura multiplica ingresos y mejora el nivel de vida de la población. Por los encadenamientos que genera, no solo multiplica los empleos, sino también los ingresos, elevando la producción y la productividad del trabajo de la economía en su conjunto. Su impacto positivo en el crecimiento de la productividad hace posible el pago de mejores salarios y beneficios para los trabajadores y sus familias. «Ayuda a elevar el estándar de vida de la población al mejorar su capacidad de adquirir bienes y servicios y de invertir en educación y salud. Permite a las empresas acumular capital, que luego pueden utilizar para continuar mejorando la tecnología o aprovechar nuevas oportunidades de inversión» (Onudi, 2013, p. 9). La manufactura emplea a muchos trabajadores altamente calificados en actividades de alta productividad y con salarios más altos que el promedio. Este patrón fue registrado en muchos países desarrollados y más recientemente en varios países del sudeste asiático. La industria es en este sentido un factor de cambio estructural, porque provoca transferencia de recursos de actividades intensivas en mano de obra hacia a actividades más intensivas en capital y en tecnología, y con mejores salarios. Por eso la industrialización sigue y seguirá siendo fundamental para el progreso y modernización de los países en desarrollo (IBEF, s/a; Scott, 2008; Onudi, 2016).

[...] En los sectores de mayor empleo manufacturero -industria textil, de vestuario y de alimentos y bebidas - muchas personas trabajan percibiendo bajos salarios, las cuales coexisten con un pequeño grupo que gana salarios mucho más altos. Esta estructura salarial no necesariamente va en contra del desarrollo del país, siempre y cuando esta mayoría de trabajadores reciban salarios más altos que en las otras importantes fuentes de empleo [la agricultura, las actividades de subsistencia y el empleo informal], una condición que generalmente se cumple (Onudi, 2013, p. 20).

La manufactura estimula el crecimiento de las exportaciones. El cambio técnico resultante de la profundización y extensión de la división del trabajo, dinamiza el crecimiento mediante la expansión de la producción manufacturera y de los aumentos de la productividad del trabajo; y, cuando aumenta la productividad, se reducen los costos unitarios de producción y, por lo tanto, aumenta la competitividad lo cual hace posible el incremento de las exportaciones (Jiménez, 2010[1982], 1999; De la Rosa Mendoza, 2006; Salazar Arias, 2013). El desarrollo del sector manufacturero entonces también estimula el crecimiento y diversificación de las exportaciones, porque aumenta su competitividad.

Los productos manufacturados tienen, en general, mayor contenido tecnológico que incrementa las oportunidades comerciales y permite ganar participación en el mercado internacional. El comercio mundial está dominado por los productos manufacturados, que «representan alrededor del 70 por ciento del valor de las exportaciones en las economías avanzadas y en desarrollo» (McKinsey \& Company, 2012; Kilavuz y Altay Topcu, 2012). En consecuencia, una industria en expansión contribuye a superar la restricción de balanza pagos de un país. La causalidad, sin embargo, va del crecimiento de la demanda externa al crecimiento de la industria manufacturera. El crecimiento de las exportaciones netas de importaciones, por ser parte de la demanda agregada, 
amplía las posibilidades de los cambios técnicos y de los aumentos de la productividad y competitividad. Las exportaciones manufactureras adquieren liderazgo cuando el sector manufacturero es más competitivo, maduro, con mayor presencia tecnológica y con una mano de obra cada vez más calificada. El efecto en el comercio de la industria manufacturera será mayor cuanto mayor sea su encadenamiento productivo interno porque se convierte en fuente de demanda de bienes y servicios de otros sectores, y crea externalidades positivas al interior de la economía impulsando la innovación tecnológica (Kaldor, 1968, 1970; Kilavuz y Altay Topcu, 2012; Felipe, 1998; De la Rosa Mendoza, 2006).

En resumen, la industria manufacturera — como dice Rodrik (2016) — tiene características que la distingue de otras y le otorgan un papel decisivo en el proceso de crecimiento:

En primer lugar, la manufactura tiende a ser tecnológicamente un sector dinámico. De hecho, [...] la actividad manufacturera exhibe convergencia incondicional en la productividad del trabajo, a diferencia del resto de la economía ${ }^{2}$. En segundo lugar, la manufactura ha absorbido tradicionalmente cantidades significativas de mano de obra no calificada, algo que la distingue de otros sectores de alta productividad como la minería o las finanzas. En tercer lugar, la manufactura es un sector comercializable (tradable sector), lo que implica que no enfrenta las restricciones de demanda de un mercado doméstico poblado por consumidores de bajos ingresos. Se puede expandir y absorber a los trabajadores incluso si el resto de la economía se mantiene tecnológicamente estancada. En conjunto, estas características hacen de la manufactura la escalera perfecta para las economías en desarrollo (2016, p. 3).

El sector manufacturero genera importantes encadenamientos productivos y acentúa el proceso acumulativo del desarrollo; se encuentra sujeto a rendimientos crecientes a escala estáticos (derivados del tamaño y escala de la producción) y dinámicos (del proceso de learning by doing). La expansión de la industria manufacturera profundiza y extiende la división del trabajo, dando lugar a aumentos de la productividad, como resultado de innovaciones y cambios técnicos endógenos, que reducen costos y aumentan su competitividad, es decir, su capacidad de ganar o penetrar otros mercados, y así sucesivamente. Se expande generando un proceso de causación circular acumulativa (Smith, (1937[1776]); Kaldor, 1966, 1970 y 1978).

Por sus efectos positivos en la productividad y la competitividad, el desarrollo de la industria manufacturera puede contribuir al relajamiento de la restricción en balanza de pagos y conducir a un mejor desempeño del PBI y de la producción no manufacturera (Felipe, 1998, p. 467). Además, absorbe trabajadores de sectores con subempleo o con rendimientos decrecientes, aumentando así la calificación de la mano de obra.

2 Se dice que las industrias manufactureras exhiben convergencia incondicional en la productividad del trabajo, cuando existe una tendencia a cerrar la brecha con los niveles de productividad de los países avanzados. Rodrik halla la existencia de esta convergencia en varios niveles de desagregación para una muestra que abarca más de 100 países en las últimas décadas (Rodrik, 2013). 
La experiencia de desarrollo de muchos países del primer mundo y más recientemente de varios países del sudeste asiático registra el notable papel desempeñado por la manufactura en la absorción del excedente de la mano de obra del sector agricultura.

\subsection{LA DEMANDA COMO DETERMINANTE DEL CRECIMIENTO MANUFACTURERO Y LAS LEYES DE KALDOR}

Para la teoría neoclásica del crecimiento — que supone rendimientos constantes a escala, sustitución perfecta de factores de producción, competencia perfecta y equilibrio de pleno empleo-, el crecimiento de la productividad se explica mediante el cambio técnico exógeno. Esta teoría privilegia los factores de oferta (factores de producción y tecnología) para explicar el crecimiento económico.

Para el enfoque kaldoriano y keynesiano, que es el que se sigue en este trabajo, los factores de demanda (consumo, inversión, demanda externa) actúan como determinantes del crecimiento económico. El aumento de la productividad no proviene de un cambio técnico exógeno, sino de un cambio técnico endógeno originado por el crecimiento de la producción manufacturera el mismo que es impulsado por el incremento de la demanda o la expansión del mercado. Igual ocurre con el crecimiento del empleo: este crece de manera multiplicada cuando crece la producción manufacturera.

Existe, por lo tanto, una relación de directa dependencia entre los aumentos de la productividad y del empleo, por un lado, y el crecimiento de la producción, por el otro. «Las manufacturas se encuentran sometidas a la ley de rendimientos crecientes, lo que causa que la productividad se incremente como consecuencia de los incrementos en el producto. La productividad es endógena» (Sánchez Juárez, 2011, p. 158). En otras palabras, el aumento de la productividad es un resultado macroeconómico endógeno asociado a los rendimientos crecientes que resulta de la expansión de la manufacturera (Jiménez, 2010 [1982]; Calderón y Sánchez, 2012; Cabezas, Laría y Lama, 2011; Sánchez Juárez, 2011).

En este enfoque Kaldoriano no solo el crecimiento del empleo sino también el crecimiento del stock de capital es endógeno. Su crecimiento está determinado principalmente por el crecimiento del producto y la expansión de este, como ya se ha dicho, depende de la extensión del mercado. El límite al crecimiento no puede estar en la dotación del stock de capital. Como este está constituido por un conjunto de mercancías destinadas a producir otras mercancías, su expansión depende del crecimiento de la demanda. El incremento de la producción y el ritmo de acumulación de capital, son partes de un mismo proceso (Kaldor, 1966, 1975; Thirlwal, 1983). El límite al crecimiento tampoco puede estar por el lado del factor trabajo. Este, sobre todo en países como el Perú, está subempleado. En resumen, según el pensamiento kaldoriano del desarrollo «un aumento en la demanda por productos manufacturados, es probable que resulte en un aumento de la productividad a través de dos canales. Por un lado, el aumento 
de la demanda por productos manufacturados conduce a más inversión y, por consiguiente, a la mejora de la tecnología incorporada. Por otra parte, y quizás lo que es más importante, el crecimiento del producto inducido por los estímulos desde el lado de la demanda crea un progreso técnico no-incorporado a través de las interacciones entre las actividades» (Jeon, 2006, p. 4).

Nicholas Kaldor sistematizó el proceso de causación circular acumulativa, o de crecimiento endógeno, en las siguientes tres leyes (Kaldor, 1966, 1967, 1968):

1) La tasa de crecimiento del producto manufacturero es la principal y directa determinante de la tasa de crecimiento del producto agregado (PBI) o, más precisamente, del crecimiento de la producción del resto de actividades económicas (agricultura, comercio, servicios, etc.). La razón, como ya se ha dicho, está en los encadenamientos hacia atrás y hacia adelante que la industria manufacturera tiene con el resto de actividades económicas. Se supone que la causalidad va del crecimiento de la producción manufacturera al crecimiento del PBI agregado. Si la correlación positiva entre el crecimiento del PBI (o el crecimiento del PBI no manufacturero) y el crecimiento del PBI de la manufactura es altamente significativa, desde el punto de vista estadístico, entonces se corrobora la hipótesis de la manufactura como motor del crecimiento del crecimiento. La alta significancia de esta correlación puede deberse a que el sector manufacturero acrecienta su participación (efecto participación) en la generación del PBI. Un coeficiente de correlación significativamente menor que la unidad implica que cuanto mayor es el exceso de la tasa de crecimiento del PBI de la manufactura respecto al PBI agregado, más rápida será la tasa de crecimiento del PBI.

2) La tasa de crecimiento de la productividad del trabajo en la manufactura está determinada positivamente por la tasa de crecimiento de la producción manufacturera. Esta es la famosa ley que Kaldor denominó Ley de Verdoorn. La determinación endógena de la productividad se explica por el hecho de que la extensión y profundización de la división del trabajo solo puede darse mediante aumentos en el volumen de la producción pues sólo así es posible una mayor racionalización y mecanización de los procesos de producción (Verdoorn, 1949). Este razonamiento también se encuentra en Adam Smith (1958 [1776]). Refiriéndose al sector manufacturero, A. Smith afirmaba que la amplitud de la división del trabajo se encuentra limitada por la extensión del mercado ${ }^{3}$. Cuando el tamaño del mercado crece, aumentan las posibilidades de extender e intensificar la división y especialización del trabajo. Este resultado, a su vez, estimula no solo el crecimiento y diversificación de la manufactura, sino también el incremento de

\footnotetext{
3 Véase A. Smith (1958, p. 20). «La agricultura por su propia naturaleza no admite tantas subdivisiones del trabajo, ni hay división tan completa de sus operaciones como en las manufacturas» (p. 9).
} 
la productividad del trabajo de todo el sector, debido a que sus actividades se encuentran estrechamente interrelacionadas. Además, como una más intensa y extensa división del trabajo acentúa dichas interrelaciones y origina mayores aumentos de la producción, la presencia de rendimientos crecientes sería concomitante al crecimiento del sector manufacturero (Kaldor, 1966, pp. 7 a 10; Jiménez, 2010[1982]).

3) Finalmente, la tasa de crecimiento de la productividad de la economía en su conjunto depende positivamente de la tasa de crecimiento de la producción manufacturera y negativamente de la tasa de crecimiento del empleo no-manufacturero. La expansión de la industria manufacturera no solo genera un crecimiento más rápido de la productividad en la manufactura, pues «también tiene efectos de derrame (spillover effects) en el conjunto de la economía. De otro lado, su crecimiento reduce las actividades ineficientes que operan con rendimientos decrecientes, como la agricultura u otros sectores no manufactureros. En consecuencia, el crecimiento de la producción y del empleo manufacturero eleva la productividad de las otras actividades económicas» (Dasgupta y Singh, 2006, p. 10). En esta misma línea de argumentación, podemos decir que cuando se expande la producción manufacturera el aumento respectivo de la demanda por trabajo se convierte «en un polo de atracción de trabajadores que se encuentran en sectores tradicionales en una situación de desempleo disfrazado». En estos sectores disminuye el empleo pero el producto no se reduce, dando lugar a un aumento de la productividad del trabajo. Asimismo, «la transferencia de recursos de sectores de baja productividad a otros de alta productividad genera un efecto favorable en la productividad agregada de la economía, ya que trabajadores poco productivos empleados en actividades tradicionales se convierten en trabajadores industriales más productivos» (Ocegueda, 2003, p. 1028; véase también Moreno Rivas, 2008).

En el enfoque kaldoriano, entonces, la productividad es un fenómeno macroeconómico endógeno. La productividad no es una variable exógena ni determinante del crecimiento, sino un resultado endógeno del crecimiento liderado por la expansión manufacturera.

\subsection{LA INDUSTRIA MANUFACTURERA Y LOS ESTILOS DE CRECIMIENTO ECONÓMICO}

No todas las economías crecen lideradas por la industria manufacturera. El sector que lidera el crecimiento es el que define el estilo y el patrón de acumulación de capital; y en el estilo del crecimiento se encuentran las razones del atraso o progreso de la economía. En otras palabras, el tipo de actividades que un país decide desarrollar determina las condiciones de auge o crisis económicas, la presencia de empleo formal calificado o de empleo informal y subempleado. Siguiendo este paradigma, un país que opta 
por desarrollar actividades manufactureras tenderá a crecer alejándose de aquellos países que se especializan en actividades mineras, agropecuarias, comerciales y/o de servicios (Sánchez Juárez, 2011; Williamson, 2012).

Pasar de un estilo de crecimiento primario exportador a un estilo de crecimiento liderado por la manufactura, es un proceso de cambio estructural caracterizado por la transferencia de empleo desde los sectores tradicionales o de aquellos donde predomina el subempleo y la informalidad, hacia las actividades manufactureras de mayor productividad. La productividad en la industria manufacturera es generalmente más alta que la de otros sectores como la agricultura o los servicios; pero lo más importante —y que lo diferencia de los sectores primarios como la minería y el petróleo que son de alta productividad—, es que la industria manufacturera «es el sector clave en el desarrollo y difusión de nuevas tecnologías que aumentan la productividad, no sólo del sector manufacturero sino también el de los demás sectores de la economía permitiendo un mayor crecimiento de toda la economía» (Kiliçaslan y Taymaz, 2007; MacKinsey \& Company, 2012).

La industrialización permite pasar de actividades de baja productividad con oportunidades limitadas de cambio tecnológico, hacia actividades de alta productividad y con mejores oportunidades de innovación tecnológica (Onudi, 2013, p. 3). Este cambio estructural no ocurre con estilos de crecimiento que no están liderados por la industria manufacturera. El objetivo no es ubicarse en la frontera tecnológica sino cambiar la estructura productiva hacia actividades de mayor productividad, asimilando tecnologías existentes y acumulando rápidamente capital físico y humano en actividades manufactureras (Onudi, 2013, pp. 5-6).

Se podría argumentar que en los países pequeños, las perspectivas de desarrollo de la industria son limitadas debido a que sus reducidos mercados internos impiden el desarrollo de las economías de escala. También se podría afirmar que en la era actual del conocimiento y del desarrollo de los servicios de alta tecnología la apuesta por el desarrollo industrial en países como el nuestro es equivocada. Pero, ninguno de estos argumentos es relevante para economías como la peruana.

Por un lado, los mercados internos se crean, se desarrollan. Pocos reparan, por ejemplo, en la desconexión de la economía peruana, con su geografía y demografía, y que hay espacios donde no existen mercados y, si existen, estos son poco dinámicos por la carencia fundamentalmente de infraestructura económica y social. Un mercado interno en expansión es, por lo tanto, necesario para poner a la industria en una senda de crecimiento a largo plazo.

De otro lado, optar por los servicios es una estrategia inadecuada para un país con 73.7\% de empleo informal. Como señala Rodrik, los servicios de alta tecnología crean poco empleo y demandan trabajo especializado; por ello su contribución al empleo total es totalmente limitada. En cambio,

El sector manufacturero [...] puede absorber gran cantidad de trabajadores con una especialización moderada, dándoles puestos de trabajo estables y buenos beneficios. 
Por tanto, para la mayoría de los países sigue siendo una importante fuente de empleos bien remunerados. [...] Sin una base manufacturera vibrante, las sociedades tienden a dividirse entre ricos y pobres: quienes tienen acceso a puestos de trabajo, estables y bien remunerados, y aquellos cuyos empleos son menos seguros y viven existencias más precarias. En última instancia, la manufactura puede ser fundamental para el vigor de la democracia de una nación (Rodrik, 2011).

La ausencia de una política pública que elimine la restricción de mercado y las bajas tasas de inversión orientadas al desarrollo industrial generalmente conviven con desequilibrios estructurales y estancamiento en el crecimiento económico de un país. «La política industrial nunca pasó de moda — dice Rodrik- . Los economistas entusiastas del neoliberal Consenso de Washington pueden haberla descartado, pero las economías de éxito siempre han confiado en las políticas estatales que fomentan el crecimiento acelerando la transformación estructural» (Rodrik, 2010).

\section{CRECIMIENTO ECONÓMICO Y PAPEL DE LA INDUSTRIA MANUFACTURERA: EVIDENCIA EMPÍRICA SOBRE LA LEYES DE KALDOR}

\subsection{NEOLIBERALISMO Y DESINDUSTRIALIZACIÓN PREMATURA}

El fracaso de la industrialización promovida desde el Estado ${ }^{4}$, que formalmente empieza el año 1959 y se prolonga hasta la primera mitad de la década de 1970, dio lugar a la aplicación de políticas de estabilización y ajuste estructural en los años 1980, y, en los años 1990, a la aplicación de políticas de desrregulación de los mercados y de minimización de la intervención del Estado en el funcionamiento del mercado. Los últimos 25 años de neoliberalismo, entonces, coinciden con el boom de las exportaciones asiáticas, en especial de China, competidores de bajos salarios. Con la liberalización del comercio del mercado, entonces, se propició una masiva penetración de importaciones. El valor del total de bienes importados pasó de cerca del $80 \%$ en 1980 a 157\% de la producción manufacturera, a precios de 2007, en 2015.

El efecto de este tipo de inserción de nuestra economía a los mercados internacionales condujo a un notable proceso de desindustrialización. La participación de la manufactura en la generación del PBI y del empleo se redujo notablemente durante el período de las políticas neoliberales. Se registró entonces una caída, en términos relativos, de la producción manufacturera junto con una pérdida de su capacidad de generar empleo, fenómeno que es denominado en la literatura especializada como desindustrialización (Saeger, 1997; Marquez y Pradilla, 2008).

\footnotetext{
4 El historiador económico Luis Bértola y J. A. Ocampo se rehúsan identificar el proceso de industrialización de América Latina como un proceso de sustitución de importaciones, prefieren denominarla «industrialización dirigida por el Estado» (Bértola y Ocampo, 2013, pp. 23, 48 y cap. IV).
} 
Este fenómeno de desindustrialización aparece asociado a la creciente «integración» de nuestra economía a la economía global, facilitada por las desregulaciones y, en especial, por la liberalización del comercio. Más precisamente, podríamos decir que la desindustrialización está relacionada con la creciente penetración de la economía global a nuestra economía aún subdesarrollada. Esta peculiar integración a la economía global redujo la capacidad de absorción de empleo de la industria manufacturera y, consecuentemente, aumentó la informalidad y el empleo en las actividades de servicios de baja productividad (Jiménez, 2012).

«Para los liberales y neoliberales, la desindustrialización es un aspecto del proceso de cambio estructural, que incluyó el paso de la agricultura a la industrialización urbana, y ahora continuaría con el tránsito hacia la terciarización» (Marquez y Pradilla, 2008, p. 25). Pero lo que no dicen es que esta terciarización es prematura porque está caracterizada por la expansión del empleo en actividades de comercio y servicios de baja calificación y productividad. Esto es lo que Rodrik (2016) llama desindustrialización prematura porque ocurre en una economía que no ha alanzado un grado de desarrollo industrial significativo ni ha llegado a niveles de ingreso per cápita similares a la de los países desarrollados.

La manufactura — dice Rodrik - suele seguir una trayectoria en forma de U invertida a lo largo del desarrollo. [...] En la mayoría de (los países en desarrollo), la industria manufacturera ha empezado a encogerse (o está encaminada a encogerse) en niveles de ingreso que son una fracción de aquellos en los que las economías avanzadas comenzaron a desindustrializarse. Los países en desarrollo se están convirtiendo en economías de servicios sin haber pasado por una experiencia adecuada de industrialización. Llamo a esto «desindustrialización prematura» (Rodrik, 2016, p. 2).

Pero, como dice Salama, “desindustrialización temprana” e industrialización dependen de la forma en la que se practique la apertura. Si las fuerzas del mercado son libres para fijar los precios y la inversión directa, la probabilidad de que un proceso de "desindustrialización temprana" ocurra es alta. Si el Estado interviene en diversas variables (tipo de cambio, tasa de interés, subsidios focalizados, desarrollo acelerado de infraestructura considerando los retrasos acumulados, y medidas proteccionistas temporales y específicas), entonces las condiciones para la reanudación de la industrialización están satisfechas» (Salama, 2012b, p. 246). Por ejemplo en el Perú, la industria textil y confecciones, así como la de cuero y calzado perdieron competitividad en el mercado mundial debido a una década de apreciación cambiaria. En general el efecto negativo de las políticas neoliberales y la ausencia de políticas de fomento de la industria manufacturera afectaron la productividad de sus trabajadores.

Con el neoliberalismo y el consecuente abandono de la política industrial en las economías en desarrollo, desaparecen los incentivos por el lado de la demanda que impulsan el crecimiento industrial manufacturero. Peor aún, en economías primario exportadoras, la apreciación del tipo de cambio junto a la penetración de importaciones 
y la creciente desigualdad, tienden a debilitar el escaso desarrollo industrial, y a provocar una desindustrialización prematura.

Como ya se ha señalado, la desindustrialización prematura ocurre conjuntamente con una terciarización también prematura de la economía, es decir, la mayor parte del exceso de mano de obra que no encuentran trabajo en la agricultura, minería y en la propia manufactura, «inevitablemente terminan en sectores productivos y de servicios informales de baja productividad» (Dasgupta y Singh, 2006, p. 6). La consecuencia es la terciarización prematura: se expanden los sectores de comercio y servicios con empleos de baja calificación y baja productividad (Jiménez, 2012; Szirmai y Verspagen, 2010).

La desindustrialización prematura es parte del cambio estructural generado por las políticas neoliberales que se expresa en la creciente importancia que adquiere el sector servicios y que explica la creciente informalidad y baja productividad de la gran mayoría de los trabajadores (74,3\% del total de la PEA ocupada en Perú, según el INEI (2014)). Rodrik (2014) se pregunta si podrán las actividades de servicios desempeñar el papel que correspondió en el pasado a la manufactura; es decir, si estas actividades sacarán a nuestros países del subdesarrollo. Su respuesta es clara:

En los países en desarrollo actuales, la mayor parte del exceso de mano de obra es absorbido por los servicios no comercializables que funcionan con un nivel de productividad muy bajo, en actividades como, por ejemplo, el comercio al por menor y las tareas domésticas. En principio, muchas de esas actividades podrán beneficiarse de unas tecnologías mejores, una mejor organización y una mayor formalización, pero a ese respecto entra en juego la segunda diferencia entre los servicios y la manufactura. Los aumentos parciales de la productividad en las actividades no comercializables son en última instancia autolimitadores, porque las actividades de servicios no pueden ampliarse sin volver su relación de intercambio contra sí mismas: bajando sus propios precios (y rentabilidad). En la manufactura, los países en desarrollo pequeños podrían prosperar a partir de algunos éxitos en la exportación y diversificarse secuencialmente en el tiempo: ahora camisetas, después el montaje de televisores y hornos de microondas y así sucesivamente, ascendiendo por la cadena de los conocimientos técnicos y del valor (Rodrik, 2014: párr. 14-15).

Podemos decir, en resumen, que la desindustrialización prematura en los países en desarrollo, es un fenómeno de mediano o largo plazo que conduce a la disminución de la base industrial de un país, a la reducción del peso relativo de la industria manufacturera en el PBI y en el empleo total y que, por esta razón, reduce también su contribución al crecimiento económico y a la generación de empleo. No es una desindustrialización causada por el progreso tecnológico; este tipo de desindustrialización es el que ocurre en los países de industrialización avanzada.

La explicación de la desindustrialización prematura, como la del Perú, que se expresa en la reducción de la participación tanto de la producción como del empleo manufacturero, tiene como causa o explicación la apertura comercial y la globalización. En países como Perú, con ventajas comparativas en la producción primaria y no en la producción 
manufacturera, la apertura comercial — como señala Rodrik — produce un doble shock. Por un lado, la débil ventaja comparativa en la producción manufacturera los convierte en importadores netos de manufacturas, lo que los hace desandar el proceso de sustitución de importaciones que antes impulsaron. Por otro lado, dado que son países tomadores de precios, la reducción de los precios relativos de las manufacturas en los países avanzados es otro factor que reduce la importancia relativa de la manufactura en la producción y el empleo, a pesar de que estos países no experimentaron mucho progreso tecnológico (Rodrik, 2016, p. 4).

La ventaja comparativa en la producción de productos primarios, dada la apertura comercial, fue otro factor de desindustrialización debido a que su consecuencia, la enfermedad holandesa (apreciación cambiaria), afectó la competitividad de los productos manufacturados. Esta apreciación cambiaria y, por lo tanto, la pérdida de competitividad de la manufactura son, además, reforzadas con la apertura al movimiento internacional de capitales. Esto es lo que algunos llaman Enfermedad Holandesa de tipo II (Schuldt, 1994; Jiménez, 1999; Sachs y Warner, 1999).

En el Perú la desindustrialización prematura se expresa justamente como la reducción de la participación de la manufactura en el empleo y la producción del conjunto de la economía (véase Gráficos 1 y 2). Su participación en la generación de empleo crece sistemáticamente desde 8,3\% en 1950 hasta 12,6\% en 1975. Estos son los ańos del apogeo de la industrialización dirigida por el Estado y que formalmente empieza en 1959. Después se derrumba con la crisis de comienzos de la década de 1980. Su posterior recuperación solo dura hasta inicios de los años 1990, para luego mostrar una notoria tendencia decreciente que llega hasta $9,4 \%$ en el año 2015. Como se sabe, este último período (1990-2015) corresponde al dominio de las políticas de liberalización y desregulación de la economía.

Gráfico 1. Participación de la manufactura en el empleo total: 1950-2015 (Porcentajes)

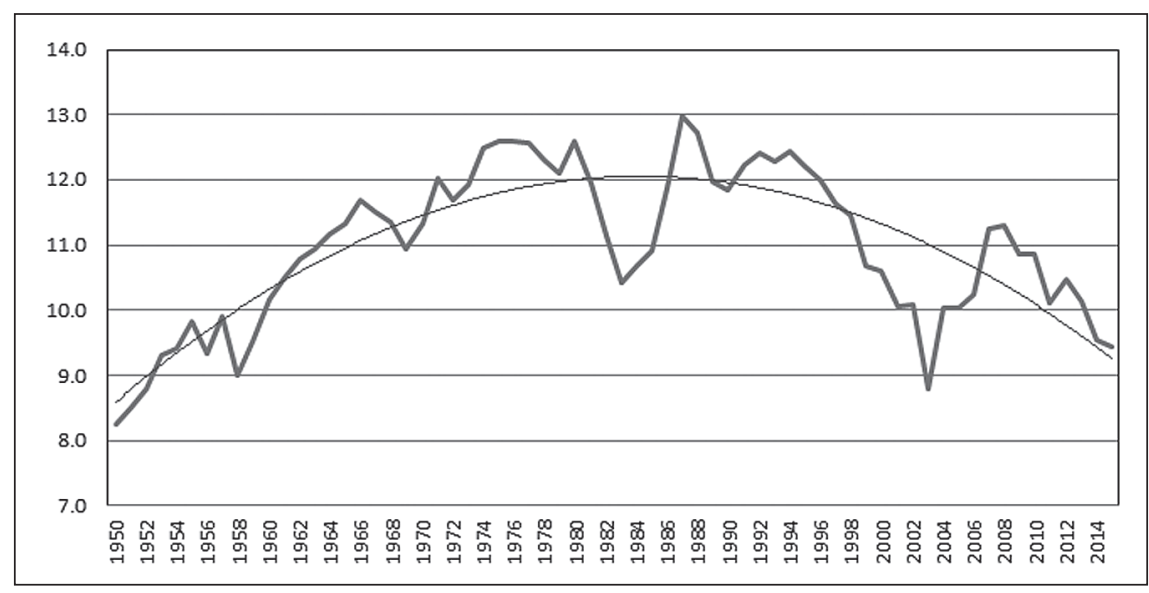


En el Gráfico 2 se observa que la desindustrialización prematura en Perú, también toma la forma de una reducción de la participación de la producción manufacturera en la generación del PBI total. Esta participación sube desde 13,8\% en 1950 hasta un poco más de $18 \%$ a comienzos de los ańos 1970 , período que corresponde, como ya se dijo, a la industrialización mediante sustitución de importaciones. Durante el período neoliberal de 1990-2015 — dejando de lado los efectos de las políticas de ajuste y estabilización de la década de 1980 - la participación de la manufactura en la producción total se reduce hasta $13,4 \%$ en 2015 .

Gráfico 2. Participación de la manufactura en el PBI total: 1950-2015

(Porcentajes)

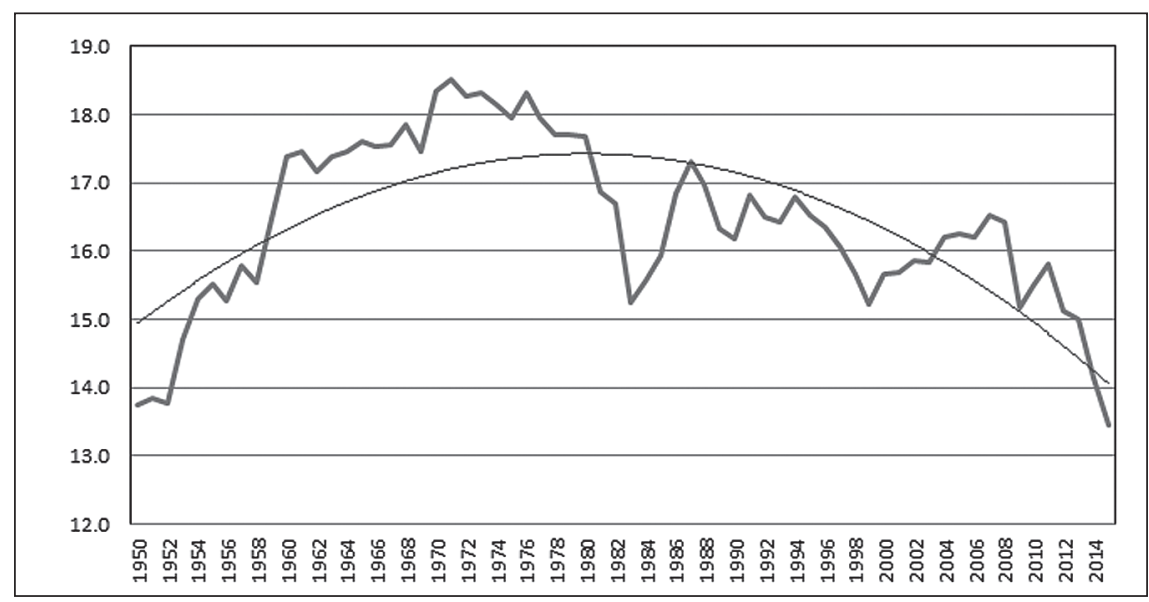

La desindustrialización —reducción de la participación de la manufactura en la generación del empleo y la producción totales - no se debe a la presencia de un rápido progreso tecnológico en la manufactura, sino a la liberalización comercial y financiera. El desempeño industrial cambia en el contexto de apertura respecto al desempeño que se registra durante el proceso de industrialización dirigido por el Estado. Esta desindustrialización es prematura porque su causa no es el progreso tecnológico y el concomitante aumento de la productividad, como si lo es en los países de industrialización avanzada. Si en nuestro país se hubiera producido un rápido progreso tecnológico, esto habría fomentado la industrialización — como dice Rodrik-, y no lo contrario (Rodrik, 2016). En países como Perú, entonces, la desindustrialización no ocurre, como en el caso de los países avanzados, por la presencia de un significativo de progreso tecnológico (véase también Szirmai y Naudé, 2012).

La desindustrialización prematura tiene efectos retardatarios sobre el crecimiento económico a largo plazo, porque reduce la contribución del sector manufacturero a este crecimiento. Como se observa en el Gráfico 3, durante los años 1950-1975 la contribución al crecimiento económico de la industria manufacturera se mantuvo por encima 
de 19\% hasta el año 1972. Después se redujo hasta 14,3\% en el año 1976. Los años posteriores hasta 1990, fueron de crisis continuas (1976-1978, 1982-1983 y 1988-1990). Estas crisis cubren más del 50\% del total de años del periodo 1976-1990. En estos años la industria manufacturera decrece a la tasa de $-0,8 \%$ promedio anual.

Durante los ańos del neoliberalismo 1990-2015, la contribución de la industria manufacturera al crecimiento económico de largo plazo, es sistemáticamente inferior a la que se registró entre 1950-1976 . Se mantiene por debajo del 15\% entre los años 1991-1999; se recupera hasta alcanzar un máximo de 17,7\% en el año 2003 — porcentaje menor al registrado en 1973-y, finalmente, decrece sistemáticamente hasta alcanzar el porcentaje de 6,4\% en el ańo 2015.

Gráfico 3. Contribución de la manufactura al crecimiento (porcentajes)

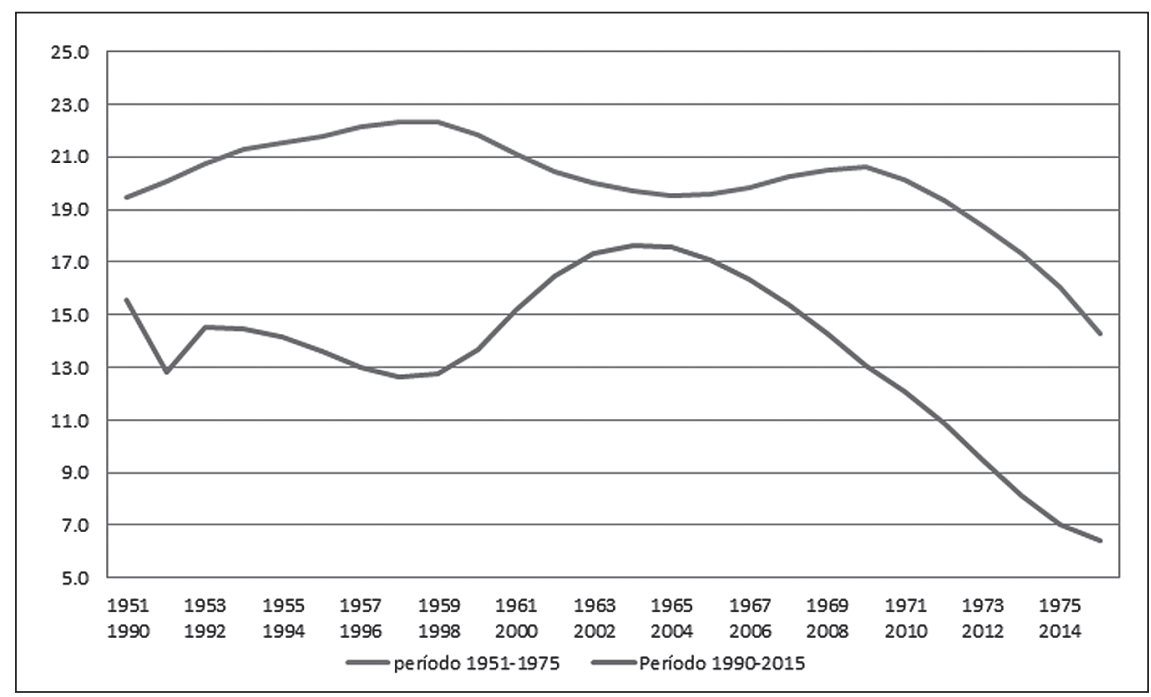

Estos años en los que se produce una disminución acelerada de la contribución de la manufactura al crecimiento económico, corresponden precisamente al apogeo del estilo de crecimiento primario exportador prohijado por la desregulación y liberalización de los mercados. El estancamiento económico actual revela la incapacidad de este estilo de crecimiento para resolver los desajustes estructurales básicos de la economía, porque - como ya ocurrió antes - no ha sido capaz de generar un adecuado aprovechamiento de los recursos, y de producir una asignación de los mismos que asegure el crecimiento sostenido y un desarrollo socialmente aceptable (Jiménez, 1991, 1999).

5 La contribución al crecimiento de largo plazo de la manufactura se calcula dividiendo el producto potencial o de largo plazo de la manufactura entre el PBI potencial total. 


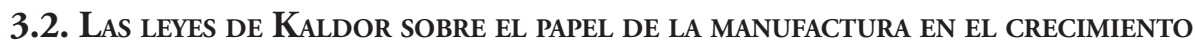

a. Primera Ley de Kaldor: la manufactura como motor de crecimiento

De acuerdo con Kaldor $(1966,1968,1970)$, la industria manufacturera se diferencia de los otros sectores porque impulsa el crecimiento de la economía en su conjunto, o el crecimiento de los otros sectores cuya producción junto a la del sector manufacturero integra el PBI. Esto quiere decir que la tasa de crecimiento de la producción manufacturera se correlaciona positivamente con la tasa de crecimiento del PBI agregado, y que la causalidad va precisamente en este sentido: del PBI de la manufactura al PBI total de la economía. Por esta razón se dice que la industria manufacturera es el motor del crecimiento. Las razones son las siguientes: 1) la producción de la industria manufacturera - a diferencia de los otros sectores económicos como, por ejemplo la minería y la agricultura-, tiene efectos multiplicadores sobre el resto de actividades o sectores económicos, debido a que genera encadenamientos productivos hacia atrás y hacia adelante; 2) los productos manufactureros tienen elevadas elasticidades-ingreso de la demanda; y 3) la industria manufacturera exhibe economías dinámicas a escala, que se obtienen conforme la división del trabajo se incrementa, como resultado del incremento de la demanda o del mercado (Kaldor, 1966, 1967 y 1968; Jiménez, 2010 [1982] y 1999).

i. La estimación con mínimos cuadrados ordinarios

Siguiendo a Kaldor (1966), Cripps y Tarling (1973), Cornwall (1976), Jiménez (2010 [1982]) y Bairam (1991), la primera forma de evaluar esta hipótesis es utilizando la siguiente especificación:

$$
q=a+b q_{m}
$$

donde:

$q$ : Tasa logarítmica de crecimiento del PBI total

$q_{m}$ : Tasa logarítmica de crecimiento del PBI manufacturero

Se espera que los parámetros estimados de la tasa de crecimiento del producto manufacturero sean positivos y estadísticamente significativos para que se cumpla la hipótesis del sector manufacturero como motor del crecimiento. Las especificaciones mencionadas han sido estimadas mediante el método de mínimos cuadrados ordinarios (OLS). El tamańo de la muestra es de 65 observaciones anuales del PBI y el PBI de la manufactura en logaritmos, a partir de los cuales se generaron las tasas de crecimiento respectivas.

La estimación de la ecuación 1 puede arrojar resultados espurios debido a que la tasa de crecimiento del PBI agregado está relacionada por definición con la tasa de crecimiento del producto manufacturero. El PBI total es la suma del PBI manufacturero y del PBI no-manufacturero. Es decir:

$$
P B I_{t}=P B \operatorname{Im}_{t}+P B \operatorname{Inm}_{t}
$$


donde $P B I_{t}, P B \operatorname{Im}_{t}$ y $P B I_{n} m_{t}$ son los niveles del PBI total, del PBI manufacturero y del PBI no-manufacturero (resto de sectores), respectivamente. De esta ecuación se obtiene la tasa de crecimiento del PBI total, que es como sigue:

$$
\hat{q}=\hat{w} q_{m}+(1-w) \hat{q}_{n m}
$$

donde las variables $w$ y $(1-w)$ son las participaciones de producto manufacturero y producto no-manufacturero en el producto total, respectivamente. Son los ponderadores de las tasas de crecimiento del PBI manufacturero y del PBI no-manufacturero. Nótese, sin embargo, que en este caso ilustrativo, las tasas de crecimiento no son logarítmicas.

En consecuencia, cualquier coeficiente obtenido usando la ecuación 1 simplemente estaría influido por la participación del PBI manufacturero en el producto total. Por lo tanto, un coeficiente $b$ positivo y estadísticamente significativo puede ser un resultado espurio que dice muy poco sobre la hipótesis de la manufactura como motor del crecimiento económico.

Para superar este problema o remover el efecto participación (share effect) de la producción manufacturera y corroborar la primera de ley de Kaldor, se puede estimar la siguiente especificación alternativa (Bairam, 1991):

$$
q_{n m}=b_{0}+b_{1} q_{m}
$$

donde:

$q_{n m}$ : Tasa logarítmica de crecimiento del PBI no manufacturero (resto de sectores)

$q_{m}$ : Tasa logarítmica de crecimiento del PBI manufacturero

Esta especificación podría ser la más adecuada para evaluar estadísticamente la primera ley de Kaldor. Cuando la tasa de crecimiento de la producción manufacturera se incrementa, la producción del resto de sectores económicos también aumenta por los encadenamientos que genera. Los resultados de las estimaciones de las ecuaciones 1 y 2 , se presentan en el Cuadro 1.

Se confirma la relación positiva estadísticamente significativa entre las tasas de crecimiento del PBI y la del PBI manufacturero, con un alto coeficiente de determinación en ambas ecuaciones ( $\mathrm{R}^{2}$ ajustado). Además, cumplen con el supuesto de normalidad, homocedasticidad y, por lo tanto, con el supuesto de correcta forma funcional. No se descarta la hipótesis nula de normalidad porque el estadístico $\mathrm{Chi}^{2}$ obtenido igual a 1,915 es menor que el valor crítico de 5,991 al 5\%, según la respectiva tabla. Tampoco se rechaza la existencia de homocedasticidad. El estadístico del test de White es menor que el valor crítico para $\mathrm{F}(5,58)$ al $5 \%$ y que es igual a 2,374 . Finalmente, por el test de Ramsey se corrobora la existencia de una buena forma funcional puesto que el valor crítico al 5\% para $\mathrm{F}(1,60)$ es 4,001 mayor que el estadístico 2,507 obtenido. 
Cuadro 1. Primera Ley de Kaldor I

\begin{tabular}{|c|c|c|}
\hline \multicolumn{3}{|c|}{ Ecuación } \\
\hline & (1) & (2) \\
\hline $\begin{array}{l}\text { Variables } \\
\text { independientes\dependientes }\end{array}$ & $q$ & $q_{n m}$ \\
\hline Constante & $\begin{array}{l}1.531^{*} \\
(0.394)\end{array}$ & $\begin{array}{l}1.818^{*} \\
(0.465)\end{array}$ \\
\hline $\mathbf{q}_{\mathrm{m}}$ & $\begin{array}{l}0.598^{*} \\
(0.036)\end{array}$ & $\begin{array}{l}0.522^{*} \\
(0.043)\end{array}$ \\
\hline $\operatorname{AR}(1)$ & $0.390^{*}$ & $0.383^{*}$ \\
\hline & $(0.119)$ & $(0.119)$ \\
\hline $\mathbf{n}$ & 65 & 65 \\
\hline $\mathbf{R}^{2}$ ajustado & 0.845 & 0.757 \\
\hline F estadistico & 173.50 & 99.447 \\
\hline D.W. & 2.046 & 2.048 \\
\hline \multicolumn{3}{|c|}{ Pruebas de Diagnóstico } \\
\hline Test de normalidad & 1.915 & 1.846 \\
\hline$J B-\chi^{2}(2)^{a}$ & $(0.383)$ & $(0.397)$ \\
\hline Test de heterocedasticidad & 1.886 & 1.747 \\
\hline de White $F(5,58)^{a}$ & $(0.110)$ & $(0.138)$ \\
\hline Test de forma funcional de & 2.507 & 2.735 \\
\hline Ramsey $F(1,60)^{a}$ & $(0.118)$ & $(0.103)$ \\
\hline Test de Wald $F(1,61)^{b}$ & $\begin{array}{l}217.77 \\
(0.000)\end{array}$ & $\begin{array}{l}212.64 \\
(0.000)\end{array}$ \\
\hline
\end{tabular}

Error estándar entre paréntesis

${ }^{*}$ Coeficiente es estadísticamente significativo al $5 \%$.

aP-value entre paréntesis, la hipótesis nula es que se tiene normalidad, homocedasticidad y buena forma funcional.

${ }^{b} S e$ muestra el estadístico $\mathrm{F}$ y entre paréntesis el $p$-value. La hipótesis nula es $\mathrm{c}(2)=1$ 
El coeficiente estimado $(0,598)$ del regresor, según el test de Wald ${ }^{6}$, es significativamente diferente (y menor) que la unidad. En consecuencia, un 1\% de crecimiento del PBI manufacturero explica el $0,59 \%$ de la tasa de crecimiento del PBI total. Además, los resultados numéricos nos permiten afirmar que a tasas más rápidas de crecimiento económico le corresponden mayores diferenciales positivos entre la tasa de crecimiento de la producción manufacturera y la tasa de crecimiento de la economía en su conjunto. En otras palabras, cuanto mayor es esta diferencia de tasas, mayor será la tasa de crecimiento del PBI. (Kaldor, 1966; Jiménez, 2010 [1982]). Por ejemplo, una tasa de crecimiento por encima 3,81\% del PBI será posible solo en el caso donde el producto manufacturero crece mucho más rápido. Por ejemplo si la producción manufacturera crece a la tasa de $8 \%$, el PBI lo hará a la tasa de aproximadamente 6,3\%. Para que el PBI crezca $7,62 \%$, el doble de $3,81 \%$, el producto manufacturero tendría que crecer a la tasa de $10,2 \%$.

La ecuación 2 tiene los mismos atributos que la ecuación 1. Satisface los supuestos básicos de una regresión lineal y, por lo tanto, tiene una correcta forma funcional. Pasa el test de normalidad para un valor crítico de 5,991 al 5\%. También pasa el test de White de homocedasticidad para un valor crítico del $\mathrm{F}(5,58)$ igual a 2,374 al 5\%. Asimismo, pasa el test de Ramsey de buena forma funcional para un valor crítico del $\mathrm{F}(1,60)$ igual a 4.001 al 5\%. Por su parte los resultados del test de Wald nos permite afirmar que el coeficiente de la tasa de crecimiento del PBI manufacturero es significativamente menor que la unidad (1).

Los resultados de las estimaciones indican que una tasa de crecimiento del PBI no manufacturero (o de los sectores no-manufactureros) por encima 3,8\% será posible solo si el PBI manufacturero crece mucho más rápido. Por ejemplo, si la producción manufacturera crece a la tasa de $8 \%$, el PBI no-manufacturero lo hará a la tasa de aproximadamente $6,0 \%$. Un coeficiente de regresión significativamente menor que la unidad, hace que la tasa de crecimiento del conjunto de la economía esté asociada a una tasa de crecimiento del PBI manufacturero que excede a la tasa de crecimiento del PBI nomanufacturero (o del resto de sectores). Cuando mayor es esta diferencia de tasas, mayor será la tasa de crecimiento del PBI no-manufacturero y, por tanto, la tasa de crecimiento de la economía en su conjunto. Esta proposición implica que las altas diferencias entre las tasas de crecimiento se encuentran usualmente en los casos donde la participación de la industria manufacturera en la generación del PBI, es creciente (Kaldor, 1966; Libanio y Moro, 2014). Por el contrario, cuando esta participación decrece, como hemos demostrado que ocurre durante el periodo neoliberal, la diferencia de tasas de crecimiento de la manufactura y del PBI (o del PBI no-manufacturero), también disminuye.

¿Podría afirmarse entonces que el liderazgo de la producción manufacturera en el crecimiento económico fue debilitado por las políticas de ajuste y las desregulaciones

\footnotetext{
${ }^{6}$ El test de Wald nos dice que el coeficiente estimado es distinto de la unidad al $1 \%$ de significancia.
} 
del mercado doméstico y externo aplicadas durante los últimos veinticinco años de neoliberalismo? Para probar esta hipótesis incorporamos una variable dummy que permita diferenciar el período 1990-2015 del anterior 1950-1989. Para justificar esta separación utilizamos el test de Zivot y Andrews con el objetivo de identificar si existe un quiebre estructural en las series que afecte el intercepto y/o la pendiente. El resultado de este test indica que el quiebre estructural que afecta al intercepto y la pendiente ocurre en el año 1988. Se construye entonces la variable dummy que denominamos dum con valores iguales a cero para el período 1950-1987 y con valores iguales a 1 para el período 1988-2015. La ecuación que capta el cambio estructural será entonces igual a:

$$
q_{n m}=b_{0}+b_{1} d u m+b_{2} q_{m}+b_{3} d u m * q_{m}
$$

Como se obtiene un coeficiente estadísticamente igual a cero para la variable $d u m$, la ecuación reestimada, cuyos resultados numéricos se presenta en el Cuadro 2, se reduce a:

$$
q_{n m}=b_{0}+b_{1} q_{m}+b_{2} d u m * q_{m}
$$

Los resultados de la estimación indican que hay un buen ajuste pues la $\mathrm{R}^{2}$ ajustada es igual a 0,745 . De otro lado, los residuos de la ecuación estimada muestran una distribución normal. No se rechaza entonces la hipótesis nula de normalidad pues el estadístico $\mathrm{Chi}^{2}$ obtenido es menor que el valor crítico de la tabla de 5,991 al 5\%. Tampoco se rechaza la hipótesis de homocedasticidad. El test de White arroja un estadístico de 1,657 menor que 2,525 que es el valor crítico del $\mathrm{F}(4,60)$ al $5 \%$. No obstante lo anterior, según el test de Ramsey la especificación adoptada no tiene una buena forma funcional. El estadístico obtenido igual a 4,349 es mayor que 3.998 que es el valor crítico de la tabla para $\mathrm{F}(1,61)$ al $5 \%$.

Por el estadístico obtenido con test de Wald se puede decir que el coeficiente de la tasa de crecimiento del PBI de la manufactura $\left(\mathrm{q}_{\mathrm{m}}\right)$ no solo es significativamente distinto de uno sino menor que uno. Además, lo que se observa es que este coeficiente de regresión aumenta a $0,669(0,504+0,165)$ en el período de los años de ajuste y del neoliberalismo, aunque sigue siendo significativamente menor que la unidad.

Entonces, como era de esperarse, el diferencial entre las tasas de crecimiento del PBI manufacturero y del PBI no-manufacturero es menor en el período neoliberal 1990-2015, que en el período anterior 1950-1989.

En el período 1990-2015 el coeficiente del regresor es de 0.669. Si el PBI manufacturero creciera a la tasa de 5,3\%, el PBI no manufacturero también crecería a la misma tasa de 5,3\%. Para obtener tasas mayores que este porcentaje, el PBI manufacturero tendría que crecer a tasas cada vez más altas. Por ejemplo, si el PBI manufacturero creciera a la tasa de $8 \%$, el PBI no manufacturero lo haría a la tasa de $7,1 \%$. O, en otras palabras, para que la economía crezca por encima de 5,3\% el producto manufacturero debe crecer a tasas mayores que este porcentaje. Sin embargo, en el actual entorno neoliberal es muy difícil que la industria manufacturera alcance tasas de crecimiento por encima de 5,3\%. 
Cuadro 2. Primera Ley de Kaldor II

\begin{tabular}{|c|c|}
\hline \multicolumn{2}{|c|}{ Ecuación } \\
\hline & (3) \\
\hline $\begin{array}{l}\text { Variables } \\
\text { independientes \dependientes }\end{array}$ & $\mathbf{q}_{\mathrm{nm}}$ \\
\hline Constante & $\begin{array}{l}1.745^{*} \\
(0.323)\end{array}$ \\
\hline$q_{m}$ & $\begin{array}{l}0.504^{*} \\
(0.054)\end{array}$ \\
\hline dum $* q_{m}$ & 0.165 \\
\hline & $(0.076)$ \\
\hline $\mathbf{n}$ & 65 \\
\hline $\mathbf{R}^{2}$ ajustado & 0.745 \\
\hline F estadístico & 94.711 \\
\hline D.W. & 1.495 \\
\hline \multicolumn{2}{|c|}{ Pruebas de Diagnóstico } \\
\hline Test de normalidad & 0.958 \\
\hline$J B-\chi^{2}(2)^{a}$ & $(0.619)$ \\
\hline Test de heterocedasticidad & 1.657 \\
\hline de White $F(4,60)^{a}$ & $(0.171)$ \\
\hline Test de forma funcional de & 4.349 \\
\hline Ramsey $F(1,61)^{a}$ & $(0.041)$ \\
\hline Test de Wald $\mathbf{F}(1,62)^{\mathrm{b}}$ & $\begin{array}{l}64.389 \\
(0.000)\end{array}$ \\
\hline
\end{tabular}

Error estándar entre paréntesis

*Coeficiente es estadísticamente significativo al $5 \%$.

ap-value entre paréntesis, la hipótesis nula es que se tiene normalidad, homocedasticidad y buena forma funcional.

${ }^{b}$ Se muestra el estadístico $\mathrm{F}$ y entre paréntesis el $p$-value. La hipótesis nula es $c(2)=1$

La situación cambia en el periodo 1950-1989 para el cual el coeficiente del regresor es igual a 0,504 . En este caso si el PBI manufacturero creciera a la tasa de 3,52\%, el PBI no manufacturero también crecería la tasa de 3,52\%. Entonces, para que este último crezca a tasas mayores que este porcentaje, el PBI manufacturero debería crecer mucho más rápido. Por ejemplo, si el PBI manufacturero creciera a la tasa de $8 \%$, 
el PBI no manufacturero lo haría a la tasa de 5,8\%. En resumen, en el período 1950 1989, no obstante las crisis que ocurren desde 1976, el diferencial de tasas es mayor porque en gran parte de este período la participación de la producción manufacturera en el PBI y el empleo total, es creciente.

Finalmente, para terminar de corroborar que la manufactura es el motor del crecimiento es necesario llevar a cabo una estimación de siete (7) ecuaciones similares a la primera para los sectores agricultura (agr), minería (min), pesca (pes), electricidad (elec), construcción (cons), comercio (come) y servicios (serv). Es decir:

donde:

$$
q=a+b q_{i}
$$

$q$ : Tasa logarítmica de crecimiento del PBI total

$q_{i}$ : Tasa logarítmica de crecimiento del PBI del sector $i$.

$i$ : agr, min, pes, elec, cons, come y serv. (Son 7 sectores)

Como puede verse en el Cuadro 3, los resultados de la estimación de las ecuaciones para la agricultura (ecuación 4), la minería (ecuación 5) y la pesca (ecuación 6) muestran un bajísimo coeficiente de determinación ( $\mathrm{R}^{2}$ ajustado) comparado con el obtenido para la manufactura. No hay buen ajuste, aunque según el test de Wald los coeficientes de los regresores son todos distintos (y menores) que la unidad. Ninguno de los tres sectores puede ser considerado, entonces motor del crecimiento.

Además, no todas las ecuaciones registran buenos diagnósticos de sus estimaciones. Primero, en todas se rechaza la hipótesis nula de normalidad. Los valores obtenidos del $\mathrm{Chi}^{2}$ son bastante altos comparados con el valor crítico de la tabla que es igual a 5,991 al 5\%. No hay normalidad en los residuos en los tres casos. De otro lado, en la ecuación (5) del Cuadro 3 que corresponde el PBI de la minería se rechaza la hipótesis nula de homocedasticidad, porque según el test de White el estadístico obtenido de 4,023 es mayor que el valor crítico de la tabla de 2,374 para $\mathrm{F}(5,58)$ al $5 \%$. En las ecuaciones (4) y (6) que corresponden a los sectores agricultura y pesca, no se rechaza la existencia de homocedasticidad al 5\%, ya que los valores obtenidos del estadístico $(0,537$ y 1,225 , respectivamente) son menores que 2,374 para $\mathrm{F}(5,58)$ al $5 \%$. Finalmente, el test de Ramsey indica que las tres ecuaciones estimadas registran una buena forma funcional. Los valores obtenidos del estadístico obtenidos ( $0,195,0.376$ y 3,279 , respectivamente) son menores que 4.001, que es el valor crítico de la tabla para $\mathrm{F}(1,60)$ al $5 \%$.

En el Cuadro 4 se muestran los resultados de las estimaciones de las ecuaciones de los sectores Electricidad (ecuación 7), Construcción (ecuación 8) y Comercio (ecuación 9). El Cuadro 5 contiene la estimación para el sector Servicios (ecuación 10). No existe un buen ajuste ( $\mathrm{R}^{2}$ ajustado) para los sectores electricidad (7) y construcción (8); en cambio, para el sector comercio la respectiva ecuación estimada si muestra un elevado coeficiente de determinación ( $\mathrm{R}^{2}$ ajustada). 
Cuadro 3. Primera Ley de Kaldor III

\begin{tabular}{|c|c|c|c|}
\hline \multicolumn{4}{|c|}{ Ecuación } \\
\hline & (4) & (5) & (6) \\
\hline $\begin{array}{l}\text { Variables } \\
\text { independientes\dependientes }\end{array}$ & $\mathbf{q}$ & $q$ & $\mathbf{q}$ \\
\hline Constante & $\begin{array}{l}2.679^{*} \\
(1.040)\end{array}$ & $\begin{array}{l}3.330^{*} \\
(1.014)\end{array}$ & $\begin{array}{c}3.705 \\
(1.195)\end{array}$ \\
\hline$q_{a g r}$ & $\begin{array}{l}0.434^{*} \\
(0.102)\end{array}$ & & \\
\hline$q_{\min }$ & & $\begin{array}{l}0.122^{*} \\
(0.061)\end{array}$ & \\
\hline$q_{\text {pes }}$ & & & $\begin{array}{c}0.023 \\
(0.021)\end{array}$ \\
\hline $\operatorname{AR}(1)$ & $\begin{array}{l}0.438^{*} \\
(0.127)\end{array}$ & $\begin{array}{l}0.405^{*} \\
(0.098)\end{array}$ & $\begin{array}{c}0.425 \\
(0.086)\end{array}$ \\
\hline $\mathbf{n}$ & 65 & 65 & 65 \\
\hline $\mathbf{R}^{2}$ ajustado & 0.353 & 0.199 & 0.155 \\
\hline F estadístico & 12.659 & 6.309 & 4.930 \\
\hline D.w. & 1.767 & 1.814 & 1.836 \\
\hline \multicolumn{4}{|c|}{ Pruebas de Diagnóstico } \\
\hline $\begin{array}{l}\text { Test de normalidad } \\
\text { JB }-\chi^{2}(2)^{a}\end{array}$ & $\begin{array}{c}145.235 \\
(0.000)\end{array}$ & $\begin{array}{l}25.159 \\
(0.000)\end{array}$ & $\begin{array}{l}57.274 \\
(0.000)\end{array}$ \\
\hline $\begin{array}{l}\text { Test de heterocedasticidad } \\
\text { de White } F(5,58)^{a}\end{array}$ & $\begin{array}{c}0.537 \\
(0.747)\end{array}$ & $\begin{array}{c}4.023 \\
(0.003)\end{array}$ & $\begin{array}{c}1.225 \\
(0.308)\end{array}$ \\
\hline $\begin{array}{l}\text { Test de forma funcional de } \\
\text { Ramsey } F(1,60)^{a}\end{array}$ & $\begin{array}{c}3.279 \\
(0.075)\end{array}$ & $\begin{array}{c}0.195 \\
(0.659)\end{array}$ & $\begin{array}{c}0.376 \\
(0.542)\end{array}$ \\
\hline Test de Wald $F(1,61)^{b}$ & $\begin{array}{l}30.647 \\
(0.000)\end{array}$ & $\begin{array}{c}202.144 \\
(0.000)\end{array}$ & $\begin{array}{c}1998.281 \\
(0.000)\end{array}$ \\
\hline
\end{tabular}

Error estándar entre paréntesis

${ }^{*}$ Coeficiente es estadísticamente significativo al $5 \%$.

ap-value entre paréntesis, la hipótesis nula es que se tiene normalidad, homocedasticidad y buena forma funcional.

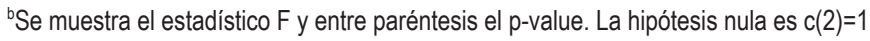


Cuadro 4. Primera Ley de Kaldor IV

\begin{tabular}{|c|c|c|c|}
\hline \multicolumn{4}{|c|}{ Ecuación } \\
\hline & (7) & (8) & (9) \\
\hline $\begin{array}{l}\text { Variables } \\
\text { independientes \dependiente }\end{array}$ & $\mathbf{q}$ & $\mathbf{q}$ & $\mathbf{q}$ \\
\hline \multirow[t]{2}{*}{ Constante } & 1.426 & $2.490^{*}$ & $1.258^{*}$ \\
\hline & $(0.824)$ & $(0.662)$ & $(0.311)$ \\
\hline \multirow[t]{2}{*}{ qelec } & $0.369 *$ & & \\
\hline & $(0.069)$ & & \\
\hline \multirow[t]{2}{*}{$\mathbf{q}_{\text {cons }}$} & & $0.292^{*}$ & \\
\hline & & $(0.036)$ & \\
\hline \multirow[t]{2}{*}{$\mathbf{q}_{\text {come }}$} & & & $0.655^{*}$ \\
\hline & & & $(0.032)$ \\
\hline \multirow[t]{2}{*}{$\operatorname{AR}(1)$} & $0.354^{*}$ & $0.373^{*}$ & $0.256^{*}$ \\
\hline & $(0.089)$ & $(0.079)$ & $(0.116)$ \\
\hline $\mathbf{n}$ & 65 & 65 & 65 \\
\hline $\mathbf{R}^{2}$ ajustado & 0.344 & 0.568 & 0.844 \\
\hline F estadístico & 12.212 & 29.115 & 116.54 \\
\hline D.W. & 1.902 & 2.011 & 1.895 \\
\hline \multicolumn{4}{|c|}{ Pruebas de Diagnóstico } \\
\hline Test de normalidad & 18.899 & 18.807 & 2.037 \\
\hline$J B-\chi^{2}(2)^{a}$ & $(0.000)$ & $(0.000)$ & $(0.361)$ \\
\hline Test de heterocedasticidad & 1.142 & 3.490 & 1.004 \\
\hline de WhiteF $(5,58)^{a}$ & $(0.348)$ & $(0.008)$ & $(0.423)$ \\
\hline Test de forma funcional de & 12.597 & 7.684 & 0.733 \\
\hline Ramsey $F(1,60)^{a}$ & $(0.000)$ & $(0.007)$ & $(0.395)$ \\
\hline Test de Wald $F(1,61)^{b}$ & 81.355 & 381.138 & 110.35 \\
\hline & $(0.000)$ & $(0.000)$ & $(0.000)$ \\
\hline
\end{tabular}

Error estándar entre paréntesis

${ }^{*}$ Coeficiente es estadísticamente significativo al $5 \%$.

aP-value entre paréntesis, la hipótesis nula es que se tiene normalidad, homocedasticidad y buena forma funcional.

${ }^{b}$ Se muestra el estadístico $\mathrm{F}$ y entre paréntesis el p-value. La hipótesis nula es $\mathrm{c}(2)=1$ 
Los primeros dos sectores (electricidad y construcción) se podrían agrupar con el sector manufacturero con el nombre de industria, como se hacen en otros trabajos. Nosotros hemos preferido mantenerlos separados. De hecho estos dos sectores no pueden ser considerados motores del crecimiento económico. Además, las pruebas de diagnóstico revelan la existencia de problemas con las especificaciones para estos dos sectores. Los valores obtenidos del Chi ${ }^{2}$ están muy por encima de su valor crítico 5,991 de la tabla al 5\%. Sus residuos no tienen una distribución normal. Esto no ocurre con la ecuación estimada para el sector comercio. Sus residuos presentan una distribución normal porque el valor del estadístico $\mathrm{Chi}^{2}$ obtenido $(2,037)$ está por debajo del valor crítico de la tabla 5,991 al 5\%.

De otro lado, las ecuaciones (7) y (9) son las únicas que pasan el de test de White. Sus estadísticos obtenidos ( 1,142 y 1,004, respectivamente) son menores que el valor crítico 2,374 de la tabla para $\mathrm{F}(5,58)$ al $5 \%$. En cambio, en la ecuación estimada (8) que corresponde al PBI del sector minería, no hay homocedasticidad. Su estadístico 3.490 es mayor que el valor crítico de la tabla al 5\%. Por último, de acuerdo al test de Ramsey las ecuaciones (7) y (8) no tienen una buena forma funcional. Los valores críticos para $\mathrm{F}(1,60)$ al $5 \%$ y al $1 \%(4,001$ y 7,08 , respectivamente), son menores que los valores del estadístico obtenidos (12,597 y 7,684, respectivamente). La estimación de la ecuación (9) si presenta una buena forma funcional. Su estadístico $(0,733)$ es menor que los valores críticos de la tabla para $\mathrm{F}(1,60)$ al $5 \%$ y al $1 \%$.

La ecuación (9) es la única que pasa todas las pruebas de diagnóstico y presenta un buen ajuste. Esta ecuación es la que relaciona la tasa de crecimiento del PBI del sector comercio con la tasa de crecimiento del PBI agregado. Lo mismo ocurre con la ecuación (10) que relaciona la tasa de crecimiento del PBI del sector servicios con la tasa de crecimiento del PBI agregado (véase Cuadro 5).

Como se puede observar en el Cuadro 5 que contiene la ecuación estimada 'para el sector servicios, existe un buen ajuste $\left(75,8 \%\right.$ de $\mathrm{R}^{2}$ ajustada) y una asociación positiva y significativa entre las tasas de crecimiento mencionadas. Sin embargo, las pruebas de diagnóstico son insatisfactorias. No pasa el test de normalidad de los residuos. El valor del estadístico obtenido $(35,471)$ es mayor que los valores críticos de la tasa al 5\% $(5,991)$ y al $1 \%(9,21)$. De acuerdo con el test de White también se rechaza la hipótesis nula de existencia de homocedasticidad (el estadístico obtenido de 5,259 es mayor que el valor crítico 2,374 para $\mathrm{F}(5,58)$ al 5\%). La única hipótesis nula que no se rechaza es la del test de Ramsey sobre la existencia de una buena forma funcional. En efecto, el valor del estadístico obtenido $(3,355)$ es menor que el valor crítico de la tabla $(3,996)$ para $\mathrm{F}(1,62)$ al $5 \%$; sin embargo se rechaza dicha hipótesis al 10\% (3,355 es mayor que 2,788 que es el valor crítico de la tabla). Por último, de acuerdo con el test de Wald, el coeficiente estimado del regresor es estadísticamente distinto y menor que la unidad, como en el caso de la estimación de la ecuación correspondiente al sector comercio. 
Cuadro 5. Primera Ley de Kaldor V

\begin{tabular}{|c|c|}
\hline \multicolumn{2}{|c|}{ Ecuación } \\
\hline & (10) \\
\hline $\begin{array}{l}\text { Variables } \\
\text { independientes/dependiente }\end{array}$ & q \\
\hline Constante & $\begin{array}{c}0.939 \\
(0.346)\end{array}$ \\
\hline $\mathbf{q}_{\text {serv }}$ & $\begin{array}{l}0.759 * \\
(0.053)\end{array}$ \\
\hline $\mathbf{n}$ & 65 \\
\hline $\mathbf{R}^{2}$ ajustado & 0.758 \\
\hline F estadístico & 202.05 \\
\hline D.W. & 1.833 \\
\hline \multicolumn{2}{|c|}{ Pruebas de Diagnóstico } \\
\hline Test de normalidad & 35.471 \\
\hline$J B-\chi^{2}(2)^{a}$ & $(0.000)$ \\
\hline Test de heterocedasticidad & 5.259 \\
\hline de WhiteF $(2,60)^{a}$ & $(0.007)$ \\
\hline Test de forma funcional de & 3.355 \\
\hline Ramsey $F(1,62)^{a}$ & $(0.072)$ \\
\hline Test de Wald $F(1,63)^{b}$ & $\begin{array}{l}20.219 \\
(0.000)\end{array}$ \\
\hline
\end{tabular}

Error estándar entre paréntesis

${ }^{*}$ Coeficiente es estadísticamente significativo al $5 \%$.

aP-value entre paréntesis, la hipótesis nula es que se tiene normalidad, homocedasticidad y buena forma funcional.

${ }^{\mathrm{b}} \mathrm{Se}$ muestra el estadístico $\mathrm{F}$ y entre paréntesis el $\mathrm{p}$-value. La hipótesis nula es $\mathrm{c}(2)=1$ 
Si bien las estimaciones de las ecuaciones correspondientes a los sectores comercio y servicios tienen buenos ajustes $\left(R^{2}\right.$ ajustada) y coeficientes de los regresores estadísticamente significativos, estos no son suficientes, de acuerdo con Kaldor, para darles el carácter de motores del crecimiento económico. El Comercio y los Servicios son sectores auxiliares y crecen en asociación con la producción manufacturera. Kaldor dice que la causalidad va desde el crecimiento del PBI al crecimiento de la producción de los sectores comercio y servicios; y, como hemos mostrado, el PBI agregado y el PBI de estos sectores están relacionados con el crecimiento de la producción manufacturera.

La creciente demanda de comercio y de servicios que acompańa al crecimiento del PBI (impulsado además por la manufactura), estimula — dice Kaldor — el crecimiento de los sectores comercio y servicios. Los servicios, el comercio al igual que los transportes dependen de la expansión de la producción manufacturera. Ciertamente, esto «es mucho menos aplicable a una actividad de servicios como el software y la programación informática, o incluso a una tecnología de uso general como las TIC. De hecho, sería más razonable sugerir que la expansión de la manufactura depende de los servicios vinculados a las TIC y no al revés» (Dasgupta y Singh, 2006, p. 9).

En resumen, los resultados obtenidos para los sectores económicos agricultura, minería, electricidad, pesca y construcción, apoyan la hipótesis de la manufactura como motor del crecimiento. Asimismo, se puede afirmar que la manufactura, por sus características, sigue manteniendo su capacidad de liderazgo, aunque debilitada por las políticas neoliberales que afectaron precisamente el tamaño del mercado interno al haber facilitado con los tratados de libre comercio y la apreciación sistemática del tipo de cambio, una notable penetración de importaciones.

ii. El enfoque de cointegración y la dirección de causalidad

Las estimaciones de las ecuaciones anteriores proporcionan información importante acerca del papel motor de la industria manufacturera en el crecimiento económico. Hay una asociación estadística significativa entre el crecimiento del producto manufacturero y del PBI total. Sin embargo, la metodología para corroborar esta hipótesis de Kaldor ha sido un análisis de regresión simple. De acuerdo con algunos estudios recientes, esta metodología no es suficiente para corroborar la hipótesis de Kaldor acerca del papel motor de la manufactura en el crecimiento económico. Las razones, según Yamak (2000) y otros, son dos:

- Primero, el análisis de regresión solo puede mostrar la presencia o ausencia de una correlación estadística entre el crecimiento de la producción manufacturara y el crecimiento del PBI; pero no dice nada acerca de la relación de causalidad existente entre estas dos variables; $y$, 
- Segundo, la validez de la hipótesis sobre el papel motor de la manufactura, requiere no solo de la existencia de una asociación positiva y estadísticamente significativa entre la tasa de crecimiento de la manufactura y la del PBI, sino también la existencia de causalidad desde la tasa de crecimiento de la manufactura hacia la tasa de crecimiento de la economía en su conjunto (Yamak, 2000, pp. 75-76).

Precisamente por estas razones, para completar este estudio, seguiremos las técnicas de series de tiempo con el objeto de determinar mediante el test de cointegración, la relación de largo plazo entre PBI manufacturero y el PBI total de la economía. Primero analizaremos si existe estacionariedad en las series, para luego estimar la ecuación de cointegración. Como pasos finales estimaremos el modelo de corrección de errores (MCE) para después determinar la dirección de causalidad entre las series.

\section{Pruebas de estacionariedad y de raiz unitaria}

Dado que las series de PBI agregado y PBI de la manufactura presentan una clara tendencia creciente en el tiempo, se somete a prueba la hipótesis nula de que ambas series presentan raíz unitaria y la hipótesis alternativa que son estacionarias con intercepto y/o con tendencia.

Para las dos series en niveles se realiza el test de Dickey-Fuller Aumentado (ADF), primero incorporando tanto el intercepto como la tendencia, y luego solo el intercepto. En el análisis de las primeras diferencias de las dos series se toma en cuenta solo el intercepto. Los rezagos máximos utilizados fueron cuatro (4) y el criterio de selección de estos rezagos fue el de Akaike (AIC - Akaike Information Criterion).

El Cuadro 6 contiene los resultados del test de estacionariedad Dickey-Fuller Aumentada (ADF) para el PBI agregado y el Cuadro 7 los resultados de este mismo test para el PBI de la manufactura. Se supone que la hipótesis nula es la existencia de raíz unitaria tanto en los niveles de las series como en sus primeras diferencias. Los respectivos estadísticos $\mathrm{t}$ indican que no se puede rechazar la presencia de raíz unitaria en las series en logaritmos de sus niveles ya sea con intercepto solamente o con intercepto y tendencia. En el caso de las series en primeras diferencias la hipótesis nula de que existe raíz unitaria se rechaza con un alto nivel de significancia.

Estos resultados permiten afirmar que ambas series (el logaritmo del PBI agregado y el logaritmo del PBI de la manufactura) son integradas del orden 1, I(1). En consecuencia, se puede realizar el test de cointegración entre las dos series utilizando el método de Engle y Granger (1987). La idea es tener evidencia estadística de que las series mantienen una relación estable de largo plazo. 
Cuadro 6. Prueba de raíz unitaria para el PBI total del Perú. 1950-2015

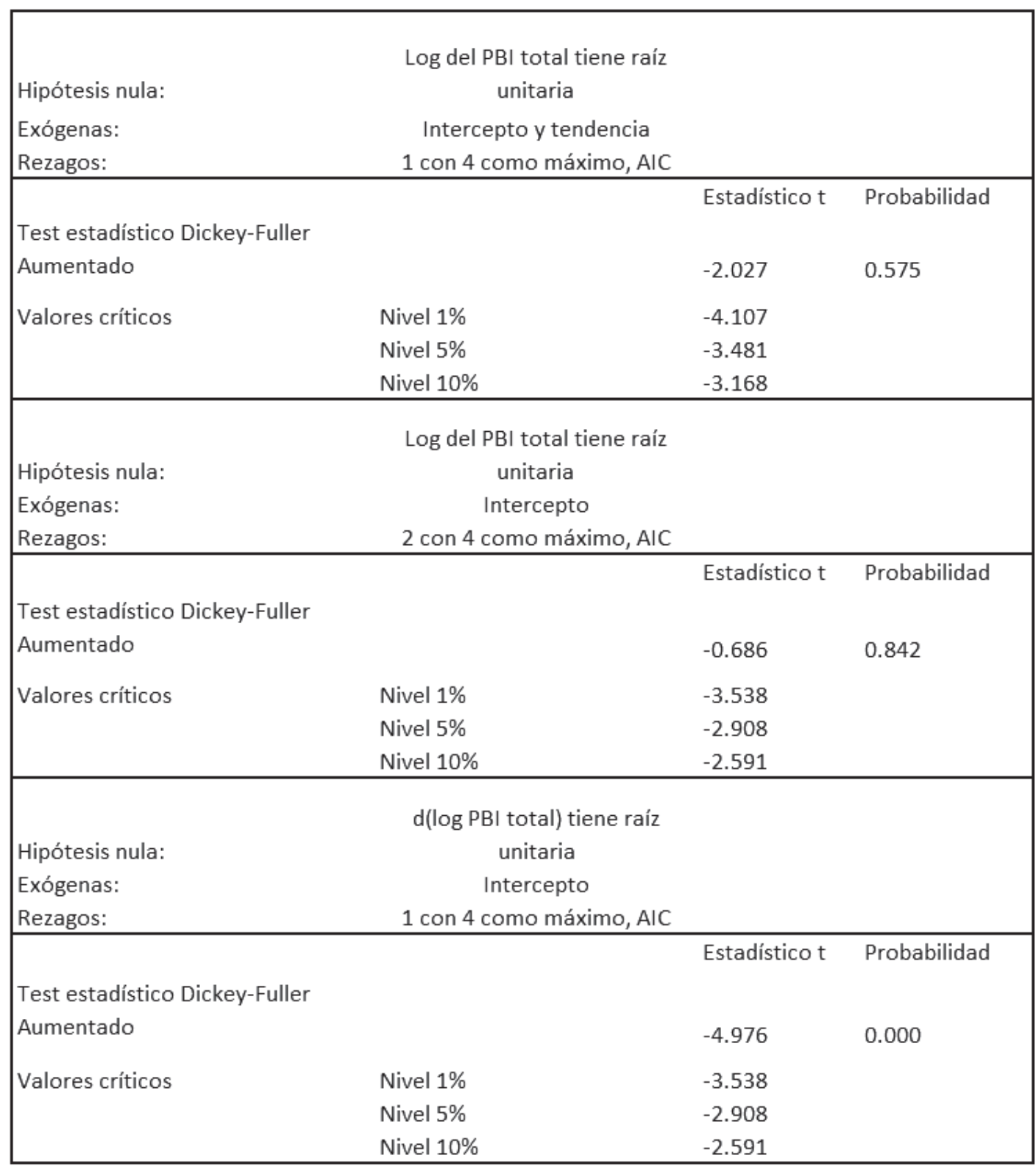

Nota: Criterio de Información de Akaike (AIC) 
Cuadro 7. Prueba de raíz unitaria para el PBI del sector manufacturero de Perú 1950-2015

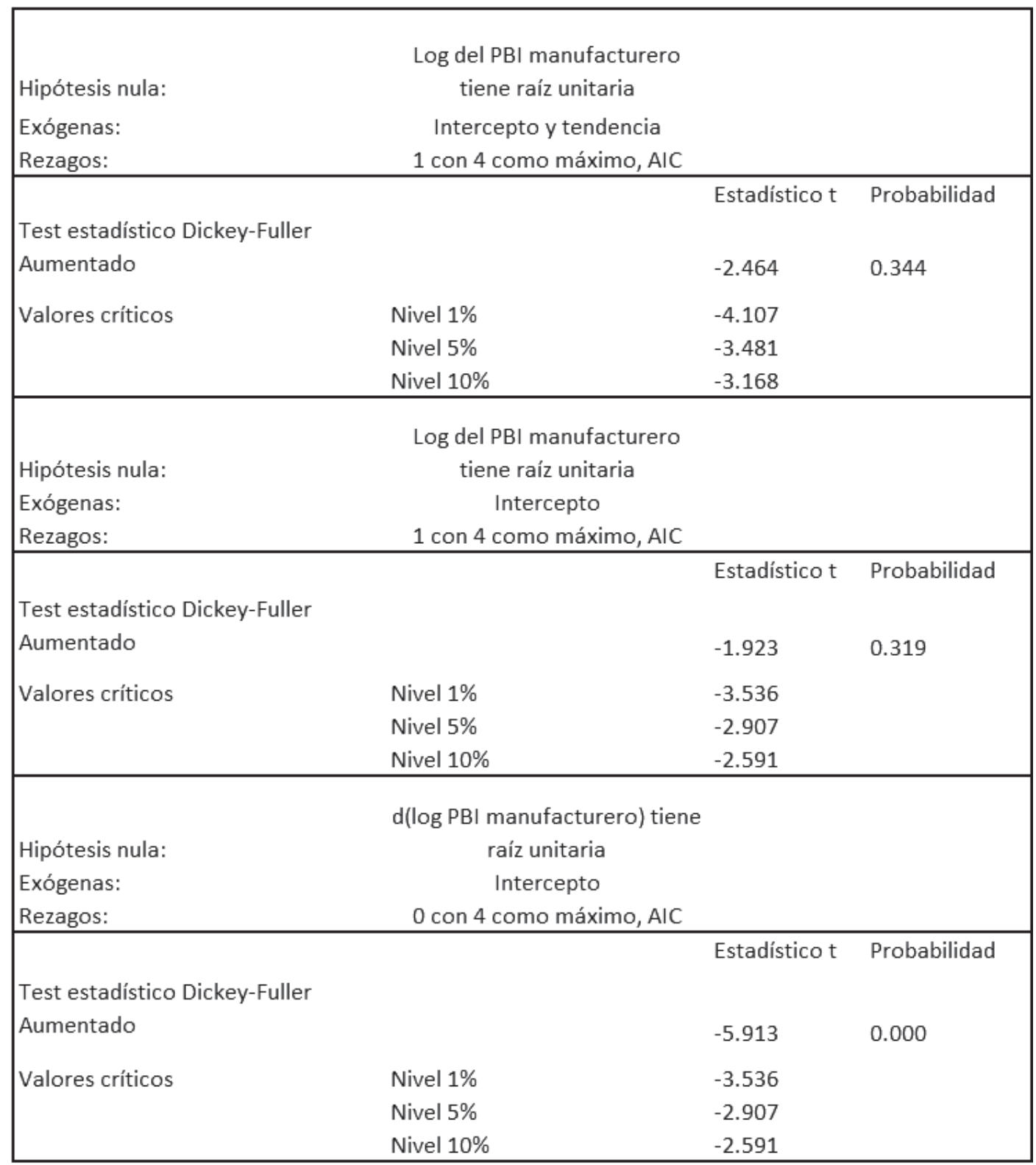

Nota: Criterio de Información de Akaike (AIC) 


\section{Cointegración entre el PBI agregado y el PBI manufacturero}

La relación de largo plazo entre el logaritmo del PBI de la manufactura y el PBI agregado se puede estimar mediante el método de cointegración desarrollado por Engle y Ganger (1987). Primero se estima una ecuación que relaciona estas dos variables, a la que se le denomina regresión de cointegración. Si los parámetros son estadísticamente significativos y tienen los signos correctos, entonces se pasa a analizar si los residuos generados por la regresión de cointegración tienen raíz unitaria o siguen un proceso estacionario.

Sin embargo, hay que señalar que la estimación de la regresión de cointegración es con cambio estructural. Las dos series registran cambio estructural a partir del año 1988, de acuerdo con el test de Zivot y Andrews, en el intercepto y la tendencia. Este cambio estructural ya lo habíamos detectado cuando hicimos la regresión con tasas de crecimiento.

La ecuación de cointegración fue estimada en base al modelo con cambio de régimen propuesto por Gregory y Hansen (1996) que considera dentro de la regresión una constante, una variable dummy, la variable independiente y el producto de la dummy con la variable independiente. Esto se hizo con el fin de captar dentro de la ecuación de cointegración, por medio de la variable dummy mencionada, la presencia de cambio estructural que se inicia el año 1988. Además, esta ecuación fue estimada usando el método de mínimos cuadrados ordinarios dinámicos (lag=1 y lead=1), motivo por el cual la muestra se reduce tanto en las observaciones iniciales como en las finales, perdiéndose en total 3 observaciones ${ }^{7}$. El Cuadro 8 contiene los resultados de la estimación de la ecuación de cointegración entre PBI agregado y el PBI de la manufactura.

Todos los coeficientes de las variables explicativas son estadísticamente significativos y tienen los signos adecuados de acuerdo a la teoría que sustenta esta investigación. Hay una relación positiva y significativa entre las series del PBI agregado y el PBI de la Manufactura. A partir del año 1988 cambian los valores del intercepto y del coeficiente del regresor, el PBI de la manufactura.

El siguiente paso entonces es realizar el test de cointegración, siguiendo la metodología de Engle y Granger (1987); es decir, corroborar la hipótesis de que los errores de la ecuación de cointegración son estacionarios. La prueba de raíz unitaria sobre los residuos, como puede observarse en el Cuadro 9, confirma que estos siguen un proceso estacionario. Por lo tanto, se rechaza la hipótesis nula de raíz unitaria y se acepta la hipótesis alternativa de que los residuos son estacionarios al 5\% de significancia. En consecuencia, las series están cointegradas lo que quiere decir que mantienen una relación estable o de equilibrio de largo plazo.

\footnotetext{
7 Se supone, por la teoría desarrollada anteriormente, que el crecimiento de la producción manufacturera genera incrementos en el PBI agregado que se extiende más allá del período contemporáneo o inmediato.
} 
Cuadro 8. Ecuación de cointegración

\begin{tabular}{|c|c|c|c|c|}
\hline Variable dependiente: & Log PBI total & & & \\
\hline Método: & $\begin{array}{l}\text { Mínimos cuadrados ordinarios } \\
\text { dinámicos }\end{array}$ & & & \\
\hline Muestra: & $1952-2014$ & & & \\
\hline Observaciones: & 63 & & & \\
\hline Variable & Coeficiente & Error estándar & Estadístico $\mathrm{t}$ & Probabilidad \\
\hline Constante & $3.118^{*}$ & 0.386 & 8.075 & 0.000 \\
\hline dummy & $-2.280^{*}$ & 0.417 & -5.463 & 0.000 \\
\hline $\log (\mathrm{PB} \mid m a n)$ & $0.866^{*}$ & 0.038 & 22.352 & 0.000 \\
\hline $\log (\mathrm{PB} \mid \mathrm{man})^{*}$ dummy & $0.230^{*}$ & 0.041 & 5.544 & 0.000 \\
\hline $\mathbf{R}^{2}$ ajustado & 0.994 & & & \\
\hline
\end{tabular}

Cuadro 9. Prueba de cointegración

\begin{tabular}{|cccc|}
\hline $\begin{array}{c}\text { Hipótesis nula: } \\
\text { Exógenas: } \\
\text { Rezagos: }\end{array}$ & $\begin{array}{c}\text { Residuos con raíz unitaria } \\
\text { Intercepto } \\
0\end{array}$ & & \\
\hline & & Estadístico t & Probabilidad \\
\hline Test estadístico Dickey-Fuller & & -3.468 & 0.012 \\
Aumentado & Nivel 1\% & -3.540 & \\
Valores críticos & Nivel 5\% & -2.909 & \\
& Nivel 10\% & -2.592 & \\
\hline
\end{tabular}

\section{Modelo de corrección del error}

Como las series están cointegradas se pasa a estimar el modelo de corrección de error (MCE) utilizando como variable dependiente a la primera diferencia del logaritmo del PBI agregado, y como variables independientes a la primera diferencia del logaritmo del PBI manufacturero, incluyendo las variables dummy para captar los cambios en el intercepto y en la pendiente, y el primer rezago de los residuos obtenidos de la ecuación de cointegración con cambio de régimen o cambio estructural. Como advertirá el lector, el modelo de corrección del error relaciona las tasas de crecimiento de ambas variables; por lo tanto, el coeficiente del regresor tasa de crecimiento del PBI de la manufactura debe ser similar al obtenido con la estimación por mínimos cuadrados ordinarios de la ecuación (1).

El método utilizado es el de mínimos cuadrados ordinarios. Los resultados pueden verse en el Cuadro 10. El coeficiente asociado a los residuos, que es el mecanismo de corrección del error, es negativo, lo que es consistente con la teoría. Este coeficiente de corrección es igual a -10.173 y, por lo tanto, las desviaciones en cada período del PBI se ajustan o reducen el desequilibrio anualmente en 10\% aproximadamente. En otras palabras, la desviación del PBI total respecto a su nivel de equilibrio de largo plazo se corrige anualmente en $10 \%$. Sin embargo, es importante notar que este factor de corrección de errores si bien tiene el signo correcto no es estadísticamente significativo al 5\%. 
Cuadro 10. Modelo de corrección del error

\begin{tabular}{|c|c|c|c|c|}
\hline Variable dependiente: & $\mathrm{dLog}(\mathrm{PBI})$ & & & \\
\hline Método: & Mínimos cuadrados ordinarios & & & \\
\hline Muestra: & $1953-2015$ & & & \\
\hline Observaciones: & 63 & & & \\
\hline Variable & Coeficiente & Error estándar & Estadístico $t$ & Probabilidad \\
\hline Constante & 1.546 & 0.274 & 5.627 & 0.000 \\
\hline $\mathrm{dLog}(\mathrm{PB} \mid \mathrm{man})$ & 0.566 & 0.045 & 12.452 & 0.000 \\
\hline $\mathrm{d}($ LogPBIman*dummy) & 0.126 & 0.064 & 1.947 & 0.056 \\
\hline$d($ dummy $)$ & -1.353 & 0.674 & -2.006 & 0.049 \\
\hline Residuos-1 $_{-1}$ & -10.173 & 6.305 & -1.613 & 0.112 \\
\hline$R^{2}$ ajustado & 0.845 & F estadístico & 85.722 & \\
\hline \multicolumn{5}{|c|}{ Pruebas de Diagnóstico } \\
\hline Test de normalidad & 0.244 & & & \\
\hline$J B-\chi^{2}(2)^{a}$ & $(0.884)$ & & & \\
\hline Test de heterocedasticidad & 0.815 & & & \\
\hline de White $F(9,53)^{a}$ & $(0.604)$ & & & \\
\hline Test de forma funcional de & 2.372 & & & \\
\hline Ramsey $F(1,57)^{\mathrm{a}}$ & $(0.129)$ & & & \\
\hline \multirow[t]{2}{*}{ Test de Wald $F(1,58)^{b}$} & 91.042 & & & \\
\hline & $(0.000)$ & & & \\
\hline
\end{tabular}

aP-value entre paréntesis, la hipótesis nula es que se tiene normalidad, homocedasticidad y buena forma funcional.

${ }^{b} S e$ muestra el estadístico $\mathrm{F}$ y entre paréntesis el $p$-value. La hipótesis nula es $c(2)=1$

*Las variables en diferencias fueron multiplicadas por 100

Además, hay que mencionar que el modelo muestra una alta bondad de ajuste, y pasa todas las pruebas de especificación. Se acepta la hipótesis nula de normalidad en los residuos de la ecuación estimada. El valor del estadístico $\mathrm{Chi}^{2}$ obtenido es 0,244 menor que el valor crítico al 5\% que es de 5,991. Tampoco se rechaza la hipótesis nula de homocedasticidad. El test de White genera un estadístico de 0,815 que es menor que el valor crítico 2,377 para el F $(5,57)$ al 5\% de significancia. De otro lado, de acuerdo con el test de Ramsey no se rechaza la existencia de buena forma funcional en el modelo. El valor crítico de $\mathrm{F}(1,59)$ al $5 \%$ es 4,004, mientras que el estadístico obtenido es de 2,372. Tampoco se rechaza al $10 \%$ pues el valor crítico de $\mathrm{F}(1,59)$ es de 2,793 . Finalmente, según el test de Wald se rechaza, con un alto nivel de significancia, la hipótesis nula de que el coeficiente de la tasa de variación del PBI manufacturero es estadísticamente igual a 1 . El coeficiente es menor que 1, como lo sostenía Kaldor. 
El coeficiente de la tasa de crecimiento del PBI manufacturero $(0,566)$, es distinto de cero y significativamente menor que la unidad. Los niveles de significancia de los otros regresores son mucho menores. Sin embargo, se puede afirmar que el coeficiente 0,692 $(0,566+0,126)$ del regresor (tasa de crecimiento del PBI del sector manufacturero) para el periodo 1990-2015, es mayor que el obtenido para el período 1950-1989 y que es igual a 0,566 .

\section{Dirección de causalidad (test de Granger)}

De acuerdo con Engle y Granger (1987) debe existir causalidad en alguna dirección debido a que las series están cointegradas. Las variables utilizadas para este test fueron corregidas por el cambio estructural pues las series originales de PBI total y PBI manufacturero en logaritmos registran quiebre estructural a partir del año 1988. Los resultados se encuentran en el Cuadro 11.

Se rechaza la hipótesis nula de que el PBI manufacturero no es causa a la Granger del PBI agregado al 5\% de significancia. Podría decirse entonces que se confirma la validez de la primera ley de Kaldor: el PBI de la manufactura es causa del PBI agregado y no ocurre lo mismo a la inversa al 5\% de significancia. La industria manufacturera es el motor de crecimiento económico porque hay causalidad desde el PBI manufacturero al PBI total y no en sentido contrario.

No obstante lo anterior, hay que señalar que el resultado obtenido depende del número de rezagos que hemos utilizado. Cuando se utiliza un número menor de rezagos, la causalidad es bidireccional, pero la teoría econométrica nos dice que es mejor utilizar más rezagos en función del número de observaciones con el que se esté efectuando el análisis. De todos modos el test de causalidad no nos da un resultado altamente significativo, resultado que puede explicarse por la pérdida de eficiencia dinámica de la producción manufacturera durante el período neoliberal.

Cuando el test de causalidad se aplica para los períodos 1950-1990 y 1990-2015, los resultados confirman esta pérdida de eficiencia dinámica (Véase Cuadros 12 y 13). Para el primer período 1950-1990 se rechaza la hipótesis nula de que el PBI manufacturero no es causa a la Granger del PBI agregado al 2\% de significancia.

Cuadro 11. Test de causalidad de Granger entre el PBI total y PBI manufacturero

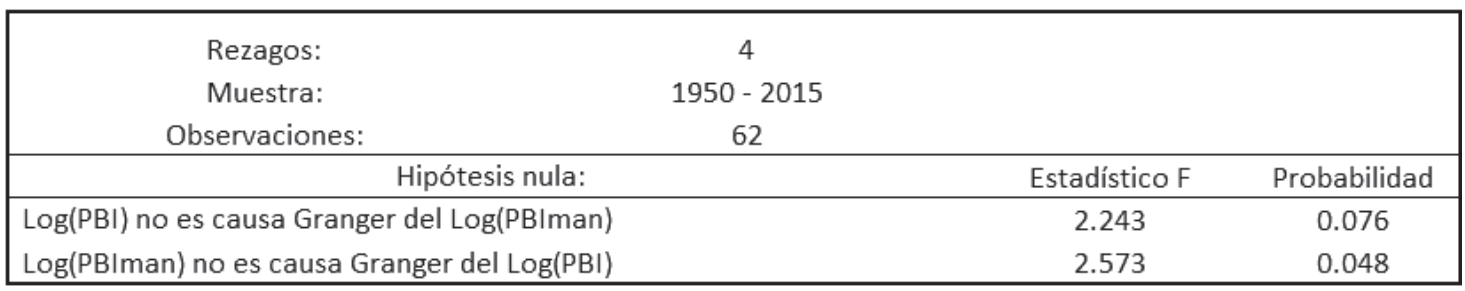

Ambas series se corrigieron considerando el cambio estructural que según el test de Zivot y Andrews ocurre a partir de 1988. 
Cuadro 12. Test de causalidad de Granger entre el PBI total y PBI manufacturero

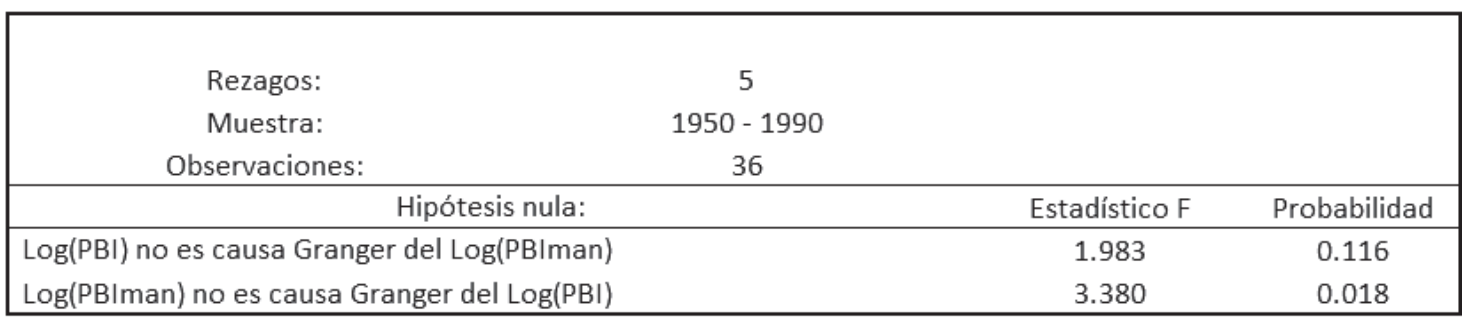

Ambas series se corrigieron considerando el cambio estructural que según el test de Zivot y Andrews ocurre a partir de 1988.

Cuadro 13. Test de causalidad de Granger entre el PBI total y PBI manufacturero

\begin{tabular}{|cccc|}
\hline Rezagos: & 1 & & \\
Muestra: & $1990-2015$ & & \\
Observaciones: & 26 & & \\
\hline \multicolumn{5}{c}{ Hipótesis nula: } & & & \\
\hline & & Estadístico $\mathrm{F}$ & Probabilidad \\
\hline Log(PBI) no es causa Granger del Log(PBIman) & 0.122 & 0.731 \\
Log(PBIman) no es causa Granger del Log(PBI) & & 1.888 & 0.183 \\
\hline
\end{tabular}

Pero, cuando el test se realiza para el período 1990-2015, ya no se puede rechazar la hipótesis nula de que el PBI manufacturero no es causa a la Granger del PBI agregado. Si se aumentan los rezagos el sentido de la causalidad no cambia.

Estos resultados confirman que la pérdida de liderazgo de la manufactura se debe al proceso de desindustrialización prematura ocurrida durante los últimos 25 años.

b. Segunda Ley de Kaldor o Ley Verdoorn-Kaldor: rendimientos crecientes en la manufacturera

La explicación de porqué hay una asociación estrecha entre el crecimiento de la producción manufacturera y el crecimiento del PBI, según el enfoque kaldoriano se encuentra en el hecho de que el primero impacta positivamente en el crecimiento de la productividad laboral de la economía en su conjunto. Se dice que hay dos razones posibles que explican el sentido de este impacto. Primero, cuando se expande la producción y el empleo manufacturero se está transfiriendo trabajo o empleo desde las actividades o sectores de baja productividad hacia actividades industriales o manufactureras con altos niveles de productividad. El resultado de este proceso es el aumento de la productividad para el conjunto de la economía con nulo o poco impacto en el producto de las actividades tradicionales debido a la existencia de excedente de mano de obra. Es el proceso que caracteriza el paso de una economía subdesarrollada a una economía más desarrollada. En la economía subdesarrollada hay mano de obra disponible subocupada o informal precisamente en las actividades tradicionales de baja productividad. Y la segunda razón 
que explica la estrecha relación entre el crecimiento de la producción manufacturera y la productividad es la existencia de rendimientos crecientes estáticos y dinámicos en la industria manufacturera. Como se ha dicho anteriormente, los rendimientos estáticos están asociados a las economías de escala internas a la firma, mientras que los rendimientos dinámicos tienen que ver con el crecimiento de la productividad derivados del learning by doing (aprender haciendo), del cambio técnico inducido o incorporado, de la acumulación de capital inducida y de economías externas que provienen de la expansión conjunta de industrias interrelacionadas.

Esto significa - de acuerdo con la interpretación que hace Kaldor del trabajo de Allyn Young (1928) — que los rendimientos crecientes constituyen un fenómeno macroeconómico que es un resultado de la interacción entre actividades productivas durante el proceso general de expansión económica. Esto — como bien señalan Libanio y Moro (2014) — se relaciona también con la idea de Adam Smith del crecimiento de la productividad, como resultado endógeno y macroeconómico de la extensión y profundidad de la división del trabajo (cambio técnico endógeno) que depende de la extensión del mercado.

Llegamos así a la segunda ley de Kaldor, más conocida como la Ley de Verdoorn. Esta ley rige solo en la manufactura porque «únicamente en este sector los aumentos en la productividad y en el empleo se encuentran estrecha y positivamente relacionados con el crecimiento de la producción. El empleo aumenta porque se expanden los requerimientos de mano de obra industrial cuando crece la extensión del mercado; y, al aumentar el tamaño de éste, las mejoras en la organización y en las técnicas de producción unidas a las nuevas inversiones, ocasionan aumentos en la productividad tanto en el mismo sector como en la economía en su conjunto. En consecuencia, desde una perspectiva a largo plazo, el crecimiento económico originado por la expansión manufacturera no está determinado ni por la disponibilidad de recursos o factores productivos, ni por un progreso técnico autónomo, sino por la expansión de la demanda» (Jiménez, 2010 [1982], p. 117). Según esta Ley que también es conocida en la literatura como la «Ley Kaldor-Verdoorn», el crecimiento de la productividad laboral en la manufactura está positivamente asociada con el crecimiento de la producción manufacturera: $p_{m}=f\left(q_{m}\right)$, donde $p_{m}$ es la tasa de crecimiento de la productividad del trabajo en la manufactura y $q_{m}$ es la tasa de crecimiento del producto manufacturero.

Se dice que la evidencia empírica de esta ley es la que muestra la presencia de rendimientos crecientes a escala, estáticos y dinámicos, en la manufactura. Los incrementos en la producción manufacturera generan aumentos en su productividad laboral si la producción manufacturera está sujeta a rendimientos crecientes a escala de naturaleza estática y dinámica.

Como señalamos, desde la perspectiva Kaldoriana-Smithiana, el incremento de la productividad es determinado por el ritmo de expansión del mercado que da lugar a rendimientos crecientes a escala «derivados de las interacciones de los factores estáticos y dinámicos asociados con los incrementos de la escala de producción industrial» (Sánchez Juárez, 2011, p. 197). 
Si la estimación de Ley de Verdoorn proporciona evidencia sobre la existencia o no de rendimientos crecientes a escala en la manufactura, entonces también proporciona evidencia sobre el proceso de causación circular acumulativa que Kaldor desarrolla basándose en las ideas de Adam Smith (1776): el crecimiento del producto genera ganancias de productividad que permiten reducir los costos de producción unitarios y los precios en la manufactura — dada la regla de fijación de precios basado en el mark-up —, dando lugar a un aumento de la competitividad de la economía. Este aumento de la competitividad permite ganar mercados y con ello permite amentar aún más la producción mediante exportaciones crecientes, y así sucesivamente (Kaldor, 1970; Libanio y Moro, 2014; Jiménez, 2010 [1982]).

\section{i. La estimación con mínimos cuadrados ordinarios}

Existen dos maneras de evaluar econométrica y estadísticamente la Ley de VerdoornKaldor. La primera consiste en efectuar una regresión entre la tasa de crecimiento de la productividad laboral (como variable dependiente) y la tasa de crecimiento del producto manufacturero (como variable independiente). La segunda es efectuar una regresión entre la tasa de crecimiento del empleo y la tasa de crecimiento del producto manufacturero, dado que la tasa de crecimiento del producto es la suma del crecimiento de la productividad y el crecimiento del empleo. En realidad esta segunda especificación se obtiene de la primera, como se muestra a continuación.

En el primer caso tendríamos una especificación lineal de la forma:

$$
p_{m}=\alpha+\lambda q_{m}
$$

Y en el segundo caso tendríamos:

$$
l_{m}=-\alpha+(1-\lambda) q_{m}
$$

donde:

$p_{m}$ : tasa logarítmica de crecimiento de la productividad del trabajo en la manufactura

$l_{m}$ : tasa logarítmica de crecimiento de la PEA ocupada en la manufactura

La estimación de la ecuación 11 puede revelar una correlación espuria —entre la variable dependiente (crecimiento de la productividad de la manufacturera) y la variable independiente (crecimiento de la producción manufacturera)—, debido a que por definición la tasa de crecimiento de la productividad del trabajo es igual a la diferencia entre la tasa de crecimiento del producto y la tasa de crecimiento del empleo manufacturero $\left(p_{m}=q_{m}-l_{m}\right)$, lo que implica que la tasa de crecimiento del producto se encuentra a ambos lados de la ecuación. Precisamente para resolver este problema se propone la especificación 12 que no tiene por qué afectar la estimación estadística del grado de rendimientos a escala. En este caso tendremos que la constante de la ecuación 12 con signo negativo será la constante de la ecuación 11, y el coeficiente de regresión de la ecuación 12 será igual a $(1-\lambda)$ donde $\lambda$ es conocido como el coeficiente de Verdoorn. 


\section{Rendimientos crecientes a escala y función progreso técnico}

Es importante señalar que las ecuaciones 11 y 12 que propone Kaldor son derivadas de su función de progreso técnico que se relaciona con la inversión y el aumento del stock de capital (Bairam, 1987; Dixon y Thirlwall, 1975; McCombie, 1982). Esta función es como sigue (Kaldor, 1957):

$$
p_{m}=\beta_{0}+\beta_{1} k_{m}
$$

El progreso técnico es concebido por Kaldor como como una función de la acumulación de capital donde $\mathrm{k}$ es el crecimiento del capital por trabajador. En otras palabras, el aumento del capital per cápita ocurre con cambios en el estado del cocimiento; además, se sostiene que las invenciones y/o innovaciones no ocurren al margen de la inversión y su subsecuente incremento en el stock de capital por trabajador (Jeon, 2006, p. 10). En la ecuación anterior, entonces, la constante $\beta_{0}$ representa el progreso técnico autónomo (innovaciones, economías externas o efectos del learning by doing). Por su parte el coeficiente $\beta_{1}$ corresponde al progreso técnico inducido por la acumulación de capital.

El progreso técnico autónomo $\beta_{0}$ puede ser considerado como una función del crecimiento del producto «cuyo efecto dinámico se amplifica a medida que el crecimiento de la producción se hace más rápido» (Jeon, 2006, p. 10). Es un progreso técnico que resulta de las innovaciones y que captura los efectos dinámicos provenientes del learning by doing y/o de las economías externas positivas que se derivan de las interrelaciones entre las diversas actividades del sector manufacturero en su conjunto y de este sector con el resto de la economía (Young, 1928).

La función de progreso técnico autónomo se puede expresar entonces como sigue:

$$
\beta_{0}=\alpha_{0}+\alpha_{1} q_{m}
$$

donde: $\alpha_{0}$ representa el progreso técnico puramente autónomo (como las innovaciones) y $\alpha_{1}$ es el coeficiente que captura los efectos dinámicos resultantes del crecimiento del producto.

Hasta aquí, podemos decir, entonces, que la función de progreso técnico kaldoriana describe las relaciones dinámicas existentes entre los cambios en la producción y los cambios en la productividad en el sector manufacturero. Precisamente, los rendimientos crecientes dinámicos relacionan los cambios en la productividad con los cambios en la producción, mientras que los rendimientos crecientes estáticos relacionan el nivel de la productividad con el tamaño y la escala de una unidad de producción o de una sola industria (Jeon, 2006, p. 10)

Por último, siguiendo el enfoque del crecimiento económico dirigido por la demanda se puede formular una ecuación donde la tasa de crecimiento del capital por trabajador (la inversión) es una función del crecimiento del producto y cuyo coeficiente representa el acelerador (Jeon, 2006, p. 10):

$$
k_{m}=\delta_{0}+\delta_{1} q_{m}
$$


Sustituyendo estas dos últimas ecuaciones en la función de progreso técnico de Kaldor, obtenemos la ecuación de Verdoorn:

$$
\begin{aligned}
& p_{m}=\left(\alpha_{0}+\alpha_{1} q_{m}\right)+\beta_{1}\left(\delta_{0}+\delta_{1} q_{m}\right) \\
& p_{m}=\left(\alpha_{0}+\beta_{1} \delta_{0}\right)+\left(\alpha_{1}+\beta_{1} \delta_{1}\right) q_{m}
\end{aligned}
$$

Esta sería la ecuación (11) presentada anteriormente y que incorpora explícitamente tanto una función de progreso técnico como los rendimientos crecientes a escala dinámicos. Es decir:

$$
p_{m}=\alpha+\lambda q_{m}
$$

donde: $\alpha=\alpha_{0}+\beta_{1} \delta_{0}$ y $\lambda=\alpha_{1}+\beta_{1} \delta_{1}$. El coeficiente de Verdoorn ( $\lambda$ ) está determinado «por el efecto de los rendimientos crecientes dinámicos, por el progreso técnico incorporado en la acumulación de capital y el grado en el que la inversión responde al crecimiento del producto, todos ellos relacionados positivamente con el grado de los rendimientos crecientes a escala» (Jeon, 2006, p. 10).

Para que empíricamente se sostenga que hay rendimientos crecientes a escala, el coeficiente de Verdoorn tiene que ser significativamente menor que la unidad desde el punto de vista estadístico.

\section{Rendimientos crecientes a escala y productividad total de los factores}

Hay otra manera de explicar la Ley de Verdoorn que se aleja en parte de la crítica kaldoriana al uso de la función de producción neoclásica. Dada la siguiente función de progreso técnico, mencionada anteriormente:

$$
p_{m}=\beta_{0}+\beta_{1} k_{m}
$$

Ahora bien, si se supone que la tasa de crecimiento del stock de capital es igual a la tasa de crecimiento del producto (porque la relación producto-capital está constante en el largo plazo), entonces:

$$
p_{m}=\beta_{0}+\beta_{1} q_{m}
$$

El razonamiento que justifica el supuesto de constancia de la relación capital producto, es el siguiente: «Si $q_{m}<k_{m}$, entonces la razón capital-producto aumenta, la tasa de beneficios disminuye ocasionando que la inversión y, por lo tanto, la tasa de crecimiento del stock de capital, disminuyan. Si $q_{m}>k_{m}$, sucede lo contrario. La relación capital-producto disminuye, y la tasa de beneficios así como la inversión y la tasa de crecimiento del stock de capital, aumentan. Esto significa que la economía tiende a una situación donde el producto y el capital crecen a la misma tasa y la relación capital-producto permanece constante» (Ocegueda, 2003, p. 1027).

Ahora se puede mostrar que, dada la constancia de la relación capital-producto, (es decir, que el producto y el stock de capital crecen a la misma tasa), la ecuación 11 
se deriva de una función de producción Cobb-Douglas, $Q=e^{\rho t} K^{\alpha} L^{\beta}$, donde $\alpha$ y $\beta$ son las elasticidades producto de los factores de producción capital y trabajo, y $\rho$ es la tasa de crecimiento de la productividad total de los factores. Tomando logaritmos a esta función de producción y diferenciando con respecto al tiempo, se obtiene la ecuación de la tasa logarítmica de crecimiento del producto (suponemos que la función de producción es la del sector manufacturero).

$$
\begin{gathered}
q_{m}=\rho+\alpha k_{m}+\beta l_{m} \\
q_{m}-\beta q_{m}+\beta q_{m}-\beta l_{m}=\rho+\alpha k_{m} \\
\beta\left(q_{m}-l_{m}\right)=\rho+\alpha k_{m}-(1-\beta) q_{m} \\
\beta p_{m}=\rho-(1-\beta) q_{m}+\alpha k_{m} \\
p_{m}=\frac{\rho}{\beta}+\frac{\beta-1}{\beta} q_{m}+\frac{\alpha}{\beta} k_{m}
\end{gathered}
$$

Si la relación capital-producto está constante (lo que implica que $q_{m}=k_{m}$ ), entonces:

$$
p_{m}=\frac{\rho}{\beta}+\frac{\alpha+\beta-1}{\beta} q_{m}
$$

Esta ecuación es equivalente a la ecuación 11 , con: $\lambda=\frac{\alpha+\beta-1}{\beta}$ y $a=\frac{\rho}{\beta}$.

De la misma manera la especificación para la tasa de crecimiento de la ocupación en la manufactura, equivalente a la ecuación 12 , será:

$$
l_{m}=-\frac{\rho}{\beta}+\frac{(1-\alpha)}{\beta} q_{m}
$$

De aquí se deduce que si $\frac{(1-\alpha)}{\beta}=1$, entonces hay rendimientos constantes a escala. Si $0<\frac{(1-\alpha)}{\beta}<1$, entonces $\alpha+\beta>1$, lo que quiere decir que los rendimientos a escala son crecientes (Ocegueda, 2003; McCombi, Roberts y Angeriz, 2008; McCombi y Roberts, 2007; Fingleton, 2001).

Si se desea captar la influencia del crecimiento del stock de capital en el crecimiento del empleo levantando el supuesto de constancia de la relación capital-producto, se puede estimar una ecuación, como la siguiente:

$$
l_{m}=-\frac{\rho}{\beta}+\frac{1}{\beta} q_{m}-\frac{\alpha}{\beta} k_{m}
$$

Sin embargo, en diversos trabajos se encuentra que la estimación del coeficiente de la tasa de crecimiento del stock de capital no es estadísticamente significativa y con frecuencia su signo difiere del esperado por la teoría (Dixon y Thirlwall, 1975, Bairam, 1987; 
McCombie y de Ridder, 1983 y 1984). Este hecho, sin duda está asociado a un error de especificación, pues para Kaldor (1957) el crecimiento está restringido por el lado de la demanda y, por lo tanto, la tasa de crecimiento del stock de capital es una variable endógena y no debe incluirse como regresor (Ocegueda, 2003, p. 1028).

Ahora bien, si el crecimiento del stock de capital es endógeno, debido a que se determina principalmente por el crecimiento del producto, entonces para obtener una especificación alternativa sobre la Ley de Verdoorn-Kaldor podríamos suponer para la industria manufacturera una función de Cobb-Douglas de la forma siguiente (McCombie, 1985; Jiménez, 1999):

$$
Q=A_{0} e^{\rho t}\left(K^{\alpha^{\prime}} L^{\beta^{\prime}}\right)^{\eta}
$$

donde: $\alpha^{\prime}+\beta^{\prime}=1$ y $\eta=\alpha+\beta$ es el grado de rendimientos a escala. Tomando logaritmos y diferenciando con respecto al tiempo, se obtiene:

$$
\begin{gathered}
q_{m}=\rho+\eta\left[\alpha^{\prime} k_{m}+\beta^{\prime} l_{m}\right] \\
{\left[\alpha^{\prime} k_{m}+\beta^{\prime} l_{m}\right]=-\frac{\rho}{\eta}+\frac{1}{\eta} q_{m}}
\end{gathered}
$$

Existen entonces dos posibilidades de estimación del grado de rendimientos a escala. La primera sería mediante la estimación de la siguiente ecuación:

$$
\text { itf }=-\frac{\rho}{\eta}+\frac{1}{\eta} q_{m}
$$

donde itf $=\left[\alpha^{\prime} k_{m}+\beta^{\prime} l_{m}\right]$ es el promedio ponderado de las tasas de crecimiento de los factores de producción capital y trabajo. Los ponderadores son las participaciones de los ingresos de los factores en el producto. La suma de estas participaciones es igual a la unidad $\left(\alpha^{\prime}+\beta^{\prime}=1\right)$ El grado de rendimientos a escala vendría dado por $\alpha+\beta=\eta$.

La otra especificación tiene como variable dependiente a la tasa de crecimiento de la productividad total de factores. De la siguiente ecuación $q_{m}=\rho+\eta\left[\alpha^{\prime} k_{m}+\beta^{\prime} l_{m}\right]$, se obtiene:

$$
\begin{gathered}
\eta q_{m}-\eta\left[\alpha^{\prime} k_{m}+\beta^{\prime} l_{m}\right]=\rho+\eta q_{m}-q_{m} \\
q_{m}-\left[\alpha^{\prime} k_{m}+\beta^{\prime} l_{m}\right]=\frac{\rho}{\eta}+\frac{\eta-1}{\eta} q_{m}
\end{gathered}
$$

La tasa de crecimiento de la productividad total de factores es igual a:

$$
p t f=q_{m}-\left[\alpha^{\prime} k_{m}+\beta^{\prime} l_{m}\right]
$$

Por lo tanto, la especificación alternativa sería:

$$
p t f=\frac{\rho}{\eta}+\frac{\eta-1}{\eta} q_{m}
$$


Sin embargo, el uso de una función de producción neoclásica desvincula el progreso técnico de la acumulación de capital por trabajador, y a esta de la tasa de crecimiento del producto. En Kaldor (1957) se encuentra una crítica al tratamiento separado del progreso técnico y de la acumulación del capital per cápita. El movimiento a lo largo de la función de producción es causado por el aumento de la intensidad de capital (o del stock de capital por trabajador), mientras que el desplazamiento de la función de producción es causado, según el modelo neoclásico de crecimiento, por el progreso técnico. Y, precisamente de este tratamiento «separado» de ambas variables, proviene el denominado Residuo de Solow como medida del progresos técnico y que se expresa como la productividad total de los factores (McCombie y Thirlwall, 1994; Leon-Ledesma, 2000).

Este progreso técnico ya no tiene lugar a través de la inversión y de la consiguiente acumulación de capital. La estimación del progreso técnico en términos de "crecimiento de la productividad total de los factores» (PTF) es el resultado de incluir el capital como uno de los factores de producción independientes, junto con el trabajo, en la función de producción neoclásica, la misma que fue sujeta a una crítica severa en la controversia de los dos Cambridge (Harcourt, 1975). La PTF «no es ni siquiera una medida del progreso técnico, ya que los supuestos aportes de los factores de producción, capital y trabajo, no son una medida real de la cantidad que el capital y el trabajo se utilizan en un sentido técnico, sino que son meras medidas de distribución entre el capital y el trabajo. Para que las variables de distribución sean consideradas como la cantidad utilizada de factores de producción, se necesita un supuesto extremadamente restrictivo como la teoría de la productividad marginal de la distribución» (Jeon, 2006, p. 11).

\section{Las estimaciones de la Ley de Verdoorn-Kaldor}

Para la estimación de las ecuaciones (13) y (14) se construye una serie de stock de capital del sector manufacturero, a partir de cifras de inversión en la industria, también estimadas. No existen series de inversión bruta y neta completas para todo el período de análisis.

Los resultados de las estimaciones de las ecuaciones (11) y (12) pueden verse en el Cuadro 14. El coeficiente de Verdoorn igual a 0,486 es estadísticamente significativo y menor que la unidad de acuerdo con el test de Wald. Un aumento en la tasa de crecimiento del producto de un punto porcentual daría lugar a un incremento de la productividad del trabajo en la propia industria manufacturera de $0,486 \%$. Además, el hecho que dicho coeficiente sea estadísticamente menor que la unidad es una condición suficiente para sostener que la industria manufacturera opera con rendimientos crecientes a escala. También el coeficiente $(0,514)$ del regresor en la ecuación (12), satisface esta condición. Por el test de Wald se rechaza la hipótesis que indica que los coeficientes del regresor sean iguales a 1. Los valores del estadístico obtenidos en ambas ecuaciones son bastante altos comparados con el valor crítico 3,993 para $\mathrm{F}(1,63)$ al 5\%. En realidad los coeficientes de los regresores son menores que la unidad. 
Cuadro 14. Segunda Ley de Kaldor I

\begin{tabular}{|c|c|c|}
\hline \multicolumn{3}{|c|}{ Ecuación } \\
\hline & (11) & (12) \\
\hline $\begin{array}{l}\text { Variables } \\
\text { independientes \dependiente }\end{array}$ & $\mathbf{p}_{\mathrm{m}}$ & $\mathrm{I}_{\mathrm{m}}$ \\
\hline Constante & $\begin{array}{l}-0.716 \\
(0.509)\end{array}$ & $\begin{array}{c}0.716 \\
(0.509)\end{array}$ \\
\hline $\mathbf{q}_{\text {man }}$ & $0.486^{*}$ & $0.514^{*}$ \\
\hline $\mathbf{n}$ & 65 & 65 \\
\hline $\mathbf{R}^{2}$ ajustado & 0.44 & 0.47 \\
\hline F estadístico & 51.26 & 57.51 \\
\hline D.w. & 2.19 & 2.19 \\
\hline \multicolumn{3}{|c|}{ Pruebas de Diagnóstico } \\
\hline $\begin{array}{l}\text { Test de normalidad } \\
\text { JB }-\chi^{2}(2)^{a}\end{array}$ & $\begin{array}{c}7.995 \\
(0.018)\end{array}$ & $\begin{array}{l}7.995 \\
(0.018)\end{array}$ \\
\hline $\begin{array}{l}\text { Test de heterocedasticidad } \\
\text { de White } F(2,62)^{a}\end{array}$ & $\begin{array}{c}0.249 \\
(0.780)\end{array}$ & $\begin{array}{c}0.249 \\
(0.780)\end{array}$ \\
\hline $\begin{array}{l}\text { Test de forma funcional de } \\
\text { Ramsey } F(1,62)^{a}\end{array}$ & $\begin{array}{c}9.050 \\
(0.003)\end{array}$ & $\begin{array}{c}9.050 \\
(0.003)\end{array}$ \\
\hline Test de Wald $F(1,63)^{b}$ & $\begin{array}{l}57.515 \\
(0.000)\end{array}$ & $\begin{array}{l}57.515 \\
(0.000)\end{array}$ \\
\hline
\end{tabular}

Error estándar entre paréntesis

${ }^{*}$ Coeficiente es estadísticamente significativo al $5 \%$.

aP-value entre paréntesis, la hipótesis nula es que se tiene normalidad, homocedasticidad y buena forma funcional.

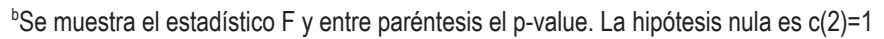

Hay evidencia, entonces, de la presencia de rendimientos crecientes a escala en la producción manufacturera y, por lo tanto, de la importancia de la proposición teórica de la causación circular acumulativa de Kaldor (McCombi y de Ridder, 1984). La productividad se determina endógenamente por el ritmo de acumulación, y el empleo crece como consecuencia del incremento de la producción. Del coeficiente $(1-\lambda=0,514)$ se puede obtener, siguiendo la metodología de McCombie y Roberts (2007) bajo el supuesto de una relación capital-producto constante, que el grado de rendimientos a 
escala es igual a 1,32. Ciertamente este es un supuesto irrelevante si nos ceñimos a los fundamentos teóricos de la ley de Veerdoorn que hemos desarrollado anteriormente.

Sin embargo, hay que señalar que la bondad de ajuste de ambas regresiones es baja ( $\mathrm{R}^{2}$ ajustado) y no pasan todas las pruebas de diagnóstico. De otro lado, según el test de White, no se puede rechazar la hipótesis nula de homocedasticidad en ninguno de los dos casos. El valor crítico asociado al $\mathrm{F}(2,62)$ al $5 \%$ es 3,145 y los valores obtenidos $(0,249)$ son mucho menores que este. El valor crítico es 2,390 al $10 \%$. Pero, ninguna de las ecuaciones pasa los test de normalidad y de buena forma funcional. Los estadísticos $\mathrm{Chi}^{2}$ indican que en ambas regresiones no se encuentra normalidad en los residuos. Al 5\% el valor crítico es 5,991 y al 2,5\%, 7,377 y los obtenidos son 7,995 en ambos casos; por lo tanto se rechaza la posibilidad de normalidad a esos niveles de significancia. Por su parte, el test de Ramsey cuya hipótesis nula indica que existe buena forma funcional muestra valores de 9,050 obtenidos en ambas regresiones, que están por encima del valor crítico 3,996 para $\mathrm{F}(1,62)$ al 5\%. Para $\mathrm{F}(1,62)$ al 1\% el valor crítico es 7,062. Por los tanto, se rechaza la hipótesis nula sobre la existencia de una buena forma funcional en las dos regresiones.

La explicación de estos resultados que ponen en duda la existencia de la ley VerdoornKaldor puede estar, como ya lo señalaba Kaldor para casos como el de la economía peruana, en la existencia de subempleo en gran parte del sector no-manufacturero y también en el sector manufacturero. Pero, también, y esto es lo más importante, en la volatilidad de la tasa de crecimiento de la productividad del trabajo que se registra desde los años 1980 hasta el final del período. La serie de esta productividad en niveles tiene una forma no lineal (véase Gráfico 4) con una tendencia creciente de 1950 hasta fines de los años 1970 y con otra decreciente desde los inicios de la década de los años 1980. Recién a partir de mediados de la década de los años 1990 se recupera con fuertes fluctuaciones.

Gráfico 4. Productividad laboral promedio en la manufactura

(En miles de soles de 2007 por trabajador)

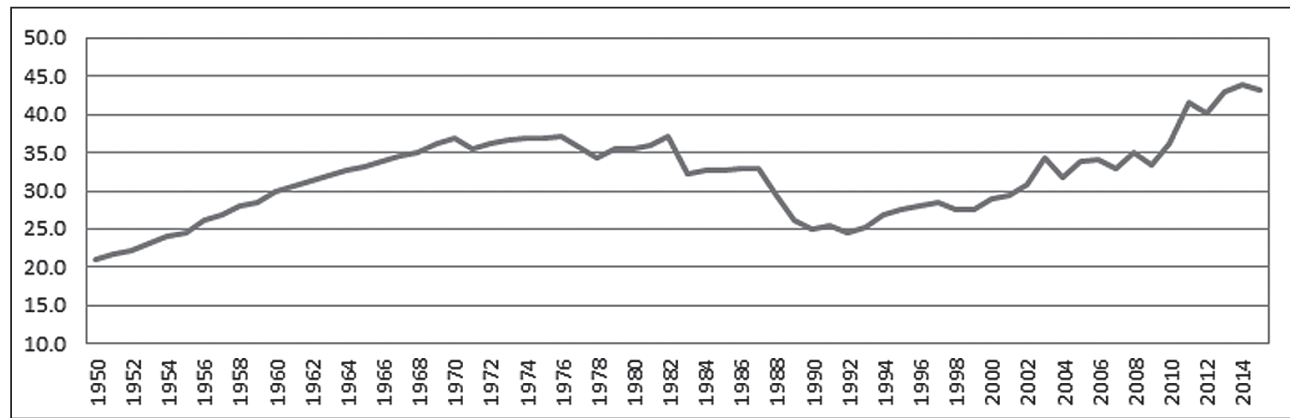

Fuente: INEI y MTPE. Elaboración propia. 
Finalmente, los resultados numéricos de las estimaciones de las ecuaciones (13) y (14) pueden verse en el Cuadro 15. Los coeficientes del regresor en ambas ecuaciones son significativamente menores que la unidad y nos revelan que existen rendimientos crecientes $(\alpha+\beta=\eta=1,575)$, aunque el grado de estos rendimientos resulta mayor que el obtenido con las estimaciones de las ecuaciones anteriores. Ciertamente este resultado está sujeto a las críticas mencionadas sobre la PTF como indicador de progreso técnico.

Cuadro 15. Segunda Ley de Kaldor II

\begin{tabular}{|c|c|c|}
\hline \multicolumn{3}{|c|}{ Ecuación } \\
\hline & (13) & (14) \\
\hline $\begin{array}{l}\text { Variables } \\
\text { independientes \dependiente }\end{array}$ & itf & ptf \\
\hline Constante & $\begin{array}{l}1.186^{*} \\
(0.320)\end{array}$ & $\begin{array}{l}-1.186 * \\
(0.320)\end{array}$ \\
\hline $\mathbf{q}_{\operatorname{man}}$ & $\begin{array}{l}0.635^{*} \\
(0.000)\end{array}$ & $\begin{array}{l}0.364^{*} \\
(0.038)\end{array}$ \\
\hline $\operatorname{AR}(1)$ & $\begin{array}{l}-0.269 * \\
(0.112)\end{array}$ & $\begin{array}{l}-0.269 * \\
(0.112)\end{array}$ \\
\hline n & 65 & 65 \\
\hline $\mathbf{R}^{2}$ ajustado & 0.692 & 0.472 \\
\hline F estadístico & 49.065 & 20.141 \\
\hline D.W. & 1.974 & 1.974 \\
\hline \multicolumn{3}{|c|}{ Pruebas de Diagnóstico } \\
\hline $\begin{array}{l}\text { Test de normalidad } \\
\text { JB }-\chi^{2}(2)^{a}\end{array}$ & $\begin{array}{l}35.628 \\
(0.000)\end{array}$ & $\begin{array}{l}35.628 \\
(0.000)\end{array}$ \\
\hline $\begin{array}{l}\text { Test de heterocedasticidad } \\
\text { de White } F(5,58)^{a}\end{array}$ & $\begin{array}{c}0.935 \\
(0.465)\end{array}$ & $\begin{array}{c}0.935 \\
(0.465)\end{array}$ \\
\hline $\begin{array}{l}\text { Test de forma funcional de } \\
\text { Ramsey } F(1,60)^{a}\end{array}$ & $\begin{array}{l}10.196 \\
(0.002)\end{array}$ & $\begin{array}{l}7.699 \\
(0.007)\end{array}$ \\
\hline Test de Wald $F(1,61)^{b}$ & $\begin{array}{l}87.497 \\
(0.000)\end{array}$ & $\begin{array}{c}266.413 \\
(0.000)\end{array}$ \\
\hline
\end{tabular}

Error estándar entre paréntesis

${ }^{*}$ Coeficiente es estadísticamente significativo al $5 \%$.

ap-value entre paréntesis, la hipótesis nula es que se tiene normalidad, homocedasticidad y buena forma funcional.

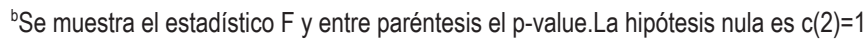


Las estimaciones de las dos ecuaciones no registran una buena bondad de ajuste ( $\mathrm{R}^{2}$ ajustada) y ninguna de las dos satisface los test de normalidad y de buena forma funcional. Por un lado, los valores del estadístico $\mathrm{Chi}^{2}$ obtenidos son considerablemente altos en comparación con los valores críticos de la tabla $\mathrm{Chi}^{2}$, que al 5\% es 5,991 y al 1\% es 9,21. Se rechaza, por lo tanto, la existencia de normalidad en los residuos de ambas estimaciones. Sin embargo, las dos regresiones pasan el test de White, lo que implica no rechazar la hipótesis nula de existencia de homocedasticidad. El valor crítico de $\mathrm{F}(5,58)$ al $5 \%$ es igual a 2,374 y los estadísticos obtenidos son iguales a 0,935 . De otro lado, el test de Ramsey indica que no existe buena forma funcional en ambos casos. El valor crítico de $\mathrm{F}(1,60)$ al $5 \%$ es 4,001 y al $1 \%$ es 7,08 , mientras que los estadísticos obtenidos son mayores, 10,196 y 7,699 respectivamente. En consecuencia, también se rechaza la hipótesis nula sobre la existencia de buena forma funcional al 5\% y $1 \%$.

Estos resultados también pueden estar asociados a la forma no lineal de la variable dependiente que, en este caso, es la productividad total de factores (PTF) en la industria manufacturera (véase Gráfico 5). La misma forma no lineal tiene la PTF de la economía en su conjunto como se muestra en Jiménez (2012). Las reformas y políticas de ajuste que se aplicaron desde los ańos 1980 afectaron notablemente la productividad de la manufactura por lo que sus tasas de variación se hacen muy volátiles.

En resumen, podemos decir que el comportamiento de la productividad del trabajo en la industria manufacturera (y también el de la productividad total de factores), está relacionado con la desindustrialización y terciarización prematura ocurrida en las últimas décadas. El crecimiento de los ańos 1990 y del período 2003-2013 no fue liderado por la manufactura, sino por los sectores primarios, un contexto de sistemática apreciación cambiaria. La desindustrialización le restó capacidad de arrastre a la manufactura (Jiménez, 2011, 2012).

Gráfico 5. Productividad total de factores en la manufactura

(En logaritmos de miles de soles de 2007)

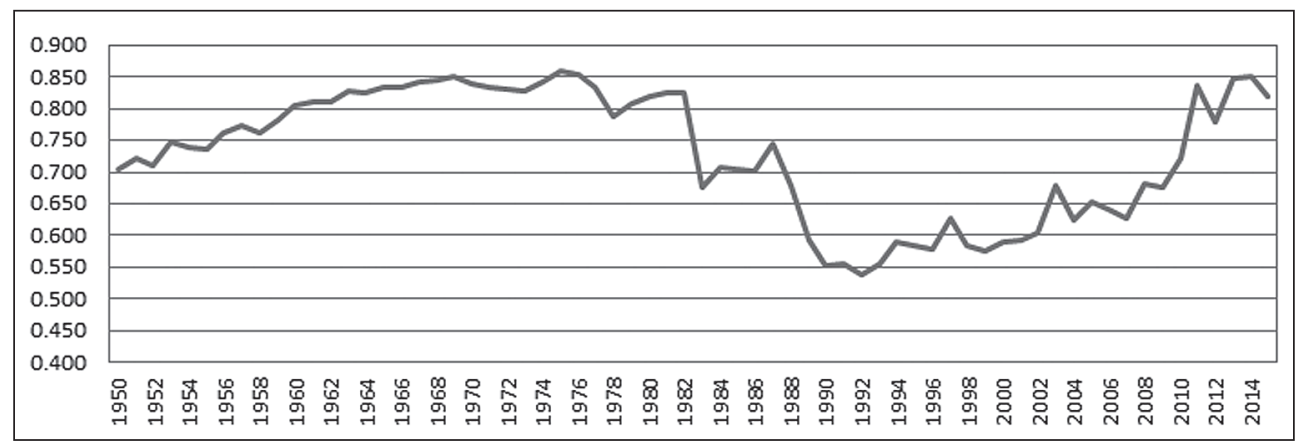

Fuente: INEI y MTPE. Elaboración propia. 
ii. El enfoque de cointegración y la dirección de causalidad

Como se indicó anteriormente la regresión adecuada para la segunda Ley de Kaldor o Ley de Kaldor-Verdoorn, es la que relaciona la tasa de crecimiento de la producción manufacturera con la tasa de crecimiento del empleo en el mismo sector. Por lo tanto, lo que hay que probar es si cointegran los niveles en logaritmos de estas dos variables.

\section{Pruebas de estacionariedad y de raiz unitaria}

En el análisis de la primera Ley de Kaldor se mostró que el logaritmo de la producción manufacturera tiene raíz unitaria y que su primera diferencia es estacionaria. En consecuencia, el test se aplicará solo a la serie en logaritmos de la PEA ocupada en el sector manufacturero.

Cuadro 16. Prueba de raíz unitaria para la PEAO del sector manufacturero de Perú 1950-2015

\begin{tabular}{|c|c|c|c|}
\hline $\begin{array}{l}\text { Hipótesis nula: } \\
\text { Exógenas: } \\
\text { Rezagos: }\end{array}$ & $\begin{array}{l}\text { Log de PEAO manufacturero tiene raíz unitaria } \\
\text { Intercepto y tendencia } \\
1 \text { con } 4 \text { como máximo, AIC }\end{array}$ & & \\
\hline & & Estadístico $\mathrm{t}$ & Probabilidad \\
\hline \multicolumn{4}{|l|}{ Test estadístico Dickey-Fuller } \\
\hline Aumentado & & -2.023 & 0.578 \\
\hline \multirow[t]{3}{*}{ Valores críticos } & Nivel $1 \%$ & -4.108 & \\
\hline & Nivel $5 \%$ & -3.482 & \\
\hline & Nivel $10 \%$ & -3.169 & \\
\hline Hipótesis nula: & Log de PEAO manufacturero tiene raíz unitaria & & \\
\hline Exógenas: & Intercepto & & \\
\hline Rezagos: & 0 con 4 como máximo, AlC & & \\
\hline & & Estadístico t & Probabilidad \\
\hline \multicolumn{4}{|l|}{ Test estadístico Dickey-Fuller } \\
\hline Aumentado & & -2.230 & 0.198 \\
\hline \multirow[t]{3}{*}{ Valores críticos } & Nivel 1\% & -3.535 & \\
\hline & Nivel 5\% & -2.907 & \\
\hline & Nivel $10 \%$ & -2.591 & \\
\hline Hipótesis nula: & $\mathrm{d}($ Log de PEAO manufacturero) tiene raíz unitaria & & \\
\hline Exógenas: & Intercepto & & \\
\hline Rezagos: & 0 con 4 como máximo, AIC & & \\
\hline & & Estadístico t & Probabilidad \\
\hline \multicolumn{4}{|l|}{ Test estadístico Dickey-Fuller } \\
\hline Aumentado & & -7.134 & 0.000 \\
\hline \multirow[t]{3}{*}{ Valores críticos } & Nivel 1\% & -3.537 & \\
\hline & Nivel 5\% & -2.908 & \\
\hline & Nivel $10 \%$ & -2.591 & \\
\hline
\end{tabular}


El Cuadro 16 muestra que el logaritmo del empleo en la manufactura de acuerdo con el test de Dickey y Fuller Aumentado también tiene raíz unitaria y que su primera diferencia es estacionaria. El test se aplicó para los casos de intercepto y tendencia, por un lado, e intercepto, por el otro. Para la primeras diferencias de la serie solo se aplicó para el intercepto. El número de rezagos máximo utilizado fue 4 y el criterio automático de selección de estos fue el de Akaike (AIC). Los resultados permiten afirmar, entonces, que la serie del empleo en la manufactura es integrada de orden 1.

\section{Cointegración entre en empleo en la manufactura y el PBI manufacturero}

Sobre la base del modelo de cambio en régimen propuesto por Gregory y Hansen (1996), se estima la ecuación de cointegración incorporando variables dummy para el intercepto y para la pendiente. La variable dummy es la misma que se utilizó en el análisis de la primera Ley de Kaldor e indica el quiebre estructural encontrado en el año 1988. Se debe mencionar que el empleo en el sector manufacturero (PEAOman) no registra un crecimiento con quiebres y tendencia similar al crecimiento de las otras variables (PBI manufacturero, PBI total $)^{8}$. Se procedió entonces a estimar la ecuación de cointegración por el método de Mínimos Cuadrados Ordinarios Completamente Modificados (FMOLS), con el cual se pierde una observación en la regresión.

Los resultados de la estimación de la ecuación de cointegración se muestran en el Cuadro 17. La $R^{2}$ ajustada es relativamente alta $\left(R^{2}\right.$ ajustada es igual a 0,986$)$ y todos los coeficientes de los regresores son estadísticamente significativos. Se observa, además, que hay cambios importantes en el intercepto y la pendiente para el período 1990-2015. La elasticidad empleo de la manufactura disminuye de 0,693 a 0,473 .

\section{Cuadro 17. Ecuación de cointegración}

\begin{tabular}{|ccccc|}
\hline Variable dependiente: & $\begin{array}{c}\text { Log PEAO manufactura } \\
\text { Mínimos cuadrados ordinarios } \\
\text { completamente modificados }\end{array}$ & & & \\
Método: & 1951 - 2015 & & & \\
Muestra: & 65 & Error estándar & Estadístico t & Probabilidad \\
Observaciones: & Coeficiente & 0.295 & -1.541 & 0.128 \\
\hline Variable & -0.455 & 0.629 & 4.107 & 0.000 \\
Constante & 2.586 & 0.030 & 22.941 & 0.000 \\
dummy & 0.693 & 0.060 & -3.638 & 0.000 \\
Log(PBIman) & -0.220 & & & \\
\hline Log(PBIman)*dummy & $\mathbf{0 . 9 8 6}$ & & & \\
$\mathbf{R}^{2}$ ajustado & & & & \\
\hline
\end{tabular}

8 Con el test de Bai-Perrón para múltiples quiebres estructurales esta variable muestra un cambio estructural en el año 1987, un año anterior a 1988 que es cuando se produce el quiebre en la producción manufacturera. 
Cuadro 18. Prueba de cointegración

\begin{tabular}{|cccc|}
\hline $\begin{array}{c}\text { Hipótesis nula: } \\
\text { Exógenas: } \\
\text { Rezagos: }\end{array}$ & $\begin{array}{c}\text { Residuos con raíz unitaria } \\
\text { Intercepto } \\
0\end{array}$ & & \\
\hline & & Estadístico t & Probabilidad \\
\hline Test estadístico Dickey-Fuller & & -3.322 & 0.017 \\
Aumentado & Nivel 1\% & -3.536 & \\
Valores críticos & Nivel 5\% & -2.907 & \\
& Nivel 10\% & -2.591 & \\
\hline
\end{tabular}

A los residuos de la estimación de la ecuación de cointegración se les aplica el test de raíz unitaria de Dickey Fuller Aumentado (ADF), en este caso considerando como exógeno el intercepto y sin ningún rezago. Los resultados obtenidos (véase Cuadro 18) muestran que se rechaza la existencia de raíz unitaria en los residuos al 5\% de significancia. Por lo tanto, se puede considerar que estos residuos siguen un proceso estacionario, es decir están integrados de orden 0. Esto permite concluir entonces que las series analizadas están cointegradas y que, por lo tanto, se puede estimar el modelo de corrección de errores.

\section{Modelo de corrección del error}

Los resultados de la estimación de este modelo se encuentran en el Cuadro 19. El signo negativo del coeficiente de los residuos con un rezago de un período, es el correcto. Este coeficiente actúa como el mecanismo de ajuste anual de las desviaciones respecto del equilibrio de largo plazo. Como su valor es igual a -12,457; las desviaciones de la relación de equilibrio se corrigen anualmente en $12,5 \%$ aproximadamente. Es importante anotar, sin embargo, que el coeficiente del residuo no es estadísticamente distinto de cero al 5\% de significancia.

De otro lado, de acuerdo con el test de Wald se rechaza la hipótesis nula de que el coeficiente del regresor sea igual a la unidad, con un alto nivel de significancia. Este es el coeficiente estimado de Verdoorn y como es significativamente menor que la unidad, indica que hay rendimientos crecientes a escala. Pero este resultado no es concluyente, como ya lo habíamos anotado en el análisis de la regresión con tasas de crecimiento de las respectivas variables. La razón es que la ecuación estimada no satisface todas las pruebas de diagnóstico. Se rechaza la hipótesis nula de normalidad porque el estadístico obtenido de 9,537 es mayor que el valor crítico de la tabla de $\mathrm{Chi}^{2}$ al $5 \%$ y que es igual a 5,991. También se rechaza la hipótesis nula de homocedasticidad porque según el test de White el estadístico obtenido igual a 3.314 es mayor que el valor crítico del $\mathrm{F}(5,58)$ al $5 \%$ que es igual a 2,374 . 


\section{Cuadro 19. Modelo de corrección del error}

\begin{tabular}{|c|c|c|c|c|}
\hline Variable dependiente: & dLog(PEAO manufactura) & & & \\
\hline Método: & Mínimos cuadrados ordinarios & & & \\
\hline Muestra: & $1952-2015$ & & & \\
\hline Observaciones: & 64 & & & \\
\hline Variable & Coeficiente & Error estándar & Estadístico $t$ & Probabilidad \\
\hline Constante & 0.360 & 0.514 & 0.699 & 0.487 \\
\hline dLog(PBIman) & 0.642 & 0.0851 & 7.547 & 0.000 \\
\hline $\mathrm{d}($ LogPBIman*dummy) & -0.211 & 0.123 & -1.713 & 0.091 \\
\hline d(dummy) & 2.275 & 1.281 & 1.775 & 0.081 \\
\hline Residuos.1 $_{-1}$ & -12.457 & 8.241 & -1.511 & 0.136 \\
\hline$R^{2}$ ajustado & 0.507 & F estadístico & 17.227 & \\
\hline \multicolumn{5}{|c|}{ Pruebas de Diagnóstico } \\
\hline Test de normalidad & 9.537 & & & \\
\hline$J B-x^{2}(2)^{a}$ & $(0.008)$ & & & \\
\hline Test de heterocedasticidad & 3.314 & & & \\
\hline de White $F(9,54)^{a}$ & $(0.002)$ & & & \\
\hline Test de forma funcional de & 8.677 & & & \\
\hline Ramsey $\mathrm{F}(1,58)^{\mathrm{a}}$ & $(0.004)$ & & & \\
\hline Test de Wald $F(1,59)^{b}$ & $\begin{array}{l}17.626 \\
(0.000)\end{array}$ & & & \\
\hline
\end{tabular}

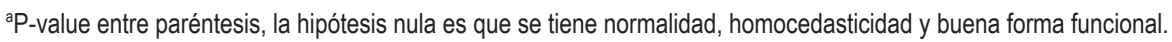

${ }^{b} S e$ muestra el estadístico $\mathrm{F}$ y entre paréntesis el p-value. La hipótesis nula es $\mathrm{c}(2)=1$

*Las variables en diferencias con excepción de la dummy fueron multiplicadas por 100 para expresarlas en tasas de crecimiento.

Además, el Modelo de Corrección del Error no tiene una buena bondad de ajuste pues la $\mathrm{R}^{2}$ ajustada es de solo 0,507 . Tampoco presenta una buena forma funcional. El test de Ramsey nos da un estadístico igual a 8,677 que es mayor que el valor crítico 4,001 de la tabla para $\mathrm{F}(1,60)$ al $5 \%$.

\section{Dirección de causalidad (test de Granger)}

Aunque es prácticamente innecesario efectuar el test de causalidad debido a que el test de cointegración no satisface todas las pruebas de diagnóstico, mostramos los resultados del test de causalidad para las series sin corregir y para las series corregidas por el cambio estructural (Cuadro 20 y Cuadro 21). Como era de esperase no hay causalidad en una sola dirección. 
Cuadro 20. Test de causalidad de Granger entre la PEA ocupada en la manufactura y PBI manufacturero

\begin{tabular}{|cccc|}
\hline $\begin{array}{c}\text { Rezagos: } \\
\text { Muestra: }\end{array}$ & 4 & & \\
Observaciones: & $1950-2015$ & & \\
\hline \multicolumn{1}{c}{ Hipótesis nula: } & 62 & & \\
\hline & Estadístico F & Probabilidad \\
\hline Log(PEAOman) no es causa Granger del Log(PBIman) & 0.866 & 0.490 \\
Log(PBIman) no es causa Granger del Log(PEAOman) & 2.332 & 0.067 \\
\hline
\end{tabular}

Cuadro 21. Test de causalidad de Granger entre la PEA ocupada en la manufactura y PBI manufacturero

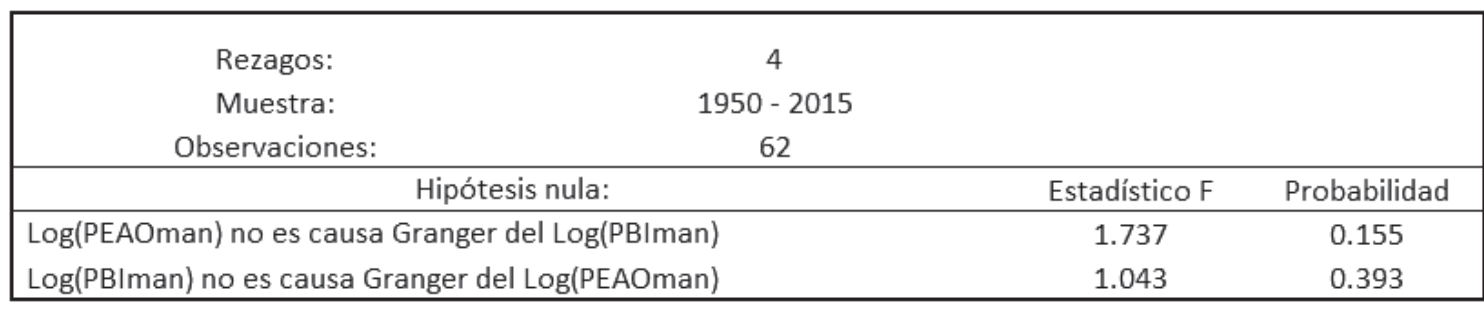

La serie de PBI de la manufactura se corrigió considerando el cambio estructural que según el test de Zivot y Andrews ocurre a partir de 1988.

En ambos casos, no se puede afirmar que el PBI del sector manufacturero es causa de la PEA ocupada en la manufactura, ni que la PEA ocupada en la manufactura (PEAOman) es causa del PBI del sector manufacturero. No hay causalidad unidireccional.

c. Tercera Ley de Kaldor: la productividad como hecho macroeconómico endógeno La tercera Ley de Kaldor sostiene que la tasa de crecimiento de la productividad del trabajo de la economía en su conjunto se relaciona positivamente con la tasa de crecimiento de la producción manufacturera. La expansión de la producción manufacturera conduce a un rápido crecimiento de la productividad en la propia manufactura (por la operación de la Ley de Verdoorn) y en el conjunto de la economía (por el efecto derrame que genera). De otro lado, la reducción de las actividades ineficientes con rendimientos decrecientes en la agricultura y en los sectores comercio y servicios donde se encuentran los trabajadores informales y los subempleados, y la transferencia de trabajo hacia la industria manufacturera desde estos sectores y actividades, también tienen un impacto positivo en la productividad del conjunto de la economía. 


\section{i. La estimación con mínimos cuadrados ordinarios}

La especificación que capta la relación positiva entre las tasas de crecimiento de la productividad del trabajo de la economía en su conjunto y de la producción manufacturera, por un lado, y la relación inversa entre dicha tasa de crecimiento de la productividad y la tasa de crecimiento del empleo en el resto de sectores, es la siguiente:

$$
p_{T}=a+b q_{m}-b l_{n m}
$$

donde: $\quad p_{T}$ : Tasa logarítmica de crecimiento del PBI por trabajador o productividad del trabajo en la economía en su conjunto.

$q_{m}$ : Tasa logarítmica de crecimiento del PBI manufacturero.

$l_{n m}$ : Tasa logarítmica de crecimiento del empleo en el sector no-manufacturero

Esta ecuación fue sugerida por Cripps y Tarling (1973). La transferencia de trabajo excedente desde las actividades tradicionales e ineficientes hacia el sector manufacturero dinámico, tiene una doble ganancia de crecimiento de la productividad en la economía en su conjunto. Por un lado aumenta la productividad al liberar trabajo y recursos desde los sectores no dinámicos o tradicionales y, por otro, también aumenta la productividad con la expansión de las sectores dinámicos (Dasgupta y Singh, 2006).

Una especificación alternativa a la anterior que también capta ambos efectos es la siguiente:

$$
p_{n m}=a+b q_{m}-c l_{n m}
$$

donde: $\quad p_{n m}$ : Tasa logarítmica de crecimiento del PBI per cápita de los sectores distintos a la manufactura o su productividad laboral media

$q_{m}$ : Tasa logarítmica de crecimiento del PBI manufacturero

$l_{n m}$ : Tasa logarítmica de crecimiento del empleo en el sector no-manufacturero

Los resultados de las estimaciones de estas dos ecuaciones pueden verse en el Cuadro 22. Ambas ecuaciones exhiben un buen ajuste por los altos valores de la $\mathrm{R}^{2}$ ajustada y, también en ambas, los coeficientes de los regresores son estadísticamente significativos y menores que la unidad, según el test de Wald. Según los resultados para la ecuación (15) la tasa de crecimiento del PBI manufacturero de 1\% explica el 0,542\% de la tasa de crecimiento de la productividad del trabajo para el conjunto de la economía. Asimismo, cada vez que se reduce el empleo no manufacturero, digamos en $1 \%$, aumenta la productividad agregada en $0,597 \%$. Un análisis parecido puede hacerse con los resultados de la regresión de la ecuación (16). El 0,525\% de la productividad en los sectores distintos a la manufactura se explicaría por un $1 \%$ de crecimiento del PBI manufacturero. Asimismo, la reducción del empleo en los sectores no manufactureros de $1 \%$ incrementa la productividad en estos mismos sectores en $0,73 \%$. 
Cuadro 22. Tercera Ley de Kaldor

\begin{tabular}{|c|c|c|}
\hline \multicolumn{3}{|c|}{ Ecuación } \\
\hline & (15) & (16) \\
\hline $\begin{array}{l}\text { Variables } \\
\text { independientes\dependientes }\end{array}$ & $\mathbf{p}_{\text {T }}$ & $\mathbf{p}_{\mathrm{nm}}$ \\
\hline Constante & $\begin{array}{c}0.811 \\
(0.144)\end{array}$ & $\begin{array}{l}1.222^{*} \\
(0.620)\end{array}$ \\
\hline$q_{m}$ & $\begin{array}{l}0.542^{*} \\
(0.027)\end{array}$ & $\begin{array}{l}0.525^{*} \\
(0.032)\end{array}$ \\
\hline$I_{n m}$ & $\begin{array}{l}-0.597^{*} \\
(0.176)\end{array}$ & $\begin{array}{l}-0.730^{*} \\
(0.209)\end{array}$ \\
\hline $\operatorname{AR}(1)$ & $\begin{array}{l}0.430^{*} \\
(0.129)\end{array}$ & $\begin{array}{c}0.383^{*} \\
(0.1333)\end{array}$ \\
\hline $\mathbf{n}$ & 65 & 65 \\
\hline $\mathbf{R}^{2}$ ajustado & 0.819 & 0.763 \\
\hline F estadístico & 73.751 & 52.727 \\
\hline D.W. & 2.017 & 1.999 \\
\hline Pruebas & gnóstico & \\
\hline $\begin{array}{l}\text { Test de normalidad } \\
\text { JB }-\chi^{2}(2)^{a}\end{array}$ & $\begin{array}{c}2.284 \\
(0.319)\end{array}$ & $\begin{array}{l}1.577 \\
(0.454)\end{array}$ \\
\hline $\begin{array}{l}\text { Test de heterocedasticidad } \\
\text { de White } F(9,54)^{a}\end{array}$ & $\begin{array}{c}1.163 \\
(0.336)\end{array}$ & $\begin{array}{l}1.279 \\
(0.269)\end{array}$ \\
\hline $\begin{array}{l}\text { Test de forma funcional de } \\
\text { Ramsey } F(1,59)^{a}\end{array}$ & $\begin{array}{c}4.757 \\
(0.033)\end{array}$ & $\begin{array}{c}2.674 \\
(0.107)\end{array}$ \\
\hline Test de Wald $F(1,60)^{b}$ & $\begin{array}{l}286.79 \\
(0.000)\end{array}$ & $\begin{array}{l}219.11 \\
(0.000)\end{array}$ \\
\hline
\end{tabular}

Error estándar entre paréntesis

${ }^{*}$ Coeficiente es estadísticamente significativo al $5 \%$.

aP-value entre paréntesis, la hipótesis nula es que se tiene normalidad, homocedasticidad y buena forma funcional.

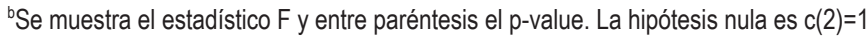


Las estimaciones de ambas ecuaciones pasan el test de normalidad. Los residuos mantienen una distribución normal porque el valor crítico al 5\% del $\mathrm{Chi}^{2}$ es 5.991, mayor que los valores de los estadísticos obtenidos: 2,284 y 1,577, respectivamente. Tampoco se rechaza la hipótesis nula de homocedasticidad del test de White. La tabla para $\mathrm{F}(9,54)$ indica un valor crítico 2,059 al 5\%, que es mayor a los valores del estadístico que se obtienen para ambas ecuaciones: 1,163 y 1,279 , respectivamente.

Por último, la ecuación (16) es la única que pasa el test de buena forma funcional. El estadístico de Ramsey obtenido tiene un valor de 2,674 que es menor que el valor crítico de 4,004 de la tabla para $\mathrm{F}(1,59)$ al 5\%. En la ecuación (15), el valor del estadístico obtenido es de 4,757 que es mayor que el valor crítico de la tabla $(4,004)$ para $\mathrm{F}(1,59)$ al 5\%. Sin embargo, el estadístico obtenido está por debajo del valor crítico 7,085 de la tabla al $1 \%$. Por lo tanto, se rechaza la hipótesis nula de buena forma funcional al 5\% más no al 1\%.

En general, puede concluirse que se corrobora la idea de los efectos positivos sobre la productividad del trabajo en el conjunto de la economía, de las transferencias de mano de obra hacia el sector manufacturero desde aquellos sectores con excedentes de trabajo como la agricultura y los sectores de servicios donde se concentra el mayor porcentaje de subempleados. Como señala la literatura sobre el tema, la productividad del trabajo en la manufactura aumenta a medida que absorbe trabajadores que le permiten producir más; y cuando la producción manufacturera aumenta, también aumenta la productividad agregada a través de los efectos dinámicos asociados al learning by doing y las externalidades económicas generadas como resultado de la interacción entre las actividades económicas. Pero, también aumentará la productividad del trabajo en el resto de sectores distintos a la manufactura porque reducirá sus trabajadores excedentes al ser absorbidos por la manufactura. Como señala Kaldor (1968), lo que determina el crecimiento de la productividad del trabajo en la economía en su conjunto es la tasa a la cual el excedente de trabajo en los sectores de baja productividad se transfiere a la manufactura (Cripps y Tarling, 1973; Kaldor, 1968; Thirlwall, 1983)

ii. El enfoque de cointegración y la dirección de causalidad

Para corroborar la tercera Ley de Kaldor se evaluará si existe una relación de largo plazo entre la productividad media del trabajo en el conjunto de sectores distintos al manufacturero, y los niveles del PBI manufacturero y del empleo en el conjunto de sectores no manufactureros.

\section{Pruebas de estacionariedad y de raíz unitaria}

En el análisis de las dos primeras leyes se probó que la serie en logaritmos del PBI de la manufactura es integrada de orden 1. Por esta razón, el test de Dickey-Fuller Aumentado se aplicará solo a las series de la productividad del trabajo (PBInm/PEAOnm) y del empleo (PEAOnm) en el conjunto de los sectores no manufactureros. Las series están en logaritmos. Los Cuadros 23 y 24, contienen los resultados. 
Cuadro 23. Prueba de raíz unitaria para PBInm/PEAOnm de Perú 1950-2015

\begin{tabular}{|c|c|c|c|}
\hline $\begin{array}{l}\text { Hipótesis nula: } \\
\text { Exógenas: } \\
\text { Rezagos: }\end{array}$ & $\begin{array}{c}\text { Log de PBInm/PEAOnm tiene raíz } \\
\text { unitaria } \\
\text { Intercepto y tendencia } \\
1 \text { con } 4 \text { como máximo, } \mathrm{AlC} \\
\end{array}$ & & \\
\hline $\begin{array}{c}\text { Test estadístico Dickey-Fuller } \\
\text { Aumentado } \\
\text { Valores críticos }\end{array}$ & $\begin{array}{l}\text { Nivel } 1 \% \\
\text { Nivel } 5 \% \\
\text { Nivel } 10 \% \\
\end{array}$ & $\begin{array}{l}\text { Estadístico t } \\
\qquad \begin{array}{c}-1.852 \\
-4.107 \\
-3.481 \\
-3.168 \\
\end{array}\end{array}$ & $\begin{array}{c}\text { Probabilidad } \\
0.667\end{array}$ \\
\hline $\begin{array}{l}\text { Hipótesis nula: } \\
\text { Exógenas: } \\
\text { Rezagos: }\end{array}$ & $\begin{array}{c}\text { Log de PBInm/PEAOnm tiene raíz } \\
\text { unitaria } \\
\text { Intercepto } \\
1 \text { con } 4 \text { como máximo, AIC }\end{array}$ & & \\
\hline $\begin{array}{l}\text { Test estadístico Dickey-Fuller } \\
\text { Aumentado } \\
\text { Valores críticos }\end{array}$ & $\begin{array}{l}\text { Nivel } 1 \% \\
\text { Nivel } 5 \% \\
\text { Nivel } 10 \% \\
\end{array}$ & $\begin{array}{l}\text { Estadístico t } \\
\qquad \begin{array}{c}-1.625 \\
-3.536 \\
-2.907 \\
-2.591 \\
\end{array}\end{array}$ & $\begin{array}{l}\text { Probabilidad } \\
0.463\end{array}$ \\
\hline $\begin{array}{l}\text { Hipótesis nula: } \\
\text { Exógenas: } \\
\text { Rezagos: } \\
\end{array}$ & $\begin{array}{c}\mathrm{d}(\text { Log de PBInm/PEAOnm) tiene raíz } \\
\text { unitaria } \\
\text { Intercepto } \\
0 \text { con } 4 \text { como máximo, } \mathrm{AIC} \\
\end{array}$ & & \\
\hline $\begin{array}{c}\text { Test estadístico Dickey-Fuller } \\
\text { Aumentado } \\
\text { Valores críticos }\end{array}$ & $\begin{array}{l}\text { Nivel } 1 \% \\
\text { Nivel } 5 \% \\
\text { Nivel } 10 \%\end{array}$ & $\begin{array}{l}\text { Estadístico t } \\
\qquad \begin{array}{c}-5.448 \\
-3.536 \\
-2.907 \\
-2.591\end{array}\end{array}$ & $\begin{array}{c}\text { Probabilidad } \\
0.000\end{array}$ \\
\hline
\end{tabular}

Según el test de raíz unitaria de Dickey-Fuller Aumentado (ADF) — para intercepto y tendencia, e intercepto únicamente-, la serie de la productividad del trabajo en el resto de sectores distintos al manufacturero, no es estacionaria y no se logra rechazar la hipótesis nula de la presencia de raíz unitaria. Por su parte, la primera diferencia de la serie no presenta raíz unitaria, con lo cual se corrobora la hipótesis que es estacionaria. Por consiguiente, se puede afirmar que la serie de la productividad del trabajo en el conjunto de sectores no manufactureros, es integrada de orden 1.

Para la serie de empleo en el conjunto de los sectores no manufactureros, los resultados del test indican que es integrada de orden 1 . No se logra rechazar la hipótesis de 
existencia de raíz unitaria con intercepto y tendencia, y con intercepto únicamente. Además, las primeras diferencias de la serie no presentan raíz unitaria sino estacionariedad. Por consiguiente la serie es integrada en primer orden.

Cuadro 24. Prueba de raíz unitaria para la PEAO de los sectores no manufactureros de Perú 1950-2015

\begin{tabular}{|c|c|c|c|}
\hline Hipótesis nula: & Log de PEAO sin manufactura tiene raíz unitaria & & \\
\hline Exógenas: & Intercepto y tendencia & & \\
\hline \multirow[t]{2}{*}{ Rezagos: } & 1 con 4 como máximo, AIC & & \\
\hline & & Estadístico $\mathrm{t}$ & Probabilidad \\
\hline $\begin{array}{l}\text { Test estadístico Dickey-Fuller } \\
\text { Aumentado }\end{array}$ & & -2.330 & 0.411 \\
\hline \multirow[t]{3}{*}{ Valores críticos } & Nivel 1\% & -4.107 & \\
\hline & Nivel 5\% & -3.481 & \\
\hline & Nivel $10 \%$ & -3.168 & \\
\hline Hipótesis nula: & Log de PEAO sin manufactura tiene raíz unitaria & & \\
\hline Exógenas: & Intercepto & & \\
\hline \multirow[t]{2}{*}{ Rezagos: } & 1 con 4 como máximo, AIC & & \\
\hline & & Estadístico $\mathrm{t}$ & Probabilidad \\
\hline $\begin{array}{l}\text { Test estadístico Dickey-Fuller } \\
\text { Aumentado }\end{array}$ & & 0.552 & 0.987 \\
\hline \multirow[t]{3}{*}{ Valores críticos } & Nivel 1\% & -3.536 & \\
\hline & Nivel 5\% & -2.907 & \\
\hline & Nivel $10 \%$ & -2.591 & \\
\hline Hipótesis nula: & $\begin{array}{c}\mathrm{d}(\text { Log de PEAO sin manufactura) tiene raíz } \\
\text { unitaria }\end{array}$ & & \\
\hline Exógenas: & Intercepto & & \\
\hline \multirow[t]{2}{*}{ Rezagos: } & 0 con 4 como máximo, AlC & & \\
\hline & & Estadístico $\mathrm{t}$ & Probabilidad \\
\hline $\begin{array}{l}\text { Test estadístico Dickey-Fuller } \\
\text { Aumentado }\end{array}$ & & -4.545 & 0.000 \\
\hline \multirow[t]{3}{*}{ Valores críticos } & Nivel $1 \%$ & -3.536 & \\
\hline & Nivel 5\% & -2.907 & \\
\hline & Nivel $10 \%$ & -2.591 & \\
\hline
\end{tabular}

Cointegración entre la productividad laboral del conjunto de sectores no manufactureros, el PBI manufacturero y el empleo agregado de los sectores no manufactureros

Dado que las tres series son integradas de orden 1, se procede a estimar la ecuación de cointegración por el método de mínimos cuadrados dinámicos. Los resultados se encuentran en el Cuadro 25. La ecuación de cointegración incluye dos variables independientes. Nuevamente se utilizan las variables dummy (en el intercepto y en la pendiente) para captar en cambio estructural que presenta la serie en logaritmos del PBI manufacturero. 
Los parámetros estimados son todos robustos al igual que la bondad de ajuste (la $\mathrm{R}^{2}$ ajustada es relativamente alta: 0,969). Lo que se observa y sorprende es que la elasticidad de la productividad laboral del conjunto de sectores no manufactureros respecto al PBI manufacturero aumenta de 0,601 en el período 1950-1989, a 0,767 en el período 1990-2015. La productividad del trabajo en estos sectores se hace más sensible a los cambios en la producción manufacturera. Recuérdese que este es un período de desindustrialización prematura que se expresa en la caída de su participación en la generación de empleo. Los datos indican que en el período 1990-2015 la productividad del trabajo de la economía en su conjunto y la productividad del trabajo de los sectores no manufactureros crecía a la tasa de $2,05 \%$ y $2,0 \%$, respectivamente; mientras la producción manufacturera lo hacía a la tasa de $3,97 \%$ promedio anual.

El test de cointegración se culmina con la prueba $\mathrm{ADF}$ de raíz unitaria de los residuos de la ecuación estimada. En efecto, como puede verse en el Cuadro 26, los residuos siguen un proceso estacionario. Se rechaza la hipótesis nula de que tienen raíz unitaria al $5 \%$ de significancia. Los residuos son integrados de orden 0.

Se puede afirmar entonces de manera que hay una relación de largo plazo entre las tres variables. Se ha obtenido coeficientes con los signos correctos y estadísticamente significativos en el caso de los regresores.

Cuadro 25. Ecuación de cointegración

\begin{tabular}{|ccccc|}
\hline Variable dependiente: & \multicolumn{1}{c|}{ Log de PBInm/PEAOnm } \\
Método: & Mínimos cuadrados dinámicos & & & \\
Muestra: & $1952-2014$ & & \\
Observaciones: & 63 & & & \\
\hline Variable & Coeficiente & Error estándar & Estadístico t & Probabilidad \\
\hline C & 1.169 & 0.402 & 2.906 & 0.005 \\
dummy & -1.788 & 0.484 & -3.689 & 0.000 \\
Log(PBIman) & 0.601 & 0.042 & 14.178 & 0.000 \\
Log(PEAOnm) & -0.483 & 0.084 & -5.726 & 0.000 \\
Log(PBIman)*dummy & 0.166 & 0.048 & 3.459 & 0.001 \\
$\mathbf{R}^{2}$ ajustado & $\mathbf{0 . 9 6 9}$ & & & \\
\end{tabular}

Cuadro 26. Prueba de cointegración

\begin{tabular}{|cccc|}
\hline Hipótesis nula: & & \\
Exógenas: \\
Rezagos: & $\begin{array}{c}\text { Residuos con raíz unitaria } \\
\text { Intercepto } \\
\end{array}$ & 0 & \\
\hline \\
\hline Test estadístico Dickey-Fuller & & Estadístico t & Probabilidad \\
Aumentado & Nivel 1\% & -3.810 & 0.004 \\
Valores críticos & Nivel 5\% & -3.540 & \\
& Nivel 10\% & -2.909 & \\
\hline
\end{tabular}




\section{Modelo de corrección del error}

El Cuadro 27 contiene los resultados de la estimación del Modelo de Corrección del Error (MCE). El signo del coeficiente de los residuos rezagados un período es el correcto, pero no es estadísticamente distinto de cero. Si fuera significativamente distinto de cero, se podría afirmar que las desviaciones de la relación de equilibrio de largo plazo se corrigen anualmente a la tasa de 7,6\%.

El modelo pasa los test de normalidad y homocedasticidad, pero no el de buena forma funcional. El estadístico $\mathrm{Chi}^{2}$ obtenido tiene un valor de 1.062 que es menor que valor crítico 5,991 de la tabla al 5\% de significancia; por lo tanto, no se rechaza la hipótesis nula de existencia de normalidad de los residuos. Tampoco se rechaza la presencia de homocedasticidad. El estadístico obtenido con el test de White es igual a 0,919 que es menor que el valor crítico 1,873 de la tabla para $\mathrm{F}(14,48)$ al $5 \%$. De otro lado, según el test de Wald los coeficientes de los regresores del producto y del empleo son distintos y menores que 1. Los estadísticos obtenidos son altos (88.895 y 96,405, respectivamente) comparados con el valor crítico 4,010 de la tabla para $\mathrm{F}(1,57)$ al 5\%.

Cuadro 27. Modelo de corrección de error

\begin{tabular}{|c|c|c|c|c|}
\hline Variable dependiente: & dLog(PBInm/PEAOnm) & & & \\
\hline Método: & Mínimos cuadrados ordinarios & & & \\
\hline Muestra: & $1953-2015$ & & & \\
\hline Observaciones: & 63 & & & \\
\hline Variable & Coeficiente & Error estándar & Estadístico $\mathrm{t}$ & Probabilidad \\
\hline Constante & 1.205 & 0.540 & 2.229 & 0.0297 \\
\hline $\mathrm{d} \log (\mathrm{PB} \mid \mathrm{man})$ & 0.486 & 0.054 & 8.925 & 0.000 \\
\hline $\mathrm{d}($ LogPBIman*dummy) & 0.130 & 0.078 & 1.653 & 0.103 \\
\hline$d($ dummy $)$ & -1.403 & 0.820 & -1.709 & 0.092 \\
\hline dLog(PEAOnm) & -0.738 & 0.177 & -4.171 & 0.000 \\
\hline Residuos-1 & -7.560 & 10.920 & -0.692 & 0.491 \\
\hline$R^{2}$ ajustado & 0.751 & F estadístico & 38.437 & \\
\hline \multicolumn{5}{|c|}{ Pruebas de Diagnóstico } \\
\hline Test de normalidad & 1.062 & & & \\
\hline$J B-x^{2}(2)^{a}$ & $(0.587)$ & & & \\
\hline Test de heterocedasticidad & 0.919 & & & \\
\hline de White $F(14,48)^{a}$ & $(0.545)$ & & & \\
\hline Test de forma funcional de & 4.382 & & & \\
\hline Ramsey $\mathrm{F}(1,56)^{\mathrm{a}}$ & $(0.040)$ & & & \\
\hline \multirow[t]{2}{*}{ Test de Wald $F(1,57)^{b c}$} & 88.895 & & & \\
\hline & $(0.000)$ & & & \\
\hline \multirow[t]{2}{*}{ Test de Wald $F(1,57)^{b c}$} & 96.405 & & & \\
\hline & $(0.000)$ & & & \\
\hline
\end{tabular}

*Las variables en diferencias fueron multiplicadas por 100

aP-value entre paréntesis, la hipótesis nula es que se tiene normalidad, homocedasticidad y buena forma funcional.

${ }^{b}$ Se muestra el estadístico $\mathrm{F}$ y entre paréntesis el $p$-value. La hipótesis nula es $\mathrm{c}(2)=1$

${ }^{C}$ El primer test de Wald corresponde a la variable del PBIman y el segundo test a la variable del PEAOnm 
No obstante todo lo anterior, el Modelo de Corrección del Error no presenta una buena forma funcional. El estadístico obtenido con el test de Ramsey igual a 4,382 es mayor que el valor crítico 4,013 de la tabla para $\mathrm{F}(1,56)$ al 5\%. Si el MCE no tiene una buena forma funcional y el coeficiente de corrección de errores no es estadísticamente significativo (aunque tiene el signo correcto), entonces no es posible afirmar de manera taxativa que la relación de cointegración expresa una relación de largo plazo estable.

Estos resultados no concluyentes pueden estar relacionados con el carácter no lineal de las series de productividad laboral promedio de la economía y de productividad laboral promedio en el conjunto de sectores distintos al sector de la manufactura (véase Gráficos 7 y 8). La misma forma no lineal, como lo señalamos antes, presenta la productividad del trabajo en el sector manufacturero.

Gráfico 7. Productividad laboral promedio en la economía (En miles de soles de 2007 por trabajador)

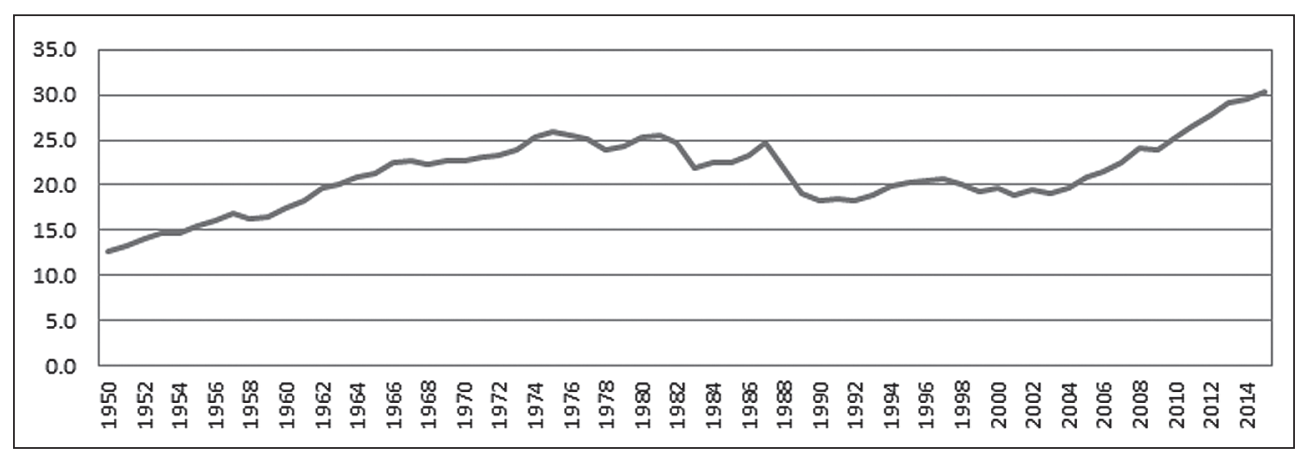

Fuente: INEI y MTPE. Elaboración propia.

Gráfico 8. Productividad laboral promedio en la economía, sin manufactura (En miles de soles de 2007 por trabajador)

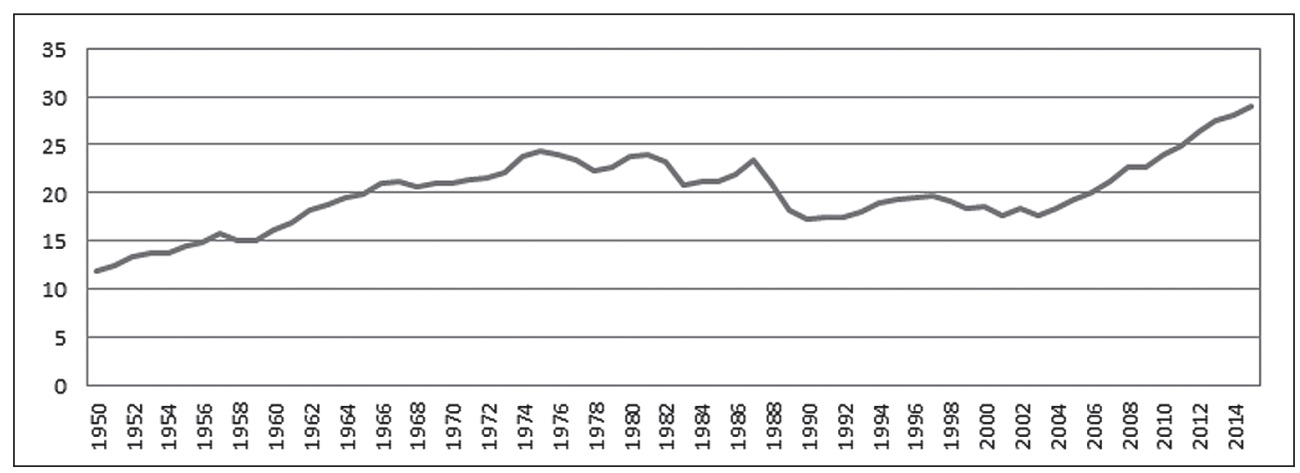

Fuente: INEI y MTPE. Elaboración propia. 


\section{Dirección de la causalidad (test de Granger)}

Si no hay una relación de cointegración significativamente estable desde el punto de vista estadístico, no se puede asegurar tampoco la causalidad de la relación evaluada. El Cuadro 28 muestra que no hay causalidad entre la productividad del trabajo de los sectores no manufactureros, por un lado, y el PBI de la manufactura y el empleo en el conjunto de sectores no manufactureros, por el otro.

No obstante los resultados del análisis de cointegración y causalidad, no se puede descartar la hipótesis kaldoriana de que el crecimiento del PBI manufacturero contribuye positivamente al crecimiento de la productividad del trabajo tanto en el conjunto de la economía como en resto de sectores distintos a de la manufactura, pues los pobres resultados estadísticos pueden estar relacionados a la existencia de subempleo e informalidad no solo en los sectores agricultura y servicios, sino también en la propia manufactura.

Cuadro 28. Test de causalidad de Granger entre el PBIman, PEAOnm y PBInm/PEAOnm

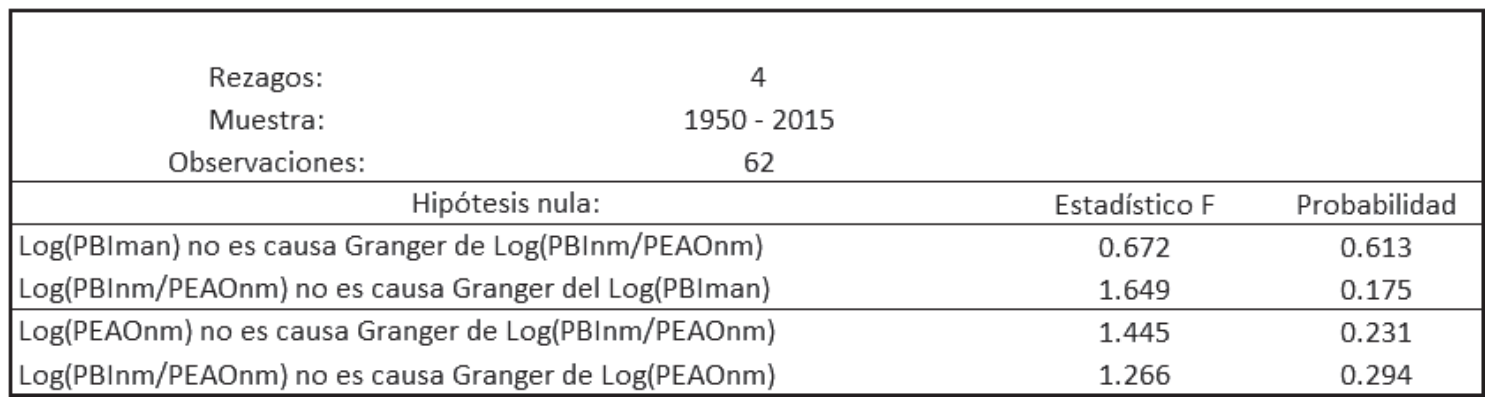

Los resultados del test de cointegración y de la estimación del MCE no permiten descartar de manera absoluta la hipótesis kaldoriana de que el crecimiento del PBI manufacturero influye positivamente en la productividad laboral del resto de sectores no manufactureros y, por lo tanto, en la productividad laboral del conjunto de la economía, cuya explicación se encuentra en la absorción de trabajo redundante desde los sectores atrasados o ineficientes como parte de la agricultura y los servicios. Pero, hay que mencionar que durante el período neoliberal estas transferencias se redujeron, pues el empleo de baja calificación y baja productividad aumentó en los sectores terciarios de comercio y servicios, en lugar de disminuir.

\section{CONCLUSIONES}

La evidencia empírica analizada hasta aquí muestra que el sector manufacturero sigue siendo importante para liderar el crecimiento. La expansión de sus mercados aumenta su producción y este aumento, mediante los encadenamientos e interrelaciones que genera, 
acrecienta el crecimiento de la economía en su conjunto. Los cambios en la tasa de crecimiento del PBI y en la tasa de crecimiento de la producción manufacturera están estrechamente relacionados tanto a corto como a largo plazo. La evidencia empírica de la primera Ley de Kaldor es estadísticamente significativa. A largo plazo, tasas de crecimiento económico superiores al 5,3\%, según los resultados para el período reciente, requieren tasas de aumento de la producción manufacturera más altas.

Cuando la producción manufacturera se expande, también se expande la productividad del trabajo y las oportunidades de empleo en el mismo sector, la productividad del trabajo y las oportunidades de empleo en el resto de actividades no manufactureras. Si bien estas características de la industria manufacturera fueron debilitadas por la prematura desindustrialización de las últimas décadas, impulsar su crecimiento con políticas adecuadas permitirá reducir la informalidad y desarrollar actividades agrícolas, de servicios y de comercio modernas. Como resultado de la desindustrialización prematura, se expandieron sectores productivos terciarios y trabajadores informales. Esta terciarización prematura (expansión de los sectores de servicios de baja productividad y la concomitante informalidad) desaparecerá con el desarrollo industrial manufacturero.

No cabe duda que, por los resultados estadísticos, la manufactura es el sector que opera generando rendimientos crecientes a escala por las interrelaciones que genera a su interior y con el resto de los sectores de la economía. Es como se ha mostrado el único sector que multiplica ingresos y empleo debido a los encadenamientos que desarrolla en el proceso de su expansión. Y su expansión está solo limitada por el tamaño del mercado; no tiene restricción de oferta. Por lo tanto, para que la expansión de la manufactura genere cambios técnicos significativos, se requiere altas tasas de expansión del mercado interno.

\section{REFERENCIAS BIBLIOGRÁFICAS}

Bairam, Erkin (1987). The Verdoorn law, returns to scale and industrial growth: A review of the literature. Australian Economic Papers, 26, 48, 20-42. https://doi. org/10.1111/j.1467-8454.1987.tb00445.x

Bairam, Erkin (1990). Verdoorn's Original Model and the Verdoorn law controversy: some new empirical evidence using the Australian manufacturing data. Australian Economic Papers, 29(54), 107-112. https://doi.org/10.1111/j.1467-8454.1990.tb00475.x

Bairam, Erkin (1991). Economic growth and Kaldor's law: the case of Trukey, 1925-78. Applied Economic, 23(8), 1277-1280. https://doi.org/10.1080/00036849100000048

Bértola, Luis y José Antonio Ocampo (2013). El desarrollo económico de América Latina desde la Independencia. México: FCE.

Beyer, Andreas, Alfred Haug y William Dewald (2009). Structural breaks, Cointegration and the Fisher effect. Working Paper series. n. 1013. European Central Bank.

Cabezas, Sergio, Laría, Patricia y Verónica Rama (2011). Industrialización y desindustrialización de Argentina en la segunda mitad del siglo XX: la paradójica validez de las leyes de Kaldor-Verdoorn. Cuadernos de Economía, 30(55), 235-272. 
Calderón Cuauhtémoc e Isaac Sánchez (2012). Crecimiento económico y política Industrial en México. Revista Problemas del Desarrollo, 170(43), 125-154.

Cornwall, John (1976). Diffusion, Convergence and Kaldor's Laws. The Economic Journal, 86(342), 307-314. https://doi.org/10.2307/2230749

Cripps, Francis y Roger Tarling (1973). Growth in Advanced Capitalist Economic 1950-1970, Occasional Paper N. ${ }^{\circ}$ 40. Cambridge: Cambridge University Press.

Dasgupta, Sukti y Ajit Singh (2006). Manufacturing, services and premature de-industrialisation in developing countries: a Kaldorian empirical analysis. Working Paper 327. Centre for Business Research, University

De La Rosa Mendoza, Juan (2006). Dos enfoques teóricos sobre el proceso de crecimiento económico: con énfasis en las exportaciones manufactureras. Análisis Económico, 21(48).

Dixon, Robert y Anthony Thirlwall (1975). A Model of Regional Growth-Rate Differences on Kaldorian Lines. Oxford Economic Papers, New Series, 27(2), 201-214. https://doi. org/10.1093/oxfordjournals.oep.a041312

Engle, R. y C. Granger (1987). Co-integration and error correction: representation, estimation, and testing. Econometrica, 55(2), 251-276. https://doi.org/10.2307/1913236

Felipe, Juan (1998). The Role of the Manufacturing Sector in Southeast Asian Development: A Test of Kaldor's. Journal of Post Keynesian Economics, 20(3), 463-485. https://doi.org/1 $0.1080 / 01603477.1998 .11490164$

Fingleton, Bernard (2001). Equilibrium and Economic Growth: Spatial Econometric Models and Simulations. Journal of Regional Science, 41(1), 117-147. https://doi.org/10.1111/00224146.00210

Gregory, Allan y Bruce Hansen (1996). Residual-based tests for cointegration in models with regime shifts. Journal of Econometrics, 70(1), 99-126. https://doi.org/10.1016/03044076(69)41685-7

Harcourt, Geoffrey C. (1975). Teoría del capital: (una controversia entre los dos. Cambridge, Oikos-Tau.

India Brand Equity Foundation (IBEF) (s/a). Role of manufacturing in employment generation in India. Working paper.

INEI (2014). Producción y empleo informal en el Perú. Cuenta satélite de la economía informal. Mayo.

Jeon, Yongbok (2006). Manufacturing, increasing returns and economic development in China, 1979-2004: a Kaldorian approach. Working Paper Series, (2006-08). University of Utah Department of Economics. https://doi.org/10.1920/wp.cem.2006.0506

Jiménez, Félix (1991). Acumulación y ciclos en la economía peruana: crisis de paradigmas y estrategia de desarrollo no-liberal. Lima, Perú: Centro de Estudios para el Desarrollo y la Participación.

Jiménez, Félix (1999). Liberalización, reestructuración productiva y competitividad en la industria peruana de los ańos noventa. Economía, 22(44), 145-185.

Jiménez, Félix (2010[1982]). Perú: la expansión del sector manufacturero como generadora de crecimiento económico y el papel del sector externo. En Félix Jiménez, La economía peruana del último medio siglo. Ensayos de interpretación (pp. 109-130). Lima: CISEPA, Pontificia Universidad Católica del Perú.

Jiménez, Félix (2011). Producto potencial, fuentes del crecimiento y productividad en la economía peruana (1950-2008). El Trimestre Económico, 78(4), 913-940. https://doi. org/10.20430/ete.v78i312.53 
Jiménez, Félix (2012). La controversia sobre la teoría del capital. Economía, 35(70), 142-189.

Kaldor, Nicholas (1957). A Model of Economic Growth. The Economic Journal, 67(268), 591-624. https://doi.org/10.2307/2227704

Kaldor, Nicholas (1966). Causes of the Slow Rate of Economic Growth of the United Kingdom: an inaugural lecture. Cambridge Inglaterra: Cambridge University Press.

Kaldor, Nicholas (1967). Strategic Factors in Economic Development, Frank Pierce Memorial Lecture at Cornell University, Ithaca: Cornell University Press

Kaldor, Nicholas (1968). Productivity and Growth in Manufacturing Industry: A Reply. Economica, New Series, 35(140), 385-391. https://doi.org/10.2307/2552347

Kaldor, Nicholas (1970). The Case for Regional Policies. Scottish Journal of Political Economy, 17(3), 337-348.

Kaldor, Nicholas (1975). Economic Growth and the Verdoorn Law: A Comment on Mr. Rowthorn's Article. The Economic Journal, 85(340), 891-896.

Kaldor, Nicholas (1978). Futher Essays of Economic Theory. Londres: Duckworth.

Kathuria, Vinish y Rajesh Raj (2010). Manufacturing an engine of growth in India. Analysis in the post nineties. Paper for conference: Frontier Issues in Technology.

Kilavuz, Emine y Betul Altay Topcu (2012). Exporta and Economic Growth in the Case of the Manufacturing Industry: Panel Data Analysis of Developing Countries. International Journal of Economics and Financial Issues, 2(2), 201-215.

Kiliçaslan, Yilmaz y Erol Taymaz (2007). The Structure of Structural Change and Growth. Department of Economics, Middle East Technical University. Recuperado el 24 de abril del 2017 de https://www.researchgate.net/publication/251810393_The_Structure_of_ Structural_Change and_Growth

Leon-Ledesma, M. A. (2000). Economic Growth and Verdoorn's Law in the Spanish Regions, 1962-91. International Review of Applied Economics, 14(1), 55-69. https://doi.org/ $10.1080 / 026921700101489$

Libanio, Gilberto (2006a). Three Essays on Aggregate Demand and Growth. Notre Dame, IN: Universidad de Notre Dame.

Libanio, Gilberto (2006b). Manufacturing Industry and Economic Growth in Latin America: A Kaldorian Approach. Paper presented at the Second Annual Conference for Development and Change, Campos do Jordão, Brazil.

Libanio, Gilberto y Sueli Moro (2014). Manufacturing Industry and Economic Growth in Latin America: A Kaldorian Approach. En Researchgate. Recuperado el 24 de abril de 2017 de https://www.researchgate.net/publication/255652796_MANUFACTURING_ INDUSTRY_AND_ECONOMIC_GROWTH_IN_LATIN_AMERICA_A_ KALDORIAN_APPROACH

Marquez, Lisett y Emilio Pradilla (2008). Desindustrialización, terciarización y estructura metropolitana: un debate conceptual necesario. Cuadernos CENDES, 25(69), 24-45. Caracas, Venezuela.

McCombie, John (1982). Economic Growth, Kaldor's Laws and the Static-dynamic Verdoorn Law Paradox. Applied Economics, 14(3), 279-294.

McCombie, J. S. L. (1985). Increasing Returns and the Manufacturing Industries: Some Empirical Issues. The Manchester School of Economic and Social Studies, 53, 55-75. https:// doi.org/10.1111/j.1467-9957.1985.tb00195.x

McCombie, John S. L. y John R. de Ridder (1983). Increasing Returns, Productivity, and Output Growth: The Case of the United States. Journal of Post Keynesian Economics, 5(3), 373-387. https://doi.org/10.1080/01603477.1983.11489377 
McCombie, J. S. L. y J. R. de Ridder (1984). «The Verdoorn Law Controversy»: Some New Empirical Evidence Using U.S. State Data. Oxford Economic Papers, 36(2), 268-284. https://doi.org/10.1093/oxfordjournals.oep.a041637

McCombie, John y Mark Roberts (2007). Returns to scale and regional growth: The static-dynamic Verdoorn law paradox revisited. Journal of Regional Science, 47(2), 179-208. https:// doi.org/10.1111/j.1467-9787.2007.00505.x

McCombie, J. S. L. y A. P. Thirlwall (1994). Economic Growth and the Balance-of-Payments Constraint, New York: St. Martin's Press. https://doi.org/10.1007/978-1-349-23121-8

McCombie, John, Mark Roberts y Alvaro Angeriz (2008). Returns to Scale for EU Regional Manufacturing. Working Paper n. 20. Centre for Globalization Research, School of Business and Management. Queen Mary, University of London.

McKinsey \& Company (2012). Manufacturing the future: The next era of global growth and innovation. McKinsey Global Institute and McKinsey Operations Practice.

Moncayo, E. (2011). Cambio estructural, crecimiento e industrialización en América Latina, 1950-2005, Universidad Nacional de Colombia.

Moreno Rivas, Álvaro Martín (2008). Las leyes del desarrollo económico endógeno de Kaldor: el caso colombiano. Revista de Economía Institucional, 10(18), 129-147.

Ocegueda, Juan Manuel (2003). Análisis kaldoriano del crecimiento económico de los estados de México, 1980-2000. Comercio Exterior, 53(11), 1024-1034.

Organización de las Naciones Unidad para el Desarrollo Industrial (Onudi) (2013). La creación sostenida de empleo: el rol de la industria manufacturera y cambio estructural. Resumen. Informe sobre desarrollo industrial.

Organización de las Naciones Unidad para el Desarrollo Industrial (Onudi) (2016). El rol de la tecnología y la innovación en el desarrollo industrial inclusivo y sostenible. Informe sobre desarrollo industrial.

Rodrik, Dani (2010). El regreso de la política industrial. Project Syndicate, 12 de abril. Disponible en: <https://www.project-syndicate.org/commentary/the-return-of-industrial-policy/ spanish>

Rodrik, Dani (2011). El imperativo manufacturero. En Proyect Syndicate. Consulta: 25 de abril del 2017. https://www.project-syndicate.org/commentary/the-manufacturing-imperativ e?version=spanish \&barrier=accessreg

Rodrik, Dani (2013). Unconditional convergence in manufacturing. Quarterly Journal of Economics, 128(1), 165-204. https://doi.org/10.1093/qje/qjs047

Rodrik, Dani (2014). ¿Son los servicios las nuevas manufacturas? Project Syndicate, 13 de octubre. Disponible en: <https://www.project-syndicate.org/commentary/are-services-the-newmanufactures-by-dani-rodrik-2014-10/spanish>

Rodrik, Dani (2016). Premature deindustrialization. Journal Economic Growth, 21, 21-33. https://doi.org/10.1007/s10887-015-9122-3

Rowthorn, R. E. (1975). What remains of Kaldor's law? The Economic Journal, 85, 10-19.

Sachs, J. D. y A. M. Warner (1999). The big push, natural resource boom and growth. Journal of Developments Economics, 59(1), 43-76. https://doi.org/10.1016/S0304-3878(99)00005-X

Saeger, Steven (1997). Globalization and Deindustrialization: Myth and Reality in the OECD. Review of World Economics, 133(4), 579-608. https://doi.org/10.1007/BF02707404

Salama, Pierre (2012b). China-Brasil: industrialización y desindustrialización temprana. Cuadernos de Economía, 31(56), 223-252. 
Salazar Arias, Juan David (2013). Arquitectura de la industrialización: una propuesta para Colombia. Working Paper. Santiago de Cali: Universidad de Colombia.

Sánchez Juárez, Isaac Leobardo (2010). Estancamiento económico e industrias manufactureras regionales en México, 1993-2010: explicación y propuestas. Tesis de doctorado en Ciencias Sociales con especialidad en Estudios Regionales. Tijuana: El Colegio de la Frontera Norte. Consulta: 24 de abril del 2017. http://www.colef.mx/posgrado/wp-content/ uploads/files/TESIS_S\%E1nchez\%20Ju\%E1rez\%20Issac\%20Leobardo.pdf

Sánchez Juárez, Isaac Leobardo (2011). En Insuficiencia dinámica manufacturera y estancamiento económico en México 1982-2010. Análisis y recomendaciones de política. Vol. 7. Autónoma Ciudad de Juárez: Colección Investigación en Ciencias Sociales y Administrativas.

Schuldt, Jürgen (1994). La enfermedad holandesa y otros virus de la economía peruana. DT 20. Lima: Universidad del Pacífico.

Scott, Robert (2008). The importance of manufacturing. Key to recovery in the states and the nation. Briefing Paper 211, 1-12. Washington: Economic Policy Institute.

Smith, Adam (1937 [1776]). Inquiry into the Nature and Causes of the Wealth of Nations. New York: Edwin Cannan. [Hay edición en español: Investigación sobre la naturaleza y causas de la riqueza de las naciones, Fondo de Cultura Económica, 1958.]

Szirmai, Adam y Bart Verspagen (2010). Is Manufacturing Still an Engine of Growth in Developing Countries? Productivity and Economic Growth. Paper prepared for the 31st General Conference of the International Association for Research in Income and Wealth.

Szirmai, Adam y Wim Naudé (2012). The importance of manufacturing in economic development: past, present and future perspective. United Nations University, Working Paper Series 2012-2041.

Thirlwal, Anthony (1983). A Plain Man's Guide to Kaldor's Growth Laws. Journal of Post Keynesian Economics, 5(3), 345-358. https://doi.org/10.1080/01603477.1983.11489375

Verdoorn, P. J. (1949). Fattori che regolano lo sviluppo della produttivitá del lavoro. L'Industria, 1, 3-10.

Villamil, Jesús (2003). Productividad y cambio tecnológico en la industria colombiana. Economía y Desarrollo, 2(1), 151-167. Fundación Universidad Autónoma de Colombia.

Williamson, Jeffrey G. (2012). Trade and Poverty, When the Third World Fell Behind. Cambridge, MA: The MIT Press.

Yamak, Nebiye (2000). Cointegration, Causality and Kaldor's Hypothesis: Evidence from Tukey, 1946-1995. Dergisi, 2(4), 75-80.

Young, Allyn (1928). Increasing Returns and Economic Progress. Economic Journal, 38(152), 527-542. https://doi.org/10.2307/2224097

Documento recibido el 2 de noviembre de 2017 y aprobado el 11 de diciembre de 2017 